Cochrane Database of Systematic Reviews

\title{
Pharmacological interventions for the treatment of depression in chronic obstructive pulmonary disease (Review)
}

Pollok J, van Agteren JEM, Carson-Chahhoud KV

Pollok J, van Agteren JEM, Carson-Chahhoud KV.

Pharmacological interventions for the treatment of depression in chronic obstructive pulmonary disease.

Cochrane Database of Systematic Reviews 2018, Issue 12. Art. No.: CD012346.

DOI: 10.1002/14651858.CD012346.pub2.

www.cochranelibrary.com 
TABLE OF CONTENTS

HEADER 1

ABSTRACT

PLAIN LANGUAGE SUMMARY ....

SUMMARY OF FINDINGS

BACKGROUND

OBJECTIVES

METHODS

Figure 1.

RESULTS

Figure 2.

Figure 3.

Figure 4.

DISCUSSION

AUTHORS' CONCLUSIONS

ACKNOWLEDGEMENTS

REFERENCES

CHARACTERISTICS OF STUDIES

DATA AND ANALYSES

Analysis 1.1. Comparison 1 Tricylic antidepressant versus placebo - final follow-up values used, Outcome 1 Change in depressive symptoms.

Analysis 1.2. Comparison 1 Tricylic antidepressant versus placebo - final follow-up values used, Outcome 2 Adverse events. ....

Analysis 1.3. Comparison 1 Tricylic antidepressant versus placebo - final follow-up values used, Outcome 3 Change in quality of life - overall score.

Analysis 1.4. Comparison 1 Tricylic antidepressant versus placebo - final follow-up values used, Outcome 4 Change in dyspnoea (Pulmonary Functional Status Instrument).

Analysis 2.1. Comparison 2 Selective serotonin reuptake inhibitor versus placebo - final follow-up values used, Outcome 1 Change in depressive symptoms.

Analysis 2.2. Comparison 2 Selective serotonin reuptake inhibitor versus placebo - final follow-up values used, Outcome 2 Adverse events.

Analysis 2.3. Comparison 2 Selective serotonin reuptake inhibitor versus placebo - final follow-up values used, Outcome 3 Change in FEV1.

Analysis 2.4. Comparison 2 Selective serotonin reuptake inhibitor versus placebo - final follow-up values used, Outcome 4 Change in quality of life.

Analysis 2.5. Comparison 2 Selective serotonin reuptake inhibitor versus placebo - final follow-up values used, Outcome 5 Change in exercise tolerance.

ADDITIONAL TABLES

APPENDICES

CONTRIBUTIONS OF AUTHORS

DECLARATIONS OF INTEREST

SOURCES OF SUPPORT

DIFFERENCES BETWEEN PROTOCOL AND REVIEW

INDEX TERMS 
[Intervention Review]

\section{Pharmacological interventions for the treatment of depression in chronic obstructive pulmonary disease}

Justyna Pollok ${ }^{1}$, Joep EM van Agteren 2,3 , Kristin V Carson-Chahhoud4

1Faculty of Health and Medical Sciences, The University of Adelaide, Adelaide, Australia. ${ }^{2}$ College of Medicine and Public Health, Flinders University, Adelaide, Australia. ${ }^{3}$ Wellbeing and Resilience Centre, South Australian Health and Medical Research Institute, Adelaide, Australia. ${ }^{4}$ School of Health Sciences, The University of South Australia, Adelaide, Australia

Contact address: Justyna Pollok, Faculty of Health and Medical Sciences, The University of Adelaide, North Terrace, Adelaide, South Australia, 5005, Australia. justyna.pollok@adelaide.edu.au.

Editorial group: Cochrane Common Mental Disorders Group.

Publication status and date: New, published in Issue 12, 2018.

Citation: Pollok J, van Agteren JEM, Carson-Chahhoud KV. Pharmacological interventions for the treatment of depression in chronic obstructive pulmonary disease. Cochrane Database of Systematic Reviews 2018, Issue 12. Art. No.: CD012346. DOI: 10.1002/14651858.CD012346.pub2.

Copyright $(2018$ The Cochrane Collaboration. Published by John Wiley \& Sons, Ltd.

\section{A B S T R A C T}

\section{Background}

Studies report that up to $80 \%$ of individuals with chronic obstructive pulmonary disease (COPD) may struggle with symptoms of depression. However, this major comorbidity in COPD is rarely managed effectively. A number of recent studies indicate that left untreated, COPDrelated depression is associated with worse quality of life, worse compliance with COPD treatment plan, increased exacerbations, hospital admissions, and healthcare costs when compared to individuals with COPD without depression. Regrettably, COPD practice guidelines do not provide conclusive treatment recommendations for the use of antidepressants in patients with COPD, and base their guidelines on findings from trials in the general population. This may be problematic, as there is an elevated risk of respiratory issues associated with antidepressant treatment and COPD. Evaluating effectiveness and safety of pharmacological interventions specifically for patients with COPD and depression was therefore paramount.

\section{Objectives}

To assess the effectiveness and safety of pharmacological interventions for the treatment of depression in patients with COPD.

\section{Search methods}

The last search was performed on 26 November 2018. We initially searched the following databases via the Specialised Trials Registers of the Cochrane Airways and Common Mental Disorders Groups (to June 2016): MEDLINE, Embase, PsycINFO, CINAHL, AMED, and the Cochrane Library trials register (CENTRAL). Searches from June 2016 to November 2018 were performed directly on Ovid MEDLINE, Embase, PsycINFO and the Cochrane Library (Issue 11, 2018). We searched ClinicalTrials.gov, the ISRCTN registry, and the World Health Organization International Clinical Trials Registry Platform to 26 November 2018. We searched the grey literature databases to identify studies not indexed in major databases and the reference lists of studies initially identified for full-text screening.

\section{Selection criteria}

All published and unpublished randomised controlled trials (RCTs) comparing the efficacy of pharmacological interventions with no intervention, placebo or co-intervention in adults with diagnosed COPD and depression were eligible for inclusion.

\section{Data collection and analysis}

Two review authors independently assessed articles identified by the search for eligibility. Our primary outcomes were change in depressive symptoms and adverse events. The secondary outcomes were: change in quality of life, change in dyspnoea, change in forced 
expiratory volume in one second $\left(\mathrm{FEV}_{1}\right)$, change in exercise tolerance, change in hospital utilisation (length of stay and readmission rates), and cost-effectiveness. For continuous outcomes, we calculated the pooled mean difference (MD) or standardised mean difference (SMD) with $95 \%$ confidence interval $(\mathrm{Cl})$ as appropriate. For dichotomous outcomes, we calculated the pooled odds ratio (OR) and corresponding $95 \% \mathrm{Cl}$ using a random-effects model. We assessed the quality of evidence using the GRADE framework.

\section{Main results}

Of the 1125 records screened for eligibility, four RCTs ( $\mathrm{N}=201$ participants), and one on-going study, met the inclusion criteria. Two classes of antidepressants were investigated in two separate comparisons with placebo: a tricyclic antidepressant (TCA) and selective serotonin reuptake inhibitors (SSRIs).

\section{TCA versus placebo}

Only one RCT ( $\mathrm{N}=30$ participants) provided results for this comparison.

Primary outcomes

The TCA (nortriptyline) reduced depressive symptoms post-treatment compared to placebo (MD $-10.20,95 \% \mathrm{Cl}-16.75$ to $-3.65 ; \mathrm{P}=0.007$; very low-quality evidence), as measured by the Hamilton Depression Rating Scale (HAM-D). Three participants withdrew from the trial due to adverse events related to the tested antidepressant (dry mouth, sedation, orthostatic hypotension).

\section{Secondary outcomes}

The overall results post-treatment indicated that nortriptyline was not effective in improving the quality of life of individuals with COPD, as measured by the Sickness Impact Profile (MD -2.80, 95\% Cl-11.02 to 5.42; P = 0.50; very low-quality evidence).

The results for the change in dyspnoea for the domains examined (e.g. dyspnoea scores for 'most day-to-day activities') post-treatment showed no improvement in the intervention group ( $\mathrm{MD} 9.80,95 \% \mathrm{Cl}-6.20$ to $25.80 ; \mathrm{P}=0.23$; very low-quality evidence).

No data were reported for change in $\mathrm{FEV}_{1}$, change in exercise tolerance, change in hospital utilisation, or cost-effectiveness. The TCA study provided short-term results, with the last follow-up data collection at 12 weeks.

The quality of the evidence for all the outcomes evaluated was very low due to a small sample size, imprecision, attrition, and selection and reporting bias.

\section{SSRIs versus placebo}

Three RCTs ( $\mathrm{N}=171$ participants) provided results for this comparison.

\section{Primary outcomes}

The pooled results for two studies showed no difference for the change in depressive symptoms post-intervention (SMD $0.75,95 \% \mathrm{Cl}-1.14$ to $2.64 ; 148$ participants; 2 studies; $P=0.44$; very low-quality evidence). High heterogeneity was observed $\left(I^{2}=95 \%\right)$, limiting the reliability of these findings.

While it was not possible to meta-analyse the total adverse events rates across the studies, it was possible to combine the results for two medication-specific adverse effects: nausea and dizziness. There were no significant post-treatment group differences for nausea (OR 2.32, $95 \% \mathrm{Cl} 0.66$ to $8.12 ; 171$ participants; 3 studies; $\mathrm{P}=0.19$; very low-quality evidence) or dizziness $(\mathrm{OR} 0.61,95 \% \mathrm{Cl} 0.09$ to $4.06 ; 143$ participants; 2 studies; $\mathrm{P}=0.61$; very low-quality evidence).

\section{Secondary outcomes}

The pooled analysis of two trials reporting data for the change in quality of life did not show improvement post-treatment in the intervention group compared to placebo (SMD $1.17,95 \% \mathrm{Cl}-0.80$ to $3.15 ; 148$ participants; 2 studies; $\mathrm{P}=0.25$; very low-quality evidence).

There was no difference between groups in change in $\mathrm{FEV}_{1}$ post-treatment (MD $0.01,95 \% \mathrm{Cl}-0.03$ to $0.05 ; 148$ participants; 2 studies; $\mathrm{P}=$ 0.60; low-quality evidence). However, two trials reported improvement in exercise tolerance in the SSRI group versus the placebo group (MD 13.88, 95\% Cl 11.73 to $16.03 ; 148$ participants; 2 studies; $\mathrm{P}<0.001$; very low-quality evidence).

The trials included in this comparison did not report data related to the change in dyspnoea, hospital utilisation rates, or cost-effectiveness.

\section{Authors' conclusions}

There is insufficient evidence to make definitive statements about the efficacy or safety of antidepressants for treating COPD-related depression. New RCTs are needed; with better methodological quality and more accurate reporting of the methods used. Moreover, longerterm follow-up data collection is needed, including outcomes such as adverse events, hospital utilisation and cost-effectiveness. 


\section{PLAIN LANGUAGE SUMMARY}

\section{Medication for the treatment of depression in chronic obstructive pulmonary disease}

Chronic obstructive pulmonary disease (COPD) is a term that mainly describes two lung conditions: chronic bronchitis and emphysema. The main symptoms of COPD include shortness of breath, persistent cough, wheezing, and/or frequent chest infections. There is no cure for COPD, but treatment can help slow the disease progress and relieve symptoms. Depression is very common in patients with COPD, but is often untreated. Studies show that untreated depression in patients with COPD can worsen quality of life, increase COPD exacerbations and hospital admissions, and make following a COPD treatment plan difficult. Treatment for depression can include antidepressant medication, psychological therapy, or both. However, evidence-based recommendations regarding antidepressant medication use specifically for patients with COPD are not currently available.

\section{Why is this review important?}

There is currently no clear overview of existing evidence showing whether antidepressants can effectively and safely reduce depressive symptoms in patients with COPD, therefore it was important to assess the existing experimental studies.

\section{Who will be interested in this review?}

Healthcare professionals, people with COPD and depression, researchers, and policymakers will be interested in the findings of this review.

\section{What questions does this review aim to answer?}

Our main aim was to assess whether pharmacological treatment (e.g. antidepressants) could effectively and safely treat COPD-related depression.

\section{Which studies were included in the review?}

This review included experimental studies called randomised controlled trials (studies in which participants are assigned to a treatment group based on a random method) that compared the effectiveness of pharmacological interventions (antidepressants) to placebo (inactive treatment in the same form as the active treatment, e.g. a pill). Study participants were adults diagnosed with COPD and depression.

\section{What does the evidence from the review tell us?}

We have identified only four studies worldwide that were eligible for inclusion in our review. This means limited evidence to support the use of antidepressants for the treatment of depression in patients with COPD. Only one study evaluated a tricyclic antidepressant, nortriptyline, finding that it reduced depressive symptoms when compared to a placebo. Three studies evaluated a newer generation class of antidepressants called selective serotonin reuptake inhibitors (SSRIs), finding no evidence for their effectiveness in improving depressive symptoms. Due to the limited evidence, we are unable to make definitive statements about the effectiveness but also safety of antidepressants when used for COPD-related depression. However, SSRIs may increase exercise capacity in patients with COPD.

Given that the current findings were based on only four small studies with evidence rated as of very low quality, it is important to interpret our results with caution.

\section{What should happen next?}

Insufficient evidence prevented us from making clear recommendations for doctors, other healthcare professionals, researchers, or policymakers. More studies with better methodological quality and a larger number of participants are needed. 
SUMMARY OF FINDINGS

Summary of findings for the main comparison. Tricylic antidepressant compared to placebo for the treatment of depression in chronic obstructive pulmonary disease

Tricylic antidepressant compared to placebo for the treatment of depression in chronic obstructive pulmonary disease (COPD)

Patient or population: COPD with depression

Setting: clinical

Intervention: tricyclic antidepressant: nortriptyline

Comparison: placebo

\begin{tabular}{|c|c|c|c|c|c|c|}
\hline \multirow[t]{2}{*}{ Outcomes } & \multicolumn{2}{|c|}{ Anticipated absolute effects ${ }^{\star}(95 \% \mathrm{Cl})$} & \multirow{2}{*}{$\begin{array}{l}\text { Relative effect } \\
(95 \% \mathrm{Cl})\end{array}$} & \multirow{2}{*}{$\begin{array}{l}\text { № of partici- } \\
\text { pants } \\
\text { (studies) }\end{array}$} & \multirow{2}{*}{$\begin{array}{l}\text { Quality of evi- } \\
\text { dence } \\
\text { (GRADE) }\end{array}$} & \multirow[t]{2}{*}{ Comments } \\
\hline & Risk with placebo & $\begin{array}{l}\text { Risk with tricyclic antide- } \\
\text { pressant }\end{array}$ & & & & \\
\hline $\begin{array}{l}\text { Change in depressive symp- } \\
\text { toms assessed with Hamilton De- } \\
\text { pression Rating Scale; scale from } \\
0 \text { to } 61 \text { (higher scores = worse } \\
\text { symptoms); follow-up: range } 1 \text { to } \\
12 \text { weeks }\end{array}$ & $\begin{array}{l}\text { The mean depressive } \\
\text { symptom score post- } \\
\text { placebo was } 22.8 \text { (SD } \\
11.3 \text { ). }\end{array}$ & $\begin{array}{l}\text { The mean difference in de- } \\
\text { pressive symptoms was } 10.2 \\
\text { lower ( } 16.75 \text { lower to } 3.65 \\
\text { lower). }\end{array}$ & - & $\begin{array}{l}30 \\
(1 \mathrm{RCT})\end{array}$ & $\begin{array}{l}\oplus \ominus \ominus \ominus \\
\text { VERY LOW } 12\end{array}$ & \\
\hline $\begin{array}{l}\text { Adverse events (disease-relat- } \\
\text { ed: all physical symptoms); fol- } \\
\text { low-up: range } 1 \text { to } 12 \text { weeks }\end{array}$ & $\begin{array}{l}\text { The mean score post- } \\
\text { placebo was } 21.6 \text { (SD } \\
\text { 12.4). }\end{array}$ & $\begin{array}{l}\text { The mean difference in dis- } \\
\text { ease-related adverse events } \\
\text { was } 6.20 \text { lower ( } 12.38 \text { lower to } \\
0.02 \text { lower). }\end{array}$ & - & $\begin{array}{l}30 \\
(1 \mathrm{RCT})\end{array}$ & $\begin{array}{l}\oplus \odot \odot \odot \\
\text { VERY LOW } 12\end{array}$ & $\begin{array}{l}\text { Adverse events } \\
\text { related to the } \\
\text { intervention } \\
\text { were not more } \\
\text { significant in } \\
\text { the treatment } \\
\text { group than in } \\
\text { the placebo } \\
\text { group. }\end{array}$ \\
\hline $\begin{array}{l}\text { Change in quality of life as- } \\
\text { sessed with Sickness Impact Pro- } \\
\text { file; scale from } 0 \text { to } 100 \text { (higher } \\
\text { scores = greater dysfunction); } \\
\text { follow-up: range } 1 \text { to } 12 \text { weeks }\end{array}$ & $\begin{array}{l}\text { The mean quality of life } \\
\text { score post-placebo was } \\
18.5 \text { (SD 10.8). }\end{array}$ & $\begin{array}{l}\text { The mean difference in quali- } \\
\text { ty of life was } 2.80 \text { lower ( } 11.02 \\
\text { lower to } 5.42 \text { higher). }\end{array}$ & - & $\begin{array}{l}30 \\
(1 \mathrm{RCT})\end{array}$ & $\begin{array}{l}\oplus \ominus \ominus \ominus \\
\text { VERY LOW } 12\end{array}$ & \\
\hline $\begin{array}{l}\text { Change in dyspnoea assessed } \\
\text { with Pulmonary Functional Sta- } \\
\text { tus Instrument: }\end{array}$ & $\begin{array}{l}\text { The mean dyspnoea } \\
\text { score post-placebo was } \\
52.7 \text { (SD 21.0). }\end{array}$ & $\begin{array}{l}\text { The mean difference in dysp- } \\
\text { noea was } 9.8 \text { higher ( } 6.2 \text { lower } \\
\text { to } 25.8 \text { higher). }\end{array}$ & - & $\begin{array}{l}30 \\
(1 \mathrm{RCT})\end{array}$ & $\begin{array}{l}\oplus \odot \Theta \odot \\
\text { VERY LOW } 123\end{array}$ & \\
\hline
\end{tabular}

to 25.8 higher). 


\begin{tabular}{|c|c|c|c|c|}
\hline Change in $\mathrm{FEV}_{1}(\mathrm{l})$ & $\begin{array}{l}\text { The authors indicate that there was no significant group } \\
\text { difference for } \mathrm{FEV}_{1} \text {, but report no data for this outcome. }\end{array}$ & - & $\begin{array}{l}30 \\
(1 \mathrm{RCT})\end{array}$ & $\begin{array}{l}\oplus \ominus \ominus \ominus \\
\text { VERY LOW } 124\end{array}$ \\
\hline $\begin{array}{l}\text { Change in exercise tolerance - } \\
\text { not reported }\end{array}$ & $\begin{array}{l}\text { The authors indicate that there was no significant group } \\
\text { difference for change in exercise tolerance, but report no } \\
\text { data for this outcome. }\end{array}$ & - & $\begin{array}{l}30 \\
(1 \mathrm{RCT})\end{array}$ & $\begin{array}{l}\oplus \ominus \ominus \ominus \\
\text { VERY LOW } 124\end{array}$ \\
\hline $\begin{array}{l}\text { Change in hospital utilisation - } \\
\text { not measured }\end{array}$ & - & - & - & - \\
\hline
\end{tabular}

${ }^{*}$ The risk in the intervention group (and its $95 \%$ confidence interval) is based on the assumed risk in the comparison group and the relative effect of the intervention (and its $95 \% \mathrm{Cl})$.

Cl: confidence interval; $\mathbf{F E V}_{\mathbf{1}}$ : forced expiratory volume in 1 second; $\mathbf{R C T}$ : randomised controlled trial; SD: standard deviation

\section{GRADE Working Group grades of evidence}

High certainty: We are very confident that the true effect lies close to that of the estimate of the effect.

Moderate certainty: We are moderately confident in the effect estimate: the true effect is likely to be close to the estimate of the effect, but there is a possibility that it is substantially different.

Low certainty: Our confidence in the effect estimate is limited: the true effect may be substantially different from the estimate of the effect.

Very low certainty: We have very little confidence in the effect estimate: the true effect is likely to be substantially different from the estimate of effect.

1Downgraded one level: no information provided on allocation concealment and imbalanced dropout.

2Downgraded two levels: low observation number: single small study with 30 participants (Borson 1992).

${ }^{3}$ Downgraded one level: imprecise estimate, large confidence interval.

${ }^{4}$ Downgraded one level: limited data provided to verify reported non-significant difference.

\section{Summary of findings 2. Selective serotonin reuptake inhibitor compared to placebo for the treatment of depression in chronic obstructive} pulmonary disease

\section{Selective serotonin reuptake inhibitor (SSRI) compared to placebo for the treatment of depression in chronic obstructive pulmonary disease (COPD)}

Patient or population: chronic obstructive pulmonary disease (COPD) with depression

Setting: clinical

Intervention: SSRI: paroxetine, sertraline

Comparison: placebo

\begin{tabular}{|c|c|c|c|c|c|c|}
\hline \multirow[t]{2}{*}{ Outcomes } & \multicolumn{2}{|c|}{ Anticipated absolute effects ${ }^{\star}(95 \% \mathrm{Cl})$} & \multirow{2}{*}{$\begin{array}{l}\text { Relative effect } \\
(95 \% \mathrm{Cl})\end{array}$} & \multirow{2}{*}{$\begin{array}{l}\text { № of partici- } \\
\text { pants } \\
\text { (studies) }\end{array}$} & \multirow{2}{*}{$\begin{array}{l}\text { Quality of evi- } \\
\text { dence } \\
\text { (GRADE) }\end{array}$} & \multirow[t]{2}{*}{ Comments } \\
\hline & Risk with placebo & Risk with SSRI & & & & \\
\hline
\end{tabular}




\begin{tabular}{|c|c|c|c|}
\hline $\begin{array}{l}\text { Mean difference in de- } \\
\text { pressive symptoms } \\
\text { (from baseline to end of } \\
\text { follow-up) assessed with } \\
\text { BDI, HAMD-17 and GDS; } \\
\text { range of possible scores: } \\
0 \text { to } 40 \text { (higher scores = } \\
\text { worse symptoms); } \\
\text { follow-up: } 6 \text { to } 12 \text { weeks }\end{array}$ & $\begin{array}{l}\text { The standardised mean difference in depressive symptoms for } \\
\text { placebo compared to SSRIs was } 0.75 \text { (-1.14 lower to } 2.64 \text { higher), } \\
\text { showing no significant difference between groups. }\end{array}$ & $\begin{array}{l}148 \\
\text { (2 RCTs) }\end{array}$ & $\begin{array}{l}\oplus \ominus \ominus \ominus \\
\text { VERY LOW } 123 \\
5\end{array}$ \\
\hline $\begin{array}{l}\text { Adverse events } \\
\text { (nausea, dizziness) }\end{array}$ & $\begin{array}{l}\text { While it was not possible to meta-analyse the total adverse events } \\
\text { rates across the studies, it was possible to meta-analyse the results } \\
\text { found for } 2 \text { types of medication-specific adverse effects: nausea } \\
\text { and dizziness. There were no significant differences between par- } \\
\text { ticipants receiving SSRIs and those receiving placebo for nausea } \\
\text { (OR } 2.32,95 \% \mathrm{Cl} 0.66 \text { to } 8.12 ; 171 \text { participants; } 3 \text { studies; } \mathrm{P}=0.19 \text { ) } \\
\text { or for dizziness (OR } 0.61,95 \% \mathrm{Cl} 0.09 \text { to } 4.06 ; 143 \text { participants; } 2 \\
\text { studies; } \mathrm{P}=0.61 \text { ). }\end{array}$ & $\begin{array}{l}171 \\
\text { (3 RCTs) }\end{array}$ & $\begin{array}{l}\oplus \ominus \ominus \ominus \\
\text { VERY LOW } 145\end{array}$ \\
\hline $\begin{array}{l}\text { Change in quality of life } \\
\text { assessed with CAT and } \\
\text { SGRQ; } \\
\text { range of possible scores: } \\
0 \text { to } 100 \text { (higher scores = } \\
\text { greater dysfunction); } \\
\text { follow-up: } 6 \text { weeks }\end{array}$ & $\begin{array}{l}\text { The standardised mean difference in quality of life for placebo } \\
\text { compared to SSRIs was } 1.17 \text { ( } 0.80 \text { lower to } 3.15 \text { higher), showing } \\
\text { no significant difference between groups. }\end{array}$ & $\begin{array}{l}148 \\
(2 \mathrm{RCTs})\end{array}$ & $\begin{array}{l}\oplus \ominus \ominus \ominus \\
\text { VERY LOW } 123 \\
5\end{array}$ \\
\hline Change in dyspnoea & $\begin{array}{l}\text { The authors indicate that dyspnoea improved post-treatment } \\
\text { without reaching statistical significance, but do not report post- } \\
\text { treatment data for this outcome. }\end{array}$ & $\begin{array}{l}23 \\
(1 \mathrm{RCT})\end{array}$ & $\begin{array}{l}\oplus \ominus \ominus \ominus \\
\text { VERY LOW } 678\end{array}$ \\
\hline $\begin{array}{l}\text { Change in } \mathbf{F E V}_{\mathbf{1}}(\mathbf{l}) \\
\text { follow-up: } 6 \text { weeks }\end{array}$ & $\begin{array}{l}\text { The mean difference } \mathrm{FEV}_{1} \text { for placebo compared to SSRIs was } 0.01 \\
\text { litre ( } 0.03 \text { lower to } 0.05 \text { higher), showing no significant difference } \\
\text { between groups. }\end{array}$ & $\begin{array}{l}148 \\
\text { (2 RCTs) }\end{array}$ & $\begin{array}{l}\oplus \odot \odot \ominus \\
\text { VERY LOW } 125\end{array}$ \\
\hline $\begin{array}{l}\text { Change in exercise tol- } \\
\text { erance } \\
\text { measured using a 6- } \\
\text { minute walk test; }\end{array}$ & $\begin{array}{l}\text { The mean difference walked on the } 6 \text {-minute walk test for placebo } \\
\text { compared to SSRIs was } 13.88 \text { metres ( } 11.73 \text { higher to } 16.03 \text { higher), } \\
\text { showing no significant difference in exercise tolerance between } \\
\text { groups. }\end{array}$ & $\begin{array}{l}148 \\
\text { (2 RCTs) }\end{array}$ & $\begin{array}{l}\oplus \ominus \ominus \ominus \\
\text { VERY LOW } 125\end{array}$ \\
\hline
\end{tabular}


Change in hospital util-

isation - not measured

${ }^{\star}$ The risk in the intervention group (and its $95 \%$ confidence interval) is based on the assumed risk in the comparison group and the relative effect of the intervention (and its $95 \% \mathrm{Cl})$.

BDI: Beck Depression Inventory; CAT: COPD Assessment Test; CI: confidence interval; FEV $\mathbf{1}$ : forced expiratory volume in 1 second; GDS: Geriatric Depression Scale; HAM-

D-17: 17-item Hamilton Depression Rating Scale; OR: odds ratio; RCT: randomised controlled trial; SGRQ: St George's Respiratory Questionnaire

\section{GRADE Working Group grades of evidence}

High certainty: We are very confident that the true effect lies close to that of the estimate of the effect.

Moderate certainty: We are moderately confident in the effect estimate: the true effect is likely to be close to the estimate of the effect, but there is a possibility that it is substantially different.

Low certainty: Our confidence in the effect estimate is limited: the true effect may be substantially different from the estimate of the effect.

Very low certainty: We have very little confidence in the effect estimate: the true effect is likely to be substantially different from the estimate of effect.

1Downgraded two levels due to risk of bias: neither of the two studies provided information regarding allocation concealment or selective reporting (Eiser 2005; He 2016). The smaller study did not describe methods of randomisation ("patients received either paroxetine $20 \mathrm{mg}$ daily for 6 weeks or matched placebo in a randomised and double-blind fashion") or blinding of outcome assessment (Eiser 2005).

2Downgraded one level: low sample size: one small study with 28 participants (Eiser 2005), and one study with 120 participants (He 2016).

3Downgraded one level: considerable heterogeneity, $I^{2}=95 \%$.

4Downgraded one level: low sample size: 23 participants (Lacasse 2004), 28 participants (Eiser 2005), 120 participants (He 2016).

${ }^{5}$ Downgraded one level: a small study with 28 participants was assessed at high risk of other potential sources of bias due to four out of 14 participants receiving a tricyclic antidepressant (lofepramine) instead of the SSRI paroxetine due to paroxetine-related side effects (Eiser 2005).

${ }^{6}$ Downgraded one level: very low sample size $(\mathrm{N}=23)$.

${ }^{7}$ Downgraded one level: limited data provided to verify reported non-significant result.

8 Downgraded one level: the process of allocation concealment and blinding of outcome assessment was not described. 


\section{B A C K G R O U N D}

\section{Description of the condition}

\section{Chronic obstructive pulmonary disease}

Chronic obstructive pulmonary disease (COPD) is primarily comprised of chronic bronchitis and emphysema, that is conditions characterised by airway inflammation and destruction of pulmonary tissue. The main risk factor for COPD is smoking. Chronic asthma may develop into COPD, particularly in adults who smoke (Yang 2018). Other causes include passive smoking, exposure to indoor and outdoor air pollutants, occupational dusts, fumes and noxious substances. A population-based study assessing the burden of COPD found that approximately $20 \%$ of COPD cases occurred in individuals who never smoked (Lamprecht 2011). The diagnosis of COPD is based on a ratio of the post-bronchodilator forced expiratory volume in one second, divided by the forced vital capacity $\left(\mathrm{FEV}_{1} / \mathrm{FVC}\right.$ ) that is less than $70 \%$ (Rabe 2007).

Chronic obstructive pulmonary disease has been recognised as a global health concern, and is one of the leading causes of morbidity and mortality (Lopez 2006). Approximately 251 million people suffered from COPD worldwide in 2016, and the World Health Organization (WHO) projects that COPD prevalence will continue to increase, becoming the world's third-leading cause of death by 2030 (Mathers 2006; WHO 2017). A number of recent studies have indicated that psychological comorbidities contribute significantly to the mortality risk in COPD (Atlantis 2013; de Voogd 2009; Yohannes 2005).

\section{Depression}

Depressive illness can have a variety of presentations that can differ in severity (Pignone 2002). The fifth edition of the Diagnostic and Statistical Manual of Mental Disorders (DSM-5) defines a diagnosis of major depressive disorder as experiencing at least five of the following symptoms, when at least one of the symptoms is depressed mood or loss of interest or pleasure:

- depressed mood;

- markedly diminished interest or pleasure in all, or almost all, activities most of the day;

- significant weight loss or weight gain, decrease or increase in appetite;

- insomnia or hypersomnia; fatigue or loss of energy;

- feelings of worthlessness or excessive guilt;

- diminished ability to think or concentrate;

- indecisiveness;

- recurrent suicidal ideation or a suicide attempt.

The symptoms must be present for at least two weeks, every day or nearly every day (APA 2013).

The World Health Organization estimates that by 2020 depression will be the second-leading public health concern, preceded only by cardiovascular disease (DeJean 2013).

\section{Depression in people with COPD}

Depression is a major comorbidity in COPD and is associated with reduced quality of life, worse compliance with COPD treatment plan, and higher rates of acute exacerbations, hospitalisations, and 30-day mortality (Abrams 2011; Dalal 2011; Pooler 2014). Amongst the three chronic conditions that affect 60 million people in the USA (diabetes, heart disease, and COPD), patients with COPD have the highest prevalence of depression (Maurer 2008; Panagioti 2014). Results from a systematic review show that the prevalence rates of COPD-related depression are equal to or higher than the rates of depression amongst people with cancer, AIDS, or heart disease (Solano 2006).

The prevalence of clinical depression in patients with COPD varies from 18\% to $80 \%$ (Bentsen 2013; Fleehart 2014; Kunik 2005; Smith 2014; van Manen 2002). This variability in rates may be due to diverse measures and cut-off scores, differences in sampling and COPD severity levels, or lack of standardisation in methodology. A number of epidemiological and clinical studies have investigated the high prevalence of clinical depression amongst patients with COPD (Di Marco 2006; Dinicola 2013; Goodwin 2012; Karajgi 1990; Maurer 2008). For example, results from a meta-analysis including 39,587 participants with COPD and 39,431 controls indicated that clinically significant depressive symptoms affected $50 \%$ of the study sample with COPD (Zhang 2011). This is compared to oneyear prevalence of $6.9 \%$ in the general population (Wittchen 2011). An evaluation by van Manen 2002 found that patients with severe COPD had a higher risk of depression compared to controls, with rates of depression up to $62 \%$ in oxygen-dependent patients. Even after adjusting for demographic variables and comorbidities, the risk of depression was 2.5 times higher in people with COPD compared to those without COPD (Omachi 2009; Zhang 2011). Moreover, in the study by Kunik 2005, the prevalence rates of depression were as high as $80 \%$, but may have been elevated due to the greater physical and psychological disease burden in the studied population of the US veterans.

The mechanisms involved in the association between COPD and depression are not fully understood. The leading risk factor for COPD is cigarette smoking, which has been shown to be highly comorbid with depression (Ng 2009; Sullivan 1998). Mental disorders and substance use co-occur (Kessler 2005), and prospective cohort studies have reported that pre-existing depression may be the reason why individuals begin smoking (Patton 1998). Given depression makes it more difficult to quit, long-term smoking can lead to respiratory illness. However, findings from a study by Hanania 2011 show that depression is more prevalent in COPD than in smokers without COPD. The findings from a systematic review and meta-analysis of 25 longitudinal trials show that COPD-specific psycho-biological responses increase the risk of developing depression (Atlantis 2013). The biological responses that can impair the function of neurotransmitters responsible for healthy cognitive function and mood include increased airflow obstruction, respiratory insufficiency or hypoxia. The same study found that the risk of exacerbation was $31 \%$ higher in participants with COPD-related depression compared to the participants with COPD and no depression (Atlantis 2013). Depressive symptoms are also the strongest predictors for avoidance of physical activity, which consequently increases the risk and frequency of exacerbations (Miravitlles 2014).

High prevalence of depression is a consistent finding in chronic disease research, but health-related impact of COPD is a challenge on everyday breathing, social and emotional functioning, and has long-term implications. Oxygen-dependent 
patients find it particularly difficult to cope with the illness due to limited mobility and fear of running out of oxygen. In brief, there are multiple aspects of COPD that contribute to the development of depression, for example restricted physical functioning, exacerbations, dyspnoea, oxygen dependence (in more severe stages of COPD), multiple comorbidities, irreversible and progressive nature of COPD, as well as disease-specific psycho-biological responses (Lecheler 2017). When combined with psychosocial aspects of daily functioning, such as potential social isolation and self blame, it is hardly surprising that the prevalence of depression in COPD population is higher than in other groups.

Importantly, depression is a particularly strong predictor for mortality in COPD (Almagro 2002; Groenewegen 2003; Ng 2007); its predictive ability persists over and above the effects of other prognostic factors, including physiological and demographic factors, or disease severity (de Voogd 2009; Fan 2007). The study by Atlantis 2013 showed that the presence of depression in patients with COPD increased the risk of mortality by $83 \%$, compared to COPD patients without comorbid depression. Interestingly, a retrospective cohort study found a $30 \%$ decrease in mortality in people with COPD who were using specialist mental health services, compared to those not referred to specialist services but treated in primary care (Hanania 2011). Despite the significant impact of COPD-related depression on a patient's daily life and on healthcare costs, it remains untreated or is treated ineffectively (Yohannes 2014).

\section{Description of the intervention}

Current management strategies for the treatment of depression in patients with COPD are based on guidelines for the general population and include both pharmacological and nonpharmacological interventions. This review aimed to examine the effectiveness of pharmacological interventions compared to placebo, no intervention or co-intervention. Available pharmacotherapies are classified by their effect on different neuromodulators and include antidepressants, antipsychotics, benzodiazepines, and anticonvulsants.

\section{Antidepressants}

The main classes of antidepressants include non-selective antidepressants and selective reuptake inhibitors.

Non-selective, or first generation antidepressants:

- Tricyclic antidepressants (TCAs) act by serotonin and noradrenaline reuptake inhibition, with effects on multiple receptor system and sodium conductance, e.g. amitriptyline, nortriptyline, and doxepin.

- Monamine oxidase inhibitors (MAOIs) act by inhibiting the activity of monoamine oxidase, thus preventing the breakdown of monamine neurotransmitters and thereby increasing their availability, e.g. phenelzine and selegiline.

Selective reuptake inhibitors, or newer generation antidepressants:

- Selective serotonin reuptake inhibitors (SSRIs) act only on the neurotransmitter serotonin, e.g. citalopram, fluoxetine, paroxetine, and sertraline.

- Serotonin and norepinephrine reuptake inhibitors (SNRIs) act by slowing down the reuptake of both serotonin and noradrenaline, but more selectively than other drugs, e.g. venlafaxine and duloxetine.

- Norepinephrine and dopamine reuptake inhibitors (NDRIs) increase the levels of norepinephrine and dopamine, e.g. bupropion.

- Serotonin modulators antagonise postsynaptic serotonin receptors and inhibit reuptake of postsynaptic serotonin, e.g. nefazadone, trazodone, and vilazodone (NICE 2010).

\section{Other medications}

- Atypical antipsychotics, e.g. olanzapine, risperidone, quetiapine, ziprasidone, and aripiprazole, can be used in the treatment of depression, especially with psychotic or delusional depression (Schatzberg 1992). Antipsychotics have a complex mechanism of action, and exert an effect to block alphaadrenergic (alpha 1 and alpha 2), dopamine (primarily D2, but also D1 and D4), histamine (H1), muscarinic (primarily $\mathrm{M} 1$ ), and serotoninergic (primarily 5-HT1A, 5-HT2a, and 5-HT1c) receptors (Sadock 2009).

- Benzodiazepines, e.g. diazepam, alprazolam, and lorazepam, show therapeutic effects by acting on the norepinephrine, serotonergic, and dopaminergic systems.

- Anticonvulsants, e.g. gabapentin, topiramate, and lamotrigine, have varied mechanisms of action, e.g. increasing gammaaminobutyric acid (GABA) function, thereby enhancing neuronal inhibition or reducing neuronal excitation by decreasing glutamatergic function (Sadock 2009).

\section{How the intervention might work}

The understanding of mechanisms involved in mood control by antidepressants has evolved over time. Since the late 1950s, a wide range of antidepressants targeting the monoaminergic neurotransmitter system have been available to alleviate the symptoms of depression. However, the efficacy of these antidepressants cannot be solely explained by their modulatory effects on brain monoamines (Hisaoka-Nakashima 2015). In the past decade, it has been postulated that glial degeneration or dysfunction, especially of astrocytes, plays a critical role in the pathogenesis of depression (Rajkowska 2013). One of the major roles of astrocytes is the production of neurotrophic or growth factors, which support neurogenesis, gliogenesis, brain development, neural plasticity, and survival (Allen 2009). Both clinical and preclinical animal studies have demonstrated that multiple neurotrophic or growth factors, such as glial cellderived neurotrophic factor (GDNF), play an important role in the therapeutic effect of antidepressants (Bespalov 2007). Not many studies tested the older TCAs or newer SSRIs in patients with COPD.

Tricyclic antidepressants are no longer first-line treatment for depression, but they have been in use for many years. Their antidepressant effect is a result of the inhibition of the reuptake of neurotransmitters such as serotonin, noradrenalin, and dopamine from synaptic cleft. Previous studies have also demonstrated that an amitriptyline-evoked matrix metalloproteinase (MMP)/ fibroblast growth factor receptor (FGFR)/FGFR substrate2 $a$ (FRS2 $\alpha$ )/extracellular signal-regulated kinase (ERK) cascade is crucial for GDNF production. However, how amitriptyline triggers this cascade remains unknown (Hisaoka-Nakashima 2015).

Selective serotonin reuptake inhibitors are commonly prescribed antidepressant drugs in current standard clinical practice. Results 
from an eight-week randomised controlled trial (RCT) assessing the effects of the SSRI fluoxetine compared to placebo in elderly physically ill individuals with depression showed improvement in depressive symptoms, particularly in individuals with more severe stages of a disease (Evans 1997). In addition, an international RCT found that the SSRI sertraline was a safe and effective treatment for recurrent depression in people with recent myocardial infarction or unstable angina (Glassman 2002). A Cochrane Review assessing the benefits of various antidepressants for the treatment of depression in people with physical illness observed that both TCAs and SSRIs led to a greater reduction in depressive symptoms than placebo, however long-term improvement was greater for SSRIs than TCAs (Rayner 2010). In patients with COPD, it has been hypothesised that antidepressant medications can be beneficial due to the reduction of excessive distress associated with COPD, which could facilitate desirable increased physical activity and compliance with a COPD treatment plan.

\section{Why it is important to do this review}

Given the prevalence and the impact of untreated depressive disorders in patients with COPD, it is essential that effective therapies with the best treatment approach are identified and implemented. Findings by Kim 2000 and Kunik 2005 suggest that fewer than one-third of patients with COPD receive treatment for depression. This is confirmed by a number of studies reporting that COPD-related depression is either untreated, Cafarella 2012; Kim 2014, or inappropriately treated (Cully 2006; Maurer 2008; van Manen 2002). Untreated depression is associated with poor quality of life, worse compliance with medical treatment (Yohannes 2008), increased hospital readmissions, prolonged length of hospital stay (Coventry 2013), and subsequently increased costs to the healthcare system (Felker 2010; Gudmundsson 2005; Kunik 2005; Maurer 2008; Ng 2007; Pumar 2014). Evidence from systematic reviews shows that the presence of psychological comorbidities inflates the costs of care for chronic conditions by at least $45 \%$, after controlling for severity of the physical illness (Hutter 2010; Naylor 2012). Regrettably, the international practice guidelines for COPD do not provide specific recommendations for screening, diagnosing, or treating depression, and current guidelines are based on poorly designed studies or recommendations for the treatment of depression in the general population (GOLD 2018 update).

A Cochrane Review examining the efficacy of antidepressants versus placebo in the general population found that both SSRIs and TCAs were beneficial; with TCAs causing more adverse effects (Arroll 2009). However, it is important to note that treatment with antidepressants can be complicated in patients with COPD due to potential adverse effects that may cause respiratory depression (Evans 1997). A recent finding shows that SSRIs/SNRIs are associated with increased rates of respiratory-related morbidity, mortality, and various adverse events, such as hospitalisation or emergency admissions, in older patients with COPD (aged 66 and over) (Vozoris 2018). This consideration necessitates an updated review of relevant evidence from only those trials that examined the use of antidepressants exclusively in COPD population.

Lung Foundation Australia's COPD Guidelines "The COPD-X Plan: Australian and New Zealand guidelines for the management of chronic obstructive pulmonary disease" do advise that screening for clinically confirmed depression should be part of routine care (Lecheler 2017), and state that evidence for effectiveness of a specific pharmacological therapy for treating COPD-related depression "is still limited" (Yang 2018). As the decision to use pharmacological therapies should be based on reliable, methodologically rigorous research, it is important to evaluate the effectiveness and safety of pharmacological therapies for patients with COPD and depression, and to provide a review of available, up-to-date evidence. Our findings may help clinicians, health professionals, and policymakers decide what pharmacological medication can be implemented as part of Global Initiative for Chronic Obstructive Lung Disease (GOLD) recommendation for safe and effective treatment of COPD-related depression.

\section{O B JECT IVES}

To assess the effectiveness of pharmacological interventions for the treatment of depression in patients with COPD.

\section{METHODS}

\section{Criteria for considering studies for this review}

\section{Types of studies}

We considered all RCTs, including cross-over trials and clusterrandomised trials, for inclusion, providing they assessed a pharmacological intervention for treatment of depression in patients with COPD. However, no cross-over or cluster-randomised trials were included in this review.

\section{Types of participants}

\section{Participant characteristics}

We included studies involving adults, 40 years of age or older, of either gender and of any ethnicity. As most patients with COPD begin experiencing COPD symptoms in their $40 \mathrm{~s}$, it is unlikely that individuals under 40 years of age would be diagnosed with clinically significant COPD (GOLD 2018 update).

\section{Diagnosis}

We included studies involving participants diagnosed with COPD ( FEV $_{1} /$ FVC less than $70 \%$ predicted) as well as a diagnosed depressive disorder (or depressive symptoms) at the time of recruitment to the trial, assessed using standardised diagnostic criteria.

The COPD diagnosis was made by a medical professional clinically or by the GOLD criteria, or both (GOLD 2018 update).

Depression diagnostic criteria included, but were not limited to, DSM-III, DSM-IV (APA 2000), and DSM-5 (APA 2013).

\section{Comorbidities}

Providing a comorbidity was not the primary focus, studies with participants who had comorbid chronic physical conditions (e.g. hypertension, cardiovascular disease, metabolic disease, asthma), comorbid mental disorders (e.g. anxiety), or both, were included. We did not include studies where e.g. anxiety was the primary focus of investigation.

\section{Setting}

All types of settings were eligible for inclusion; e.g. inpatient (psychiatric setting, inpatient treatment for COPD), outpatient, and primary care. 


\section{Subset data}

As per protocol, studies containing subsets of eligible participants were permitted, providing $60 \%$ of the population had clinically diagnosed COPD and a depressive disorder. However, participants with clinically diagnosed COPD and a depressive disorder were the primary population in all of the studies included in the review.

\section{Types of interventions}

We included studies that used pharmacological interventions (of any dosage, as specified by original study authors) for the treatment of depression in patients with COPD, and where comparisons to either placebo or no treatment were used. We included studies in which a pharmacological intervention was delivered in combination with another intervention (cointervention) only if there was a comparison group that received the co-intervention alone; however, we did not identify any such studies.

\section{Experimental intervention}

- Pharmacological

* Non-selective, or first generation antidepressants:

$\square$ tricyclic antidepressants (TCAs), e.g. amitriptyline, nortriptyline, and doxepin

$\square$ monamine oxidase inhibitors (MAOIs), e.g. phenelzine and selegiline

* Selective reuptake inhibitors, or newer generation antidepressants:

$\square$ selective serotonin reuptake inhibitors (SSRIs), e.g. citalopram, fluoxetine, paroxetine, and sertraline

serotonin and norepinephrine reuptake inhibitors (SNRIs), e.g. venlafaxine and duloxetine

$\square$ norepinephrine and dopamine reuptake inhibitors (NDRIs), e.g. bupropion

$\square$ serotonin modulators, e.g. nefazadone, trazodone, and vilazodone

* Other medications:

$\square$ a atypical antipsychotics, e.g. olanzapine, risperidone, quetiapine, ziprasidone, and aripiprazole

benzodiazepines, e.g. diazepam, alprazolam, and lorazepam

anticonvulsants, e.g. gabapentin, topiramate, and lamotrigine

- Pharmacological and co-intervention. As per protocol, we planned to include studies with co-interventions, such as pulmonary rehabilitation, self management, written action plans, or psychotherapy (e.g. cognitive behavioural therapy). However, no such studies were included.

\section{Comparator intervention}

- No treatment (e.g. waiting list and usual care)

- Placebo

- Co-intervention (only if it is the same co-intervention used in the intervention arm of the study)

We intended to include natural products as a comparator cointervention, provided usage was similar between intervention and control arms; or the intervention was a natural therapy alone; or use was as part of a package of pharmacological, psychological, and natural treatments. We planned to document additional natural product therapies received by participants in each potential study. However, we identified no such studies.

We planned to include multi-arm trials, provided there was an intervention arm with any of the interventions mentioned above, and a control arm with any of the controls mentioned above. However, we included no such study in this review.

\section{Types of outcome measures}

\section{Primary outcomes}

- Change in depressive symptoms, measured by a standardised or validated measure. We accepted the following depressive symptoms measures: Beck Depression Inventory (BDI; Beck 1961), Hamilton Depression Rating Scale (HAM-D; Hamilton 1960), Patient Health Questionnaire (PHQ; Spitzer 1999), Depression Anxiety Stress Scales (Lovibond 1995), or any other depression scale

- Adverse events, separated into three subgroups:

- treatment-related adverse events as a result of:

* TCAs (e.g. constipation, dry mouth, urinary retention, sedation, weight gain, confusion);

* SSRIs (e.g. sexual dysfunction, drowsiness, insomnia, dizziness, nausea, tremors, constipation);

* atypical antipsychotics (e.g. hypotension, sedation, cardiac effects, extrapyramidal side effects, cataracts);

* benzodiazepines (e.g. drowsiness, apnoea, bradypnoea, amnesia, confusion).

- disease-related adverse events (e.g. exacerbation of illness, breathlessness, respiratory infections, pulmonary hypertension)

- mortality (30-day and long term) measured by the total number of deaths

\section{Secondary outcomes}

- Change in quality of life from baseline (measured by the St George's Respiratory Questionnaire (SGRQ; Jones 1991), 36-item Short Form Health Survey (SF-36; Ware 1993), or other validated tools, in this order if trial authors report multiple scales)

- Change in dyspnoea from baseline (measured by the Borg scale or other validated tools) (Borg 1982)

- Change in forced expiratory volume in one second $\left(\mathrm{FEV}_{1}\right)$ from baseline

- Change in exercise tolerance from baseline (measured by the six-minute walk test (6MWT), 12-minute walk test (ATS 2002; Butland 1982), or other validated tools)

- Change in hospital utilisation (length of stay or readmission rates) from baseline

- Cost-effectiveness (e.g. measured as a potential reduction in treatment costs, reduced number of appointments with a health professional, reduced use of additional services, or ability to work)

\section{Timing of outcome assessment}

We defined time frames as short term (less than six months), medium term (six to 12 months), and long term (12 months or longer) follow-up assessment periods. In studies with multiple reported long-term follow-up times, for example 12 and 24 months, 
we planned to use the final follow-up assessment reported. The primary time point reported in the 'Summary of findings' tables is the final follow-up assessment.

\section{Hierarchy of outcome measures}

We considered most of the validated and commonly used depressive symptom measures as equivalent: e.g. BDI, HAM-D, PHQ, HDRS, GDS or DASS. If a study used two or more scales to measure the same outcome, we planned to use the scale that was first reported or employed in the other trials included in the same comparison. If a study employed more than one quality of life measure, we applied the following hierarchy of scales: 1 . SGRQ, 2. SF-36, 3. any other quality of life measures used. For reduction in length of hospital stay or readmission rate, we planned to apply the following hierarchy: 1 . length of stay, 2. readmission rate; however, no studies reported this outcome. In case of other measures used, we planned to use them as defined and reported by the study authors.

With regard to the secondary outcomes, we aimed to show treatments that provide short- or medium-term benefits in remission. However, the included studies reported only short-term follow-up data.

\section{Search methods for identification of studies}

We conducted searches to identify all published and unpublished RCTs and applied no date or language restrictions.

\section{Electronic searches}

\section{Cochrane Specialised Registers}

\section{Cochrane Common Mental Disorders Controlled Trials Register (CCMDCTR)}

The Cochrane Common Mental Disorders Group maintains a register of RCTs, the CCMDCTR. The register contains over 40,000 reference records (reports of RCTs) for depression, anxiety, and other common mental disorders. It is a partially studies-based register with more than $50 \%$ of reference records tagged to approximately 12,500 individually $\mathrm{PICO}$-coded study records, which can help facilitate precision searching. Reports of trials for inclusion in the register are collated from weekly generic searches of MEDLINE, Embase and PsycINFO; quarterly searches of the Cochrane Central Register of Controlled Trials (CENTRAL); and review-specific searches of additional databases. Reports of trials are also sourced from international trial registries, drug companies, the handsearching of key journals, conference proceedings, and other (non-Cochrane) systematic reviews and meta-analyses. Details of CCMD's core search strategies can be found on the Group's website, with an example of the core MEDLINE search displayed in Appendix 1. This register is current to June 2016 only.

The search of the CCMDCTR was conducted on 13 June 2016.

The Group's Information Specialist cross-searched the CCMDCTR (studies and references) using the following terms (all years to date):

\#1 (depress* or dysthymi* or "mood disorder" or "affective disorder" or "affective symptom"):ti,ab,kw,ky,emt,mh \#2 (lobstruct ${ }^{\star}$ and (pulmonary or lung ${ }^{\star}$ or airway ${ }^{\star}$ or airflow* ${ }^{*}$ or bronch $^{\star}$ or respirat $\left.\left.{ }^{\star}\right)\right)$ or COPD or emphysema or (chronic* and bronchiti $\left.{ }^{\star}\right)$ :ti,ab,kw,ky,emt,mh
\#3 (\#1 and \#2)

We screened records for pharmacological interventions for the treatment of depression in COPD.

\section{CAG Register (CAGR)}

The Cochrane Airways Group's Specialised Register is also derived from systematic searches of bibliographic databases including: the Cochrane Central Register of Controlled Trials (CENTRAL), MEDLINE, Embase, CINAHL (Cumulative Index to Nursing and Allied Health Literature), AMED (Allied and Complementary Medicine), and PsycINFO, and handsearching of respiratory journals and meeting abstracts (details of the CAGR can be found on the Group's website).

The Group's Information Specialist searched their register for records coded as 'COPD' and 'depression'.

The search of the CAGR was conducted on 28 June 2016.

\section{Other bibliographic database searches}

In March 2017 and November 2018 the Information Specialist with the Cochrane Common Mental Disorders Group ran update searches directly on the following bibliographic databases (Appendix 2). We did not request an additional search of the CAGR register at this time.

- Ovid cross-search (MEDLINE, Embase, PsycINFO) (1-Jan-2016 to 20-March-2017);

- Ovid MEDLINE (1-Jan-2016 to 26-November-2018);

- Ovid Embase (1-Jan-2016 to 2018 Week 48);

- Ovid PsycINFO (1-Jan-2016 to November Week 32018 );

- Cochrane Central Register of Controlled Trials (to Issue 11 of 12, November 2018).

\section{Searching other resources}

We searched online clinical trial registers for ongoing or recently completed studies, including the ISRCTN Registry, US National Institutes of Health Ongoing Trials Register ClinicalTrials.gov, and the World Health Organization (WHO) International Clinical Trials Registry Platform (who.int/trialsearch/).

\section{Grey literature}

We searched sources of grey literature, including theses and dissertations, clinical guidelines, and reports from relevant regulatory agencies, in order to reduce the risk of publication bias and to identify as much relevant evidence as possible.

- Open Grey (opengrey.eu)

- Trove (trove.nla.gov.au)

- The Agency for Healthcare Research and Quality (ahrq.gov)

- Grey Literature Network Service (greynet.org)

\section{Handsearching}

We did not perform any handsearching for this review.

\section{Reference lists}

We searched the reference lists of all included studies and relevant systematic reviews to identify studies that may have been missed 
by the original electronic searches (for example, unpublished or inpress citations). We also conducted a cited reference search on the Web of Science.

\section{Correspondence}

We contacted the authors of Momtaz 2015 study to request additional data.

\section{Data collection and analysis}

\section{Selection of studies}

Two review authors (JP and JA) independently assessed the titles, abstracts, and descriptors identified by the search strategies to determine potential eligibility. We obtained full-texts of the studies deemed potentially eligible, and two review authors (JP and $\mathrm{JA}$ ) independently assessed the full-texts to determine final inclusion. Any disagreements over eligibility were resolved through discussion, or by consulting the third review author (KCC) when consensus could not be reached.

We recorded the decision process in detail to complete a PRISMA flow diagram (Figure 1). 
Figure 1. Study Flow Diagram.

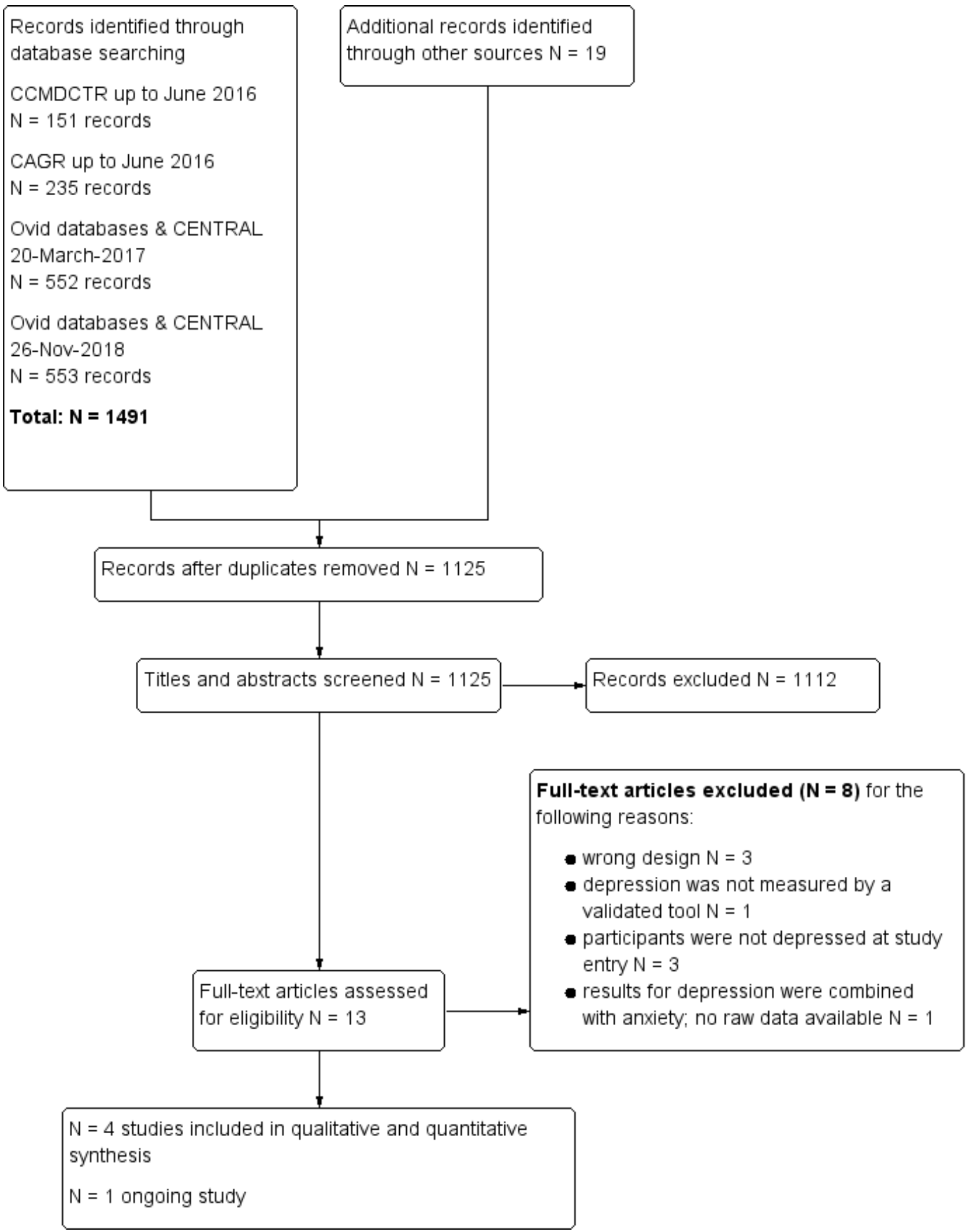




\section{Data extraction and management}

Two review authors (JP and JA) independently extracted data from each study onto a piloted standardised data extraction form. Any disagreements were resolved through consensus or by consulting the third investigator (KCC) when necessary. The following data were extracted:

Study eligibility

- General study information: authors, year of publication, country

- Study design, population group, and description of pharmacological intervention

\section{Participants}

- Number of participants, age, gender distribution, ethnicity, and other relevant information, e.g. comorbidities, severity of condition, inclusion and exclusion criteria

Interventions

- Medication name, trade name, dose, duration of treatment, or placebo

- Outcomes: primary and secondary outcome measures, time points, loss to follow-up

- Descriptives (mean and standard deviation, frequency (\%), or other reported statistics such as odds ratio or $\mathrm{P}$ value)

\section{Main comparisons}

We presented summarised evidence separately for each class of drugs (i.e. first generation and newer generation antidepressants). We grouped the comparisons within each class according to a broad pharmacological category, compared to placebo. We also planned to compare medications with co-interventions versus the same cointervention alone, as outlined in the protocol. Although including an individual medication (within a class) as a main comparison could potentially increase clinical relevance of the findings, we did not find enough studies to evaluate specific medications, nor did we find head-to-head comparisons to include.

Non-selective, or first generation antidepressants

- TCAs versus placebo or no treatment

- MAOIs versus placebo or no treatment

- TCAs and co-intervention versus co-intervention alone

- MAOIs and co-intervention versus co-intervention alone

Selective reuptake inhibitors, or newer generation antidepressants

- SSRIs versus placebo or no treatment

- SNRIs versus placebo or no treatment

- NDRIs versus placebo or no treatment

- Serotonin modulators versus placebo or no treatment

- SSRIs and co-intervention versus co-intervention alone

- SNRIs and co-intervention versus co-intervention alone

- NDRIs and co-intervention versus co-intervention alone

- Serotonin modulators and co-intervention versus cointervention alone

Other medications
- Atypical antipsychotics versus placebo or no treatment

- Benzodiazepines versus placebo or no treatment

- Anticonvulsants versus placebo or no treatment

- Atypical antipsychotics and co-intervention versus cointervention alone

- Benzodiazepines and co-intervention versus co-intervention alone

- Anticonvulsants and co-intervention versus co-intervention alone

\section{Assessment of risk of bias in included studies}

Two review authors independently assessed the risk of bias for the included studies, as per guidelines specified in the Cochrane Handbook for Systematic Reviews of Interventions, using a domainbased evaluation (Higgins 2017). We assessed the risk of bias for each domain as either low, high, or unclear risk of bias (Higgins 2017). Any disagreements were resolved either by consensus or by consulting a third party. We evaluated the following domains (Higgins 2017).

\section{Sequence generation}

Methods considered to be adequate included: random number table, computer random number generator, coin toss, shuffling cards or envelopes, throwing dice, and drawing lots.

\section{Allocation concealment}

Methods considered to be adequate included: central allocation (phone, web, pharmacy), sequentially numbered, identical drug containers, and serially numbered, sealed, and opaque envelopes.

\section{Blinding (of participants and personnel)}

We considered blinding to be adequate if participants and personnel were blinded to the allocation concealment; blinding was not broken; and an identical placebo was used for pharmacological interventions.

\section{Blinding (of outcome assessors)}

We considered blinding to be adequate if authors mentioned that outcome assessors had been blinded to sequence allocation.

\section{Incomplete outcome data}

Our assessment of risk of bias due to incomplete outcome data was based on whether the incomplete outcome data had been adequately addressed by the original trial authors (Higgins 2017).

\section{Selective outcome reporting}

We considered studies to have minimal bias if a protocol was available and all prespecified outcomes had been reported, or (in the absence of a protocol) if all expected outcomes had been reported (Higgins 2017).

\section{Other bias}

We considered studies to be at low risk of other potential sources of bias if the methods ensured that no other factors that could potentially influence the outcomes were evident. Examples of such bias include carry-over in a cross-over trial or extreme baseline imbalance. 
We considered studies with inadequate or unclear randomisation or allocation concealment, or both, as at high risk of bias.

We presented the results of our assessment in a 'Risk of bias' table in the Characteristics of included studies section and provided a description in the text using narrative synthesis.

In addition, we used the GRADE framework to evaluate the overall quality of the evidence supporting the primary outcomes and selected secondary outcomes (Ryan 2016). Using the GRADE approach, the quality of the evidence is downgraded due to withinstudy risk of bias (methodological quality), indirect evidence, unexplained heterogeneity, imprecision of effect estimates, or risk of publication bias. We assigned each outcome one of the following scores: high quality (future research is unlikely to change confidence in the estimate); moderate quality (future research is likely to impact confidence in the estimate); low quality (future research is very likely to impact confidence in the estimate); or very low quality (the estimate is uncertain).

\section{Measures of treatment effect}

We presented all data (continuous and dichotomous) as final values (post-intervention).

\section{Continuous data}

For continuous outcomes, we entered data from validated depression rating scales, quality of life questionnaires, and other clinical measures. We summarised available data by either mean difference (MD) or standardised mean difference (SMD) if various tools were used to measure the same outcome, with corresponding $95 \%$ confidence intervals $(\mathrm{Cl})$, using mean values and standard deviations (SD).

\section{Dichotomous data}

For binary data, we calculated the odds ratio (OR) with corresponding $95 \% \mathrm{Cl}$.

\section{Unit of analysis issues}

\section{Cross-over trials}

As prespecified in the protocol, we did not plan to use data from cross-over trials from the second period (after the cross-over) if there was any doubt about the validity of the data due to a significant carry-over effect. The study by Eiser 2005 was an RCT in its first phase and an open-label treatment in its second phase, conducted in a cross-over manner. We included only the results from the first phase of the study in our analysis.

\section{Cluster-randomised trials}

Cluster randomised controlled trials, i.e. trials in which outcomes relate to individual participants whilst allocation to the intervention is by hospital, clinic, or practitioner, may introduce unit of analysis errors. Statistical methods which assume, for example, that all patients' chances of benefit are independent, ignore the possible similarity between outcomes for patients seen by the same provider. This may provide misleading, narrow confidence intervals, leading to the possibility of a type 1 error. We planned to perform analyses at the level of individuals, whilst accounting for clustering in the data by using estimates that had been adjusted for clustering by the original study authors. For those studies not adjusting for clustering, the actual sample size was to be replaced with the effective sample size (ESS), calculated using a rho $=0.02$ as per Campbell 2000. However, we did not identify any cluster-randomised trials that were eligible for this review.

\section{Studies with multiple treatment groups}

We planned to include multi-arm trials, provided there was an intervention arm with any pharmacological treatment listed above and a control arm with any of the comparators listed above. We planned to include each pair-wise comparison separately, but shared intervention groups were to be equally divided amongst the comparisons. If we deemed the intervention groups similar enough to be pooled, we planned to combine the groups using appropriate formulae described in Chapter 16 of the Cochrane Handbook for Systematic Reviews of Interventions (Higgins 2011). However, we included no multi-arm trials in the review.

\section{Dealing with missing data}

As prespecified in our protocol, we planned to evaluate missing participant information on an available-case analysis basis (Higgins 2011). However, we deemed this to be unnecessary. We did not need to contact authors for missing data for any of the included studies. We intended to address missing standard deviations by imputing data from studies within the same meta-analysis, or from a different meta-analysis but with studies that used the same measurement scales, had the same degree of measurement error, and the same time periods between baseline and final value measurement, per Chapter 16 of the Cochrane Handbook for Systematic Reviews of Interventions (Higgins 2011). However, we deemed this to be unnecessary. Where statistics essential to conduct the analyses were missing and could not be calculated from other available data (e.g. group means and standard deviations for both groups were not reported), we would contact the study authors to obtain the data. However, this was not necessary. We assumed that the loss of participants before baseline measurements were obtained would not affect the outcome data. Attrition was discussed in the 'Risk of bias' tables and in the main text. We also planned that a dropout rate higher than $20 \%$ would be reported descriptively; however, no such study was found.

\section{Assessment of heterogeneity}

We expected this review to have some heterogeneity contributed by factors such as baseline severity of depression, severity of underlying COPD, time of measurement of results, or varying measuring tools used to assess outcomes. We used $\mathrm{Chi}^{2}$ and $\mathrm{I}^{2}$ statistics to quantify inconsistency across studies in combination with visual inspection of the data for differences between studies (e.g. types of interventions, participants, etc.). The observed value of $\mathrm{I}^{2}$ depends on various factors including a magnitude and direction of effects, and strength of evidence for heterogeneity (e.g. $P$ value from the $\mathrm{Chi}^{2}$ test, or a confidence interval for $\mathrm{I}^{2}$ ) (Deeks 2017). A P value of less than 0.10 , rather than 0.05 , was to be considered evidence of statistically significant heterogeneity due to potential low power of the $\mathrm{Chi}^{2}$ statistic when only a small number of trials is available (Deeks 2017). For the purposes of this review, we planned to investigate possible causes of an $\mathrm{I}^{2}$ statistic representing considerable heterogeneity through subgroup analyses, however this was deemed inappropriate. Further details are provided in the Subgroup analysis and investigation of heterogeneity section. We examined the $\mathrm{I}^{2}$ value using the following overlapping bands provided in Chapter 9 of the Cochrane Handbook for Systematic Reviews of Interventions (Deeks 2017). 
- $0 \%$ to $40 \%$ might not be important;

- $30 \%$ to $60 \%$ may represent moderate heterogeneity;

- $50 \%$ to $90 \%$ may represent substantial heterogeneity;

- $75 \%$ to $100 \%$ considerable heterogeneity.

\section{Assessment of reporting biases}

We planned to assess potential reporting bias by visual inspection of a funnel plot. Asymmetry in the plot could potentially be attributed to publication bias, but may well be due to true heterogeneity or poor methodological design. However, we included fewer than 10 studies in the review, and the method is not effective in such cases (Egger 1997). We therefore presented reporting bias in the 'Risk of bias' table.

\section{Data synthesis}

We calculated pooled MD or SMD with $95 \% \mathrm{Cl}$ for continuous outcomes as appropriate. We calculated pooled OR with corresponding $95 \% \mathrm{Cl}$ for dichotomous outcomes. We obtained categorical and continuous treatment effects from a randomeffects model to allow for expected heterogeneity in the interventions and populations. Due to the very small number of included studies, neither sensitivity analyses nor subgroup analyses were conducted. For trials reporting data at more than one time point, we extracted data from the final follow-up period reported by the study authors. We analysed data using Review Manager 5.3 (RevMan 2014).

\section{Subgroup analysis and investigation of heterogeneity}

We expected that the included studies would be heterogeneous due to multiple factors, including baseline severity of depression, severity of underlying COPD, duration of intervention, and the use of multiple measuring tools to assess the same outcome. As such, in our protocol, we prespecified that we would explore a potential difference in the effect of a pharmacological intervention on depression scores across particular subgroups. We planned to investigate heterogeneity and reduce the likelihood of spurious findings, first by 1) limiting the number of subgroups investigated, and 2) preventing knowledge of the studies' results from influencing the choice of subgroups for the analysis (Deeks 2017).

We planned to conduct the following subgroup analyses within each drug classification:

- age (40 to 55 years of age, above 55 to 70 years of age; above 70 years of age);

- gender (male compared to female)

- comorbidity (patients with (non-psychological) comorbidity compared to patients with no comorbidity)

- dosage (low, medium, or high, as defined by each study author);

- duration of the intervention (less than two months compared to two month or longer);

- intervention setting (inpatient compared to outpatient);

- severity of COPD (mild, moderate, severe);

- severity of depression symptoms (mild, moderate, severe).

\section{Sensitivity analysis}

We planned to perform sensitivity analyses to evaluate the impact of our methodology on the overall results. However, due to the small number of included studies, it proved unnecessary to perform sensitivity analysis. We planned to test the validity and robustness of the findings by removing studies based on the following criteria:

- inadequate sequence generation (unclear or high risk of bias);

- inadequate allocation concealment (unclear or high risk of bias);

- significant attrition of the study population (20\% or higher attrition);

- cluster randomised trials;

- cross-over studies;

- studies containing data imputed by the review authors;

- quality of the studies (i.e. high risk of bias for: two or fewer domains, three or four domains, or five to seven domains).

We planned to conduct sensitivity analysis only for primary outcomes.

\section{Summary of findings}

We used the GRADE approach to evaluate the quality of evidence (Schünemann 2017). We used GRADEpro GDT to prepare a 'Summary of findings' table for each comparison and the following domains were evaluated: limitations in design, indirectness, inconsistency, imprecision, and risk of bias (GRADEpro GDT 2015).

We included the following seven outcomes in the 'Summary of findings' table:

- Change in depressive symptoms

- Adverse events

- Change in quality of life

- Change in dyspnoea

- Change in $\mathrm{FEV}_{1}$

- Change in exercise tolerance

- Change in hospital utilisation

Available data were reported based on the final follow-up time points. None of the included studies collected data regarding hospital utilisation or cost-effectiveness.

\section{RES U LTS}

\section{Description of studies}

\section{Results of the search}

All searches conducted to 26 November 2018, identified a total of $\mathrm{N}$ $=1491$ records. We identified an additional $\mathrm{N}=19$ records through other sources, including reference lists of included studies. After removal of duplicates, we screened $N=1125$ records for eligibility of which $\mathrm{N}=13$ were selected for full-text review. A total of five studies met the inclusion criteria, of which one was classified as an ongoing study (NCT02813447 still recruiting November 2018) and four were included in the qualitative and quantitative synthesis (Figure 1).

However, due to the small number of included studies, the subgroup analyses were not conducted. 


\section{Included studies}

We included four studies involving a total of 201 participants, plus one ongoing study, in the review (see also Characteristics of included studies and Table 1).

\section{Design}

All studies used a double-blind RCT design (Borson 1992; Eiser 2005; He 2016; Lacasse 2004). One study used an open-label design in the second phase of their trial (after six weeks of a randomised trial) when, due to ethical reasons, an active intervention was provided to all control participants (Eiser 2005). We included only the first phase of the study in this review.

\section{Sample sizes}

Sample sizes were overall small to moderate, with the smallest sample size 23 participants (Lacasse 2004), and the largest 120 participants (He 2016). The remaining two trials reported sample sizes of 28 and 36 participants for Eiser 2005 and Borson 1992, respectively.

Only one study had no dropouts during their trial (Eiser 2005). In the study by Lacasse 2004, of the 23 randomised participants, 15 completed the trial, but the findings were reported for the 23 randomised participants. In the He 2016 study, of 120 participants, eight dropped out and were lost to follow-up; however, the data for 120 participants were analysed according to the intentionto-treat principle. In the Borson 1992 trial, of 36 participants, six participants left the trial and data were reported for the 30 participants who completed the trial.

\section{Setting}

The included trials were conducted in outpatient clinics. In the study by Eiser 2005, recruited participants attended the University Hospital Lewisham Chest Clinic in the UK. Borson 1992 recruited outpatients from the pulmonary clinics of Seattle Veterans Affairs Medical Center and via private practices in Seattle, the USA. The Lacasse 2004 trial took place within an outpatient service affiliated with Laval Hospital in Quebec, Canada. Lastly, He 2016 recruited participants via the Department of Respiratory Medicine of the Haui'an Second Hospital in China.

\section{Participants}

The lowest reported mean age was 58.7 years (standard deviation (SD) 9.9) for the intervention group in the study by Eiser 2005, while the highest reported mean age was 71.2 (SD 8.4) in the intervention group of the Lacasse 2004 study. All four trials reported on gender breakdown, with a total of 113 male and 94 female participants (Borson 1992; Eiser 2005; He 2016; Lacasse 2004).

Baseline COPD status slightly varied between the studies, but most participants had moderate to severe COPD. Only the study by $\mathrm{He}$ 2016 included participants with mild to severe COPD were included ( $\mathrm{FEV}_{1}$ equal to or less than $80 \%$ predicted). Borson 1992 and Eiser 2005 included participants with $\mathrm{FEV}_{1}$ of equal to or less than $60 \%$ predicted (moderate to severe COPD). In the study by Borson 1992, four participants in each group (31\% of treatment and $24 \%$ of placebo participants) required continuous home oxygen. Similarly, Lacasse 2004 included participants with $\mathrm{FEV}_{1}$ of equal to or less than $50 \%$ predicted, and all participants were on long-term oxygen therapy.
Diagnosed, coexisting depression was an inclusion criterion in all of the included studies. Baseline depression scores varied between the studies. No data were provided for baseline depression scores in the study by Borson 1992, however it was reported that out of the 36 randomised participants, 33 fulfilled the diagnostic criteria for major depressive episode. Three participants had dysthymia (mild but chronic depression). Lacasse 2004 reported mean baseline Geriatric Depression Scale (GDS) scores for the treatment group $(\mathrm{N}=12)$ as 18.7 (SD 3.6), and for the placebo group ( $\mathrm{N}=11)$ as 17.9 (SD 5.2) ( $P=0.6)$. Eiser 2005 reported mean baseline Hospital Anxiety and Depression Scale (HADS) scores for the treatment group $(N=14)$ as $13(S D 2)$ and for the placebo group $(N=14)$ as 10 (SD 4). Aside from the HADS, on each study day participants completed the Beck Depression Inventory (BDI), and at the end of the study a psychiatrist completed the ratings for the MontgomeryAsberg Depression Rating Scale (MADRS); baseline BDI score for the treatment group $(\mathrm{N}=14)$ was $20(\mathrm{SD} 8)$ and for the placebo group ( $\mathrm{N}=14$ ) was 22 (SD 7), and the mean MADRS score for the treatment group was 22 (SD 7) and for the placebo group was 23 (SD 8). The He 2016 study reported baseline 17-item Hamilton Depression Rating Scale (HAM-D) scores for depression as treatment group $(\mathrm{N}=60)$ mean $25.1(\mathrm{SD} 4.7)$ and placebo group $(\mathrm{N}=$ 60) mean 24.4 (SD 5.2). Participants with a HAM-D-17 score between 7 and 17 were considered mildly depressed and were therefore excluded with the justification that psychosocial interventions, rather than pharmacological, are recommended for people with mild depression.

\section{Interventions}

All included studies compared the effectiveness of an active antidepressant treatment to a matched placebo: one study compared a TCA to a placebo (Borson 1992), and three studies compared an SSRI to a placebo (Eiser 2005; He 2016; Lacasse 2004).

\section{TCA versus placebo comparison}

In the study by Borson 1992, nortriptyline was used with each participant starting at one-fourth of the final dose, which was set at $1 \mathrm{mg} / \mathrm{kg}$ body weight. The dose was increased with weekly increments and maintained for eight weeks after reaching the final dose.

\section{SSRIs versus placebo comparison}

In the studies by Lacasse 2004 and Eiser 2005, paroxetine was used as an active antidepressant treatment. In the study by Lacasse 2004, the participants started at $5 \mathrm{mg}$ of paroxetine once daily. The dose was increased weekly up to a maximum of $20 \mathrm{mg}$ or a maximum lower dose that was not associated with side effects. The trial lasted for 12 weeks. After a two-week run-in period, participants in the study by Eiser 2005 took $20 \mathrm{mg}$ of paroxetine for six weeks; four of these participants suffered intolerable side effects and were offered a TCA instead ( $140 \mathrm{mg}$ of lofepramine every night). Participants in the study by He 2016 were treated with $50 \mathrm{mg}$ sertraline for six weeks.

\section{Outcomes}

\section{Changes in depressive symptoms}

Mood was assessed using a number of questionnaires, including the Hospital Anxiety and Depression Scale (HADS) (Eiser 2005), BDI (Eiser 2005), MADRS (Eiser 2005), HAM-D (Borson 1992; He 2016), Clinical Global Improvement scale (CGI) (Borson 1992), GDS 
(Lacasse 2004), and Chronic Respiratory Questionnaire (CRQ) with the "emotional functioning" domain (Lacasse 2004). Coexisting depression was an inclusion criterion in all of the included studies. In the study by Borson 1992, depression was confirmed by a psychiatrist using the Structured Clinical Interview for the Diagnostic and Statistical Manual of Mental Disorders, 3rd edition) (DSM-III). Lacasse 2004 reported that significant depressive symptoms had been confirmed by a psychiatrist before completing the GDS. In the study by Eiser 2005, participants were screened for depression using the self administered HADS, after which depression was confirmed by a psychiatric interview based on Tenth Revision of the International Statistical Classification of Diseases and Related Health Problems (ICD-10) classification of mental and behavioural disorders. In the study by He 2016, depression was confirmed using the Chinese version of the HAMD-17.

\section{Adverse events}

In our review we separated adverse events into three subgroups:

- adverse events as a result of antidepressant medication (reported in all included studies);

- adverse events as a result of disease (reported by Borson 1992 and Eiser 2005);

- mortality (reported in Borson 1992).

In the study by Borson 1992, severity of functional impairment was assessed by describing physical and psychophysiologic symptoms.

\section{Change in quality of life}

All four included trials collected data regarding quality of life. Various measures were used, including the 36-item Short Form Health Survey (SF-36) (Lacasse 2004), the Sickness Impact Profile (SIP) (Borson 1992), and measures targeting disease-specific quality of life such as the St George's Respiratory Questionnaire (SGRQ) (Eiser 2005), the CRQ (Lacasse 2004), and the COPD Assessment Test (CAT) (He 2016).

\section{Change in dyspnoea}

Only Borson 1992 and Lacasse 2004 reported data regarding dyspnoea scores. In the study by Eiser 2005, an open-label study followed six weeks of an RCT, and dyspnoea scores were only reported for the open-label arm, which we did not include in the review. He 2016 did not measure changes in dyspnoea scores.

\section{Change in forced expiratory volume in one second $\left(\mathrm{FEV}_{1}\right)(\mathrm{l})$}

Three trials reported change in $\mathrm{FEV}_{1}$ (Borson 1992; Eiser 2005; He 2016). One trial only reported baseline $\mathrm{FEV}_{1}$ data (Lacasse 2004).

\section{Change in exercise tolerance}

Two studies assessed change in exercise tolerance using the sixminute walk distance (6MWD) test (Eiser 2005; He 2016), while Borson 1992 used the 12MWD test. Lacasse 2004 did not report exercise tolerance data.

\section{Change in hospital utilisation (hospital length of stay or readmission} rates)

None of the studies measured this outcome.

\section{Cost-effectiveness}

None of the studies measured this outcome.

\section{Excluded studies}

We excluded seven studies with reasons provided in Characteristics of excluded studies.

In the study by Gordon 1985, none of the participants met the DSMIII criteria for clinical depression, and only $31 \%$ of the participants reached the threshold for mild depression as measured by the BDI. As the results were not split, it was not possible to determine the effects for depressed participants, and for this reason the study was excluded. Strom 1995 did not include depression as an entry criterion, nor did they focus explicitly on reducing mood symptoms, instead focusing on hypoxaemia. Participants in the study by Yohannes 2001 were not randomised; this was a single-blinded, open study. The study by Light 1986 was also not a randomised trial, and the participants did not meet DSM-III criteria for depression. In the study by Momtaz 2015, the results for anxiety and depression were combined and we were unable to obtain raw data from the study authors. Singh 1993 measured depressive symptoms, however the focus of the study was on anxiety; depression was not an inclusion criterion and individuals were not screened for depression at the time of recruitment. In the Subbe 2004 study, depression was not measured by a validated tool, that is the participants were only asked: "Does feeling low or anxious impair your quality of life?"

\section{Ongoing studies}

We identified one study as eligible but not completed (Mathews 2016); see details in Characteristics of ongoing studies.

\section{Studies awaiting classification}

We found no studies awaiting classification.

\section{Risk of bias in included studies}

A graphical representation of the overall risk of bias in the included studies is presented in Figure 2 and Figure 3. 
Figure 2. Risk of bias graph: review authors' judgements about each risk of bias item presented as percentages across all included studies.

Random sequence generation (selection bias)

Allocation concealment (selection bias)

Blinding of participants and personnel (performance bias)

Blinding of outcome assessment (detection bias)

Incomplete outcome data (attrition bias)

Selective reporting (reporting bias)

Other bias

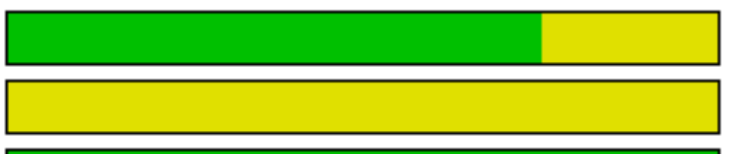

L

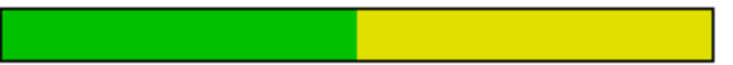

L
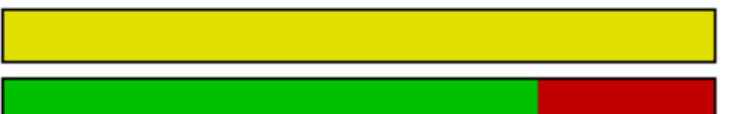

\begin{tabular}{|lllll}
\hline $0 \%$ & & 1 & & 1 \\
& $25 \%$ & $50 \%$ & $75 \%$ & $100 \%$
\end{tabular}

Low risk of bias

Unclear risk of bias

High risk of bias 
Figure 3. Risk of bias summary: review authors' judgements about each risk of bias item for each included study.

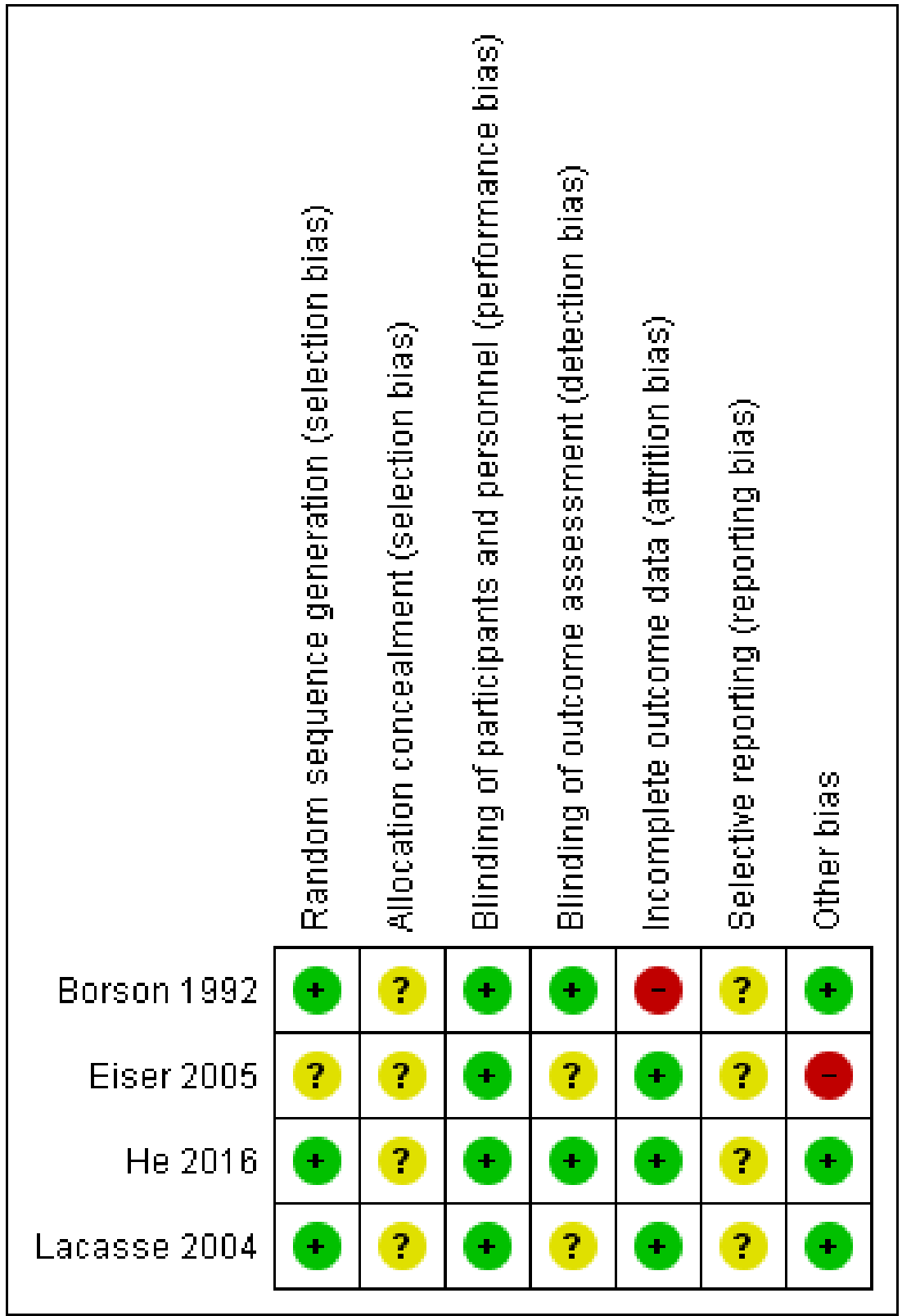

\section{Allocation}

We deemed three studies that adequately described their randomisation methods as at low risk of bias for random sequence generation (Borson 1992; He 2016; Lacasse 2004). Eiser 2005 did not provide sufficient information to permit a judgement and was therefore assessed as at unclear risk of bias for random sequence generation.

All four included studies provided insufficient information on allocation concealment procedures and were therefore assessed as at unclear risk of bias for allocation concealment.

\section{Blinding}

All four included studies stated that they were double-blinded and were therefore considered to be at low risk of performance bias. Two studies provided information on the blinding of outcome assessors and were rated as at low risk of detection bias (Borson 1992; He 2016). The remaining two studies did not provide sufficient information to permit judgement and were assessed as at unclear risk of detection bias.

\section{Incomplete outcome data}

Three studies provided detailed descriptions of attrition as well as a breakdown per group (intervention versus control) and were therefore rated as at low risk of attrition bias (Eiser 2005; He 2016; Lacasse 2004). In the study by Borson 1992, attrition was reported to be considerably higher in the intervention group, and therefore the study was assessed as at high risk of attrition bias. 


\section{Selective reporting}

We assessed all included studies as at unclear risk of reporting bias due to insufficient detail provided regarding publication and adherence to study protocols, or trial registrations.

\section{Other potential sources of bias}

We identified no other potential sources of bias in three studies (Borson 1992; He 2016; Lacasse 2004). In the study by Eiser 2005, it was reported that side effects of paroxetine (SSRI) resulted in a change in medication in four out of 28 participants; these four participants were given lofepramine (TCA) instead of paroxetine. We rated this study as at high risk of other potential sources of bias.

\section{Effects of interventions}

See: Summary of findings for the main comparison Tricylic antidepressant compared to placebo for the treatment of depression in chronic obstructive pulmonary disease; Summary of findings 2 Selective serotonin reuptake inhibitor compared to placebo for the treatment of depression in chronic obstructive pulmonary disease

\section{Comparison 1: TCA versus placebo}

One study with 30 participants (13 in intervention group and 17 in control group) contributed data to this comparison of TCA (nortriptyline) versus placebo (Borson 1992). See also: Summary of findings for the main comparison.

\section{Primary outcomes}

\subsection{Change in depressive symptoms}

Borson 1992 reported HAM-D post-treatment mean scores for depression as 12.6 (SD 6.9) in the intervention group and 22.8 (SD 11.3) in the placebo group (mean difference (MD) -10.20, 95\% confidence interval $(\mathrm{Cl})-16.75$ to $-3.65 ; 30$ participants; 1 study; $P=0.007$ ) (Analysis 1.1). The GRADE quality of evidence for this outcome was very low due to the small sample size, imprecision of the result and risk of selection, attrition, and reporting bias (Summary of findings for the main comparison).

\subsection{Adverse events}

\subsubsection{Disease-related adverse events: all physical symptoms}

Borson 1992 reported several disease-related outcomes. Overall, all physical symptoms associated with distress (measured by PatientRated Anxiety Scale) were reduced in the intervention group from a mean of 26.1 (SD 7.6) to 15.4 (SD 3.4) $(P=0.001)$, whereas in the control group the symptoms were reduced from 23.2 (SD 9.4) to 21.6 (SD 12.4). There was no difference between groups post-treatment (MD $-6.20,95 \% \mathrm{Cl}-12.38$ to $-0.02 ; 30$ participants; 1 study; $\mathrm{P}=$
0.09) (Analysis 1.2). However, Borson 1992 calculated the average difference between change scores in the intervention and control groups and reported a statistically significant result $(P=0.008)$. The GRADE quality of evidence for this outcome was very low (Summary of findings for the main comparison).

\subsubsection{Disease-related adverse events: breathlessness symptoms}

Similarly, symptoms related to breathlessness (measured by Patient-Rated Anxiety Scale) decreased substantially from baseline to follow-up in the intervention group, 17.8 (SD 5.9) to 11.5 (SD 2.9) $(P=0.006)$, compared to the placebo group, 15.9 (SD 7.2) to 14.9 (SD 9.5). There was no difference between groups posttreatment (MD -3.40, $95 \% \mathrm{Cl}-8.18$ to $1.38 ; 30$ participants; 1 study; $P$ $=0.22$ ) (Analysis 1.2). Borson 1992 calculated the average difference between change scores in the intervention and control groups and reported a statistically significant result $(P=0.04)$.

\subsubsection{Treatment-related adverse events}

Three participants left the trial due to side effects of nortriptyline, specifically dry mouth, feelings of sedation, and/or orthostatic hypotension, which resulted in a dropout disparity (5:1 ratio) between the intervention and control group.

\subsubsection{Mortality}

One case of death was reported in the placebo group due to cardiorespiratory arrest.

\section{Secondary outcomes}

\subsection{Change in quality of life}

The SIP was used to measure illness-related dysfunctional behaviour. The overall score encompassing both physical and psychosocial domains improved in the treatment group from 24.5 (SD 9.9) to 15.7 (SD 11.8) and in the placebo group from 21.2 (SD 10.6) to 18.5 (SD 10.8). However, the results of our analysis were not statistically significant (MD $-2.80,95 \% \mathrm{Cl}-11.02$ to $5.42 ; 30$ participants; 1 study; $P=0.50$ ) (Analysis 1.3 ). The GRADE quality of the evidence for this outcome was very low (Summary of findings for the main comparison).

\subsection{Change in dyspnoea}

Dyspnoea was measured using the Pulmonary Functional Status Instrument (and a 100-millimetre horizontal visual analogue scale before and after a standard 12-minute walk test). The comparison between placebo and nortriptyline groups showed no evidence of a significant effect on dyspnoea for any of the eight subgroups (MD 9.80, 95\% Cl -6.20 to $25.80 ; 30$ participants; 1 study; $P=$ 0.23 ) (Analysis 1.4; Figure 4). The GRADE quality of evidence for this outcome was very low (Summary of findings for the main comparison). 
Figure 4. Forest plot of comparison: 1 Tricylic antidepressant versus placebo, outcome: 1.4 Change in dyspnoea (Pulmonary Functional Status Instrument).

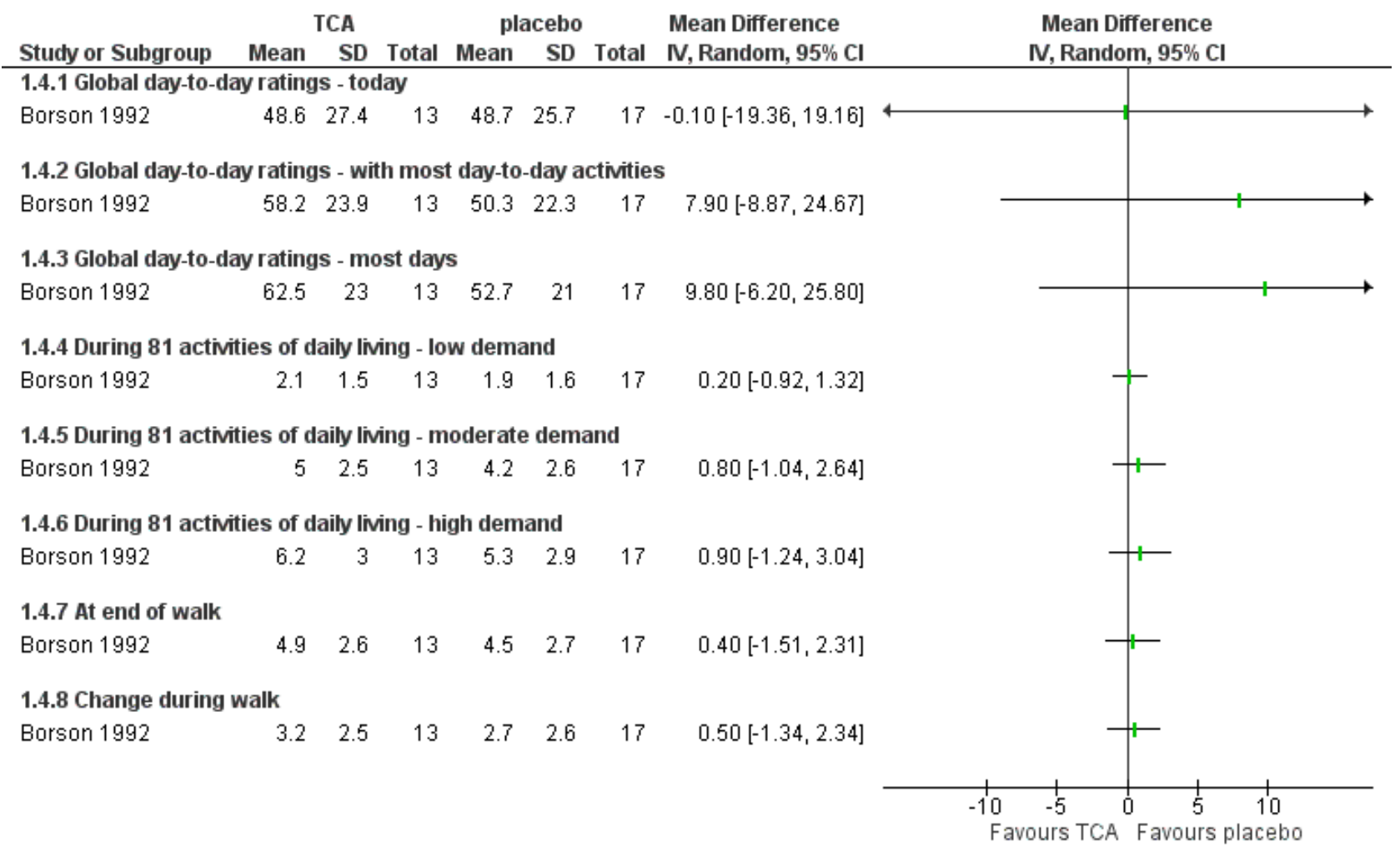

\subsection{Change in $\mathrm{FEV}_{1}(\mathrm{l})$}

Borson 1992 reported observing no change between groups for respiratory function, as measured by spirometry and arterial blood gasses. However, no data were reported, making it impossible to verify the claims of the authors. The GRADE quality of evidence for this outcome was very low (Summary of findings for the main comparison).

\subsection{Change in exercise tolerance}

While 12MWD was measured, no results were reported on the actual distance travelled. The authors reported observing no significant change during the trial in either group $(P>0.10)$. The GRADE quality of evidence for this outcome was very low (Summary of findings for the main comparison).

\subsection{Change in hospital utilisation (length of stay or readmission rate)}

Borson 1992 did not collect data for this outcome.

\subsection{Cost-effectiveness}

Borson 1992 did not collect data for this outcome.

\section{Comparison 2: SSRI versus placebo}

Three studies with 171 participants contributed data to this comparison of SSRIs (paroxetine and sertraline) versus placebo. See also: Summary of findings 2.

\section{Primary outcomes}

\subsection{Change in depressive symptoms}

Three studies examined the effect of SSRIs on depressive symptoms (Eiser 2005; He 2016; Lacasse 2004). Two studies provided sufficient data to permit meta-analysis (Eiser 2005; He 2016). When pooled using standardised mean difference (SMD) to account for variability in scales employed (HADS and HAM-D-17), there was no difference between groups post-treatment (SMD $0.75,95 \% \mathrm{Cl}-1.14$ to 2.64; 148 participants; 2 studies; $\mathrm{P}=0.44$ ) (Analysis 2.1). However, the results must be interpreted with caution as considerable heterogeneity was observed $\left(I^{2}=95 \%\right)$. The heterogeneity can be explained by significant methodological and clinical variability across the trials, for example differences in depression levels and types of medication and doses used. Overall, the GRADE quality of evidence for this outcome was very low, as neither of the two studies provided information regarding allocation concealment or selective reporting. Additionally, the study by Eiser 2005 did not provide details regarding methods of randomisation or blinding of outcome assessment. Moreover, this study was at high risk of other potential sources of bias due to four out of 14 participants receiving lofepramine (TCA) instead of the tested paroxetine (SSRI). The change of medication occurred due to side effects caused by paroxetine (Summary of findings 2 ).

Lacasse 2004 also reported data regarding depression, finding that depressive symptoms improved amongst participants treated with paroxetine as measured by the GDS. Within-group difference at final follow-up was reported to be significant $(P=0.04)$. However, in the control arm within-group difference at final follow-up was 
reported as not significant $(P=0.60)$. No post-intervention scores were available.

\subsection{Adverse events}

All three trials reported medication-specific adverse events. It was not possible to combine the adverse events into a total count, however it was possible to meta-analyse the results for two types of medication-specific adverse effects: nausea and dizziness (Analysis 2.2). Data were reported on nausea in three studies (Eiser 2005; He 2016; Lacasse 2004), and on dizziness in two studies (He 2016; Lacasse 2004). There were no significant differences between SSR and placebo groups for nausea (odds ratio (OR) 2.32, 95\% Cl 0.66 to 8.12; 171 participants; 3 studies; $\mathrm{P}=0.19 ; \mathrm{I}^{2}=0 \%$ ) or dizziness (OR $0.61,95 \% \mathrm{Cl} 0.09$ to $4.06 ; 143$ participants; 2 studies; $P=0.61 ; I^{2}=$ $0 \%)$. Heterogeneity was not a concern. Overall, the GRADE quality of evidence for this outcome was very low (Summary of findings 2).

Lacasse 2004 reported that there was no significant difference in side effects between the paroxetine group and the placebo group. In the paroxetine group, participants experienced constipation ( $\mathrm{N}$ $=2)$, taste perversion $(N=1)$, nausea $(N=2)$, headache $(N=2)$, dry mouth $(N=1)$, somnolence $(N=5)$, and tremor $(N=2)$. Overall, only one participant discontinued treatment due to side effects. In the placebo group, participants experienced dizziness $(\mathrm{N}=2)$, flatulence $(\mathrm{N}=1)$, nausea $(\mathrm{N}=1)$, dry mouth $(\mathrm{N}=1)$, and somnolence $(\mathrm{N}=2)$.

In the study by Eiser 2005, four participants experienced paroxetine-related nausea and vomiting and were offered lofepramine (140 mg every night) instead. One participant in the placebo group developed nausea. After six weeks of active treatment, three participants were admitted to hospital due to acute exacerbations of COPD.

In the study by He 2016, no significant differences were observed between the intervention and placebo groups $(P>0.05)$. In the sertraline group, participants experienced nausea $(\mathrm{N}=3)$, diarrhoea $(\mathrm{N}=1)$, dizziness $(\mathrm{N}=1)$, insomnia $(\mathrm{N}=2)$, sweating $(\mathrm{N}=1)$, and anorexia $(\mathrm{N}=1)$. In the placebo group, participants experienced nausea $(N=2)$, diarrhoea $(N=1)$, dizziness $(N=1)$, insomnia $(N=2)$, sweating $(\mathrm{N}=1)$, and anorexia $(\mathrm{N}=1)$. All the reported side effects were mild in intensity.

\section{Secondary outcomes}

\subsection{Change in quality of life}

Pooled analysis of two studies found no improvement postintervention for change in quality of life (SMD $1.17,95 \% \mathrm{Cl}-0.80$ to 3.15; 148 participants; 2 studies; $P=0.25$ ) (Analysis 2.4) (Eiser 2005; He 2016). In addition, considerable heterogeneity was observed $\left(I^{2}\right.$ $=95 \%$ ), which can be explained by variability in medication doses and in tools used to measure quality of life. The overall GRADE quality of evidence for this outcome was very low (Summary of findings 2).

One study was not included in the pooled analysis for this outcome as no post-intervention data were provided (Lacasse 2004). Quality of life was measured using the SF-36 and CRQ (for emotional function, mastery, dyspnoea, and fatigue). Statistically significant improvement favouring the treatment arm was reported for the CRQ domains of 'emotional function' (MD 1.1, $95 \% \mathrm{Cl} 0.0$ to 2.2 ) and 'mastery' (MD 1.1, 95\% Cl 0.4 to 1.8). However, the authors reported that statistical significance was not reached when using intention- to-treat analysis. The other two domains, 'dyspnoea' and 'fatigue', were also reported to have improved but statistical significance was not reached.

\subsection{Change in dyspnoea}

No data were provided for this outcome. Out of the three studies evaluating SSRIs, one study reported only baseline dyspnoea scores (Lacasse 2004), with no post-intervention data reported. Eiser 2005 and He 2016 did not measure dyspnoea.

\subsection{Change in $\operatorname{FEV}_{1}(\mathrm{l})$}

Pooled analysis found no difference in change of $\mathrm{FEV}_{1}$ between the intervention and placebo groups (MD $0.01,95 \% \mathrm{Cl}-0.03$ to 0.05 ; 148 participants; 2 studies; $\mathrm{P}=0.60)$, and heterogeneity was not a concern $\left(I^{2}=0 \%\right.$ ) (Analysis 2.3). Overall, the GRADE quality of evidence for this outcome was very low (Summary of findings 2 ).

The study by Lacasse 2004 only reported baseline FEV $_{1}$ scores and did not provide post-intervention data.

\subsection{Change in exercise tolerance}

Pooled analysis found significantly higher scores post-intervention on the 6MWD test for participants treated with SSRIs compared to those treated with placebo (MD 13.88, 95\% Cl 11.73 to $16.03 ; 148$ participants; 2 studies; $\mathrm{P}<0.001$ ) (Analysis 2.5 ). Heterogeneity was not a concern $\left(I^{2}=0 \%\right)$. However, the GRADE quality of evidence for this outcome was very low (Summary of findings 2).

Lacasse 2004 was not included in this meta-analysis as no data were reported for exercise tolerance.

\subsection{Change in hospital utilisation (length of stay or readmission rate)}

None of the studies collected data for this outcome.

\subsection{Cost-effectiveness}

None of the studies collected data for this outcome.

\section{Reporting bias}

Due to the small number of included studies, we did not assess publication bias using a funnel plot.

\section{DISCUSSION}

\section{Summary of main results}

The findings of this review were based on four randomised, double-blind, placebo-controlled trials involving a total of 201 participants. One trial with 30 participants studied the effects of the TCA nortriptyline on depressive symptoms and other outcomes in participants with COPD (Borson 1992), and three trials (with 171 participants) evaluated SSRIs (Eiser 2005; He 2016; Lacasse 2004). All of the included studies presented short-term results (up to three months). The main characteristics of the included studies are summarised in Table 1.

\section{TCA versus placebo}

\section{Primary outcomes}

Based on a single study, the results suggest that TCA (nortriptyline) was more efficacious than placebo in reducing depressive symptoms in adults with COPD. Post-intervention scores on the 
HAM-D showed an improvement of $60 \%$ in the treatment group compared to $17 \%$ in the placebo group. This score exceeded the minimal clinically important difference of $27 \%$ change commonly reported for the HAM-D (Masson 2013). The benefits observed for this comparison may be clinically relevant, however we could draw no conclusions as this finding is based on a small study with very low-quality evidence (Summary of findings for the main comparison).

Three participants withdrew from the trial due to side effects typically associated with TCAs, such as dry mouth and sedation (Remick 1988), which contributed to the difference in attrition rates between the intervention and control groups, 5:1 respectively.

\section{Secondary outcomes}

We found that quality of life as measured by the SIP did not improve in the treatment group. However, Borson and colleagues calculated the average difference between change scores and identified a statistically significant result (Borson 1992).

There was insufficient evidence to support the use of nortriptyline to manage dyspnoea, which is a current gap in knowledge also identified by the Canadian Thoracic Society clinical practice guidelines (Marciniuk 2011). No statistically significant change was observed for the outcomes of respiratory function $\left(\mathrm{FEV}_{1}\right)$ or exercise capacity, which is in line with the findings of other studies (Gordon 1985; Light 1986; Strom 1995). No data were collected for the hospital utilisation, or for cost-effectiveness.

\section{SSRIs versus placebo}

\section{Primary outcomes}

Three studies contributed data to this comparison (Eiser 2005; He 2016; Lacasse 2004). Pooled analysis of two studies ( $N=$ 148) showed no evidence of any effect for change in depressive symptoms post-treatment. Given that considerable heterogeneity was observed, the reliability of these findings is limited. Although the third study could not be included in the analysis (Lacasse 2004), it identified a statistically significant improvement in the paroxetine group post-intervention. However, these results were not maintained when analysed using the adjusted mean difference between groups at final follow-up. In the literature, results from other studies that used SSRIs in patients with COPD have indicated improvements in depression scores favouring treatment with SSRIs (Momtaz 2015; Papp 1995; Yohannes 2001); however, the methodological quality of these studies was also low.

Three trials reported common medication-specific side effects such as nausea, dizziness, and dry mouth (Ferguson 2001), with several participants withdrawing or needing to be switched to a different antidepressant. It is generally thought that SSRIs are better tolerated than TCAs (Anderson 2000), however our results show that adverse effects can occur with both treatment types, hindering treatment compliance. Hickie 2011 reported that in studies of elderly participants side effects related to TCAs were more serious than those related to SSRIs, but Mottram 2006 found withdrawal rates to be similar for participants receiving SSRIs and TCAs.

\section{Secondary outcomes}

We found that SSRIs did not improve quality of life and respiratory function $\left(\mathrm{FEV}_{1}\right)$ compared to placebo. However, some improvement was observed in the SSRI group in exercise capacity.

The included trials did not collect or report data on dyspnoea, hospital utilisation rates, or cost-effectiveness, thus no conclusions could be drawn for these outcomes.

\section{Overall completeness and applicability of evidence}

Our comprehensive global search identified only four RCTs that met our eligibility criteria and were included in the review.

Findings from this review are applicable to adults with COPD and comorbid depression (defined by validated diagnostic criteria). The included studies had small or very small sample sizes, and recruited participants had for the most part moderate to severe COPD and moderate to severe depression. Taking into account that depression is a highly prevalent comorbidity in patients with COPD (Maurer 2008; Panagioti 2014; Zhang 2011), that negatively affects the quality of life, disease severity, exercise capacity, and frequency of healthcare service use (Atlantis 2013), the evidence summarised in this review may be considered an important step forward in the search for effective and safe management of COPDrelated depression. However, as the evidence is based on four small trials, caution is required when interpreting the results.

It is worth considering why there are so few relevant RCTs published worldwide. The authors of the Lacasse 2004 study found that out of 105 eligible participants, only 23 enrolled (and only 15 completed the trial). One of the reasons reported was refusal to take medication, despite the fact that potential participants met the criteria for depression. This finding is in line with the results from a systematic review and meta-analysis showing that patients favour non-pharmacological treatments (e.g. psychological therapies such as cognitive behavioural therapy or mindfulness-based therapies) (McHugh 2013). Other studies also published data indicating that chronically ill patients suffering from depression and other comorbidities do not wish to be treated with yet another medication (Yin 2017; Yohannes 2001; Yohannes 2011; Yohannes 2014), which might partly explain the undertreatment of depression in this cohort (Kim 2014; Kunik 2005; Mignogna 2012). Moreover, issues in recruiting participants suggest that individuals with COPD and depression may have low motivation to participate in experimental research, hence the low number of trials globally. The British Lung Foundation conducted a survey whose qualitative findings show that people with COPD strongly emphasise 'inability to do anything', isolation, restriction, low confidence, and depression (BLF 2006).

The age and gender distribution of participants recruited in the included studies reflects the average age and gender profile of patients with COPD, including the growing prevalence rates of female patients. The participants were recruited from hospital pulmonary outpatient clinics, and the included trials were conducted in four countries: the USA, Canada, the UK, and China.

The findings of this review are based only on short-term efficacy, as all four included studies were of short duration: six weeks in Eiser 2005 and He 2016 and 12 weeks in Borson 1992 and Lacasse 2004. It is worth noting that Eiser and colleagues, after completion of their six-week RCT, continued with an open-label 
trial with the same participants (Eiser 2005). At six-month followup assessment, they found significant improvements not only in mood symptoms, but also in quality of life and exercise capacity. However, these scores were not compared to a control group. The study authors concluded that six weeks treatment with paroxetine (SSRI) was insufficient to reduce depressive symptoms in the experimental group. However, depressive symptoms, quality of life, and exercise capacity improved significantly after 12 weeks of continued treatment in the open-label trial that followed the RCT.

The fact that this review presents no evidence for sustained effects after treatment is a clear limitation in terms of applicability of the findings, given that treatment recommendations for antidepressants often exceed four months (Piek 2010), and longterm use of antidepressants has different implications for patients in terms of variability in side effects (Moret 2009).

Lack of data on hospital utilisation and cost-effectiveness is an important gap in knowledge. A systematic review and metaanalysis by Atlantis 2013 found that depression in patients with COPD predicted increased frequency of hospital admissions and readmissions. Consequently, costs associated with COPD-related hospitalisations are substantial and contribute to the global burden of disease (Carey 2016; WHO 2017).

Considering very small number of studies in each comparison and limited reporting of adverse events and each of the secondary outcomes, the overall completeness and acceptability of the evidence found by this review is very poor.

\section{Quality of the evidence}

\section{TCA versus placebo}

We assessed the evidence for all outcomes on the effect of TCA versus placebo ( $\mathrm{N}=30$ participants) as of very low quality. Information regarding allocation concealment was insufficient; there was a potential risk of selective reporting due to the absence of a protocol; and the trial was at high risk of attrition bias. The dropout rate in the intervention group was much higher than in the control group, and only participants who completed the trial in the intervention group were included in the original analyses. Additionally, one participant had been treated with doxepin prior to the study entry, and the study authors reported that the participant experienced "marked improvement in mood and functional status". We downgraded the quality of the evidence for change in dyspnoea for imprecision due to a very large confidence interval, and for change in $\mathrm{FEV}_{1}$ due to insufficient data reported.

\section{SSRIs versus placebo}

Similarly, the evidence for the outcomes on the effects of SSRIs was of very low quality. Three studies ( $N=171$ participants) did not report details regarding the process of allocation concealment or the publication of a protocol. One study did not describe methods of randomisation, and two studies did not state whether outcome assessors were blinded to sequence allocation. In addition, in one study that evaluated paroxetine, four participants (out of 14) had their treatment changed to a TCA due to paroxetine-related side effects.

There were two main sources of heterogeneity across the included SSRI studies: the use of different doses of antidepressants and the use of different instruments to measure depressive symptoms
(HAM-D, BDI, HADS, MADRS, GDS; see also Table 1). Self reported measures as screening tools for depression are convenient to use, however there is a substantial variability amongst the available questionnaires. Although validated, investigators question their suitability for chronically ill (older) patients and the inability to distinguish between overlapping symptoms of depression and, for example, COPD (Cosco 2011; Meader 2011).

We found very high statistical heterogeneity $\left(I^{2}=95 \%\right)$ in the analyses of two studies for the outcomes of depressive symptoms and quality of life. The following differences may be relevant: differences in study samples $(\mathrm{N}=28$ in the smaller UK study versus $N=120$ in the bigger Chinese study), medication and doses used, screening tools, and severity of COPD and depression. In the smaller study, participants had moderate to severe COPD, while the bigger study from China recruited participants with all levels of COPD severity, including mild COPD. Importantly, in the Chinese study, the investigators used a translated and culturally adapted HAM-D-17 to confirm clinically relevant depression, whereas in the UK study HADS was used. The bigger study from China was the only study that did not use a psychiatric interview to confirm depression following self reported scores.

All studies were small with up to 30 participants, except for the Chinese trial, which included 120 participants.

In this review, the main reason for exclusion of the studies that were assessed as potentially eligible, was the fact that the participants did not have clinically diagnosed depression (Gordon 1985; Light 1986; Singh 1993; Strom 1995; Subbe 2004). It is a common and significant limitation across relevant literature, and it contributes to the low certainty of published evidence, as trials with participants who do not have clinically significant depression may present erroneous results.

\section{Potential biases in the review process}

Potential biases related to the selection of studies, data extraction, or data analyses were limited, as Cochrane guidelines were followed. Searches were obtained from the registers of two Cochrane groups: Cochrane Common Mental Disorders Group and Cochrane Airways Group. Trial registers and reference lists of relevant published, unpublished, and ongoing studies were also searched. Two review authors independently made decisions about inclusion and exclusion of potential studies, according to prespecified eligibility criteria described in the published protocol. We did not examine funnel plots given the small number of trials identified.

\section{Agreements and disagreements with other studies or reviews}

The results of this review and meta-analysis reflect the inconclusiveness of investigations on the efficacy and effectiveness of antidepressants for patients with COPD. A few literature reviews and overviews have already addressed the question of effective management of depression in the COPD population (Mikkelsen 2004; Panagioti 2014; Pumar 2014; Stage 2006; Tselebis 2016; Yohannes 2011; Yohannes 2014). Our review, however, is the first systematic review and meta-analysis on the subject. We included only RCTs that focused exclusively on depression, rather then depression combined with anxiety. Most of the reviews used broader eligibility criteria and included non-controlled trials. 
Overall, the results of published trials that examined TCAs and SSRIs in people with COPD-related depression are weakened due to poor methodology, small sample size, short-term trials, variability in medication dosage, and in tools measuring depressive symptoms. Consequently, none of the literature reviews found adequate evidence on the efficacy of antidepressants for improving our primary outcome of COPD-related depression.

Contrary to the finding from the small trial by Borson 1992, that the TCA nortriptyline may be beneficial to patients with COPD and depression, other small studies that were not included in this review, evaluated TCAs compared to placebo and found no significant improvement between the groups with regard to depressive symptoms (Light 1986; Strom 1995). Also, although results of a Cochrane Review indicate that TCAs may have even higher efficacy than SSRIs in physically ill individuals with depression (Rayner 2010), some investigations show that caution is necessary when using TCAs in COPD patients, specifically patients with hypercapnia (Cafarella 2012). It is unlikely that further trials using TCAs will be conducted, as SSRIs are now considered the firstline treatment for depressive disorders.

Similarly, the efficacy and safety of SSRIs in patients with COPD have not been investigated thoroughly in RCTs (Papp 1995; Yohannes 2001), and our findings should be interpreted with caution until larger, well-designed trials provide a more reliable level of evidence. One study included in our review that tested paroxetine reported that four participants experienced treatmentrelated severe nausea and vomiting (Eiser 2005). In the same study, three participants were admitted to hospital due to acute COPD exacerbations. A recent retrospective cohort study provided data on adverse events linked to SSRIs and SNRIs in older participants (>66 years) with COPD (Vozoris 2018). Increased rates of exacerbations and respiratory-related mortality were observed in this study; it is therefore extremely important to take into consideration adverse respiratory outcomes when considering treatment with SSRIs (or other antidepressants) in older individuals with COPD.

Similar to non-systematic literature reviews, the current review and meta-analysis found the same methodological challenges when evaluating the effectiveness of pharmacological interventions on depressive symptoms (and other outcomes) in patients with COPD and depression. Given the paucity of information reported in the original studies, we were not able to quantify some outcomes. However, compared to a descriptive summary presented in other published reviews (Mikkelsen 2004; Pumar 2014; Stage 2006), our review and meta-analysis provides a quantitative summary of the magnitude of treatment effects for our primary outcomes. Future research is needed to more reliably determine safety and potential benefits of pharmacological interventions for patients with COPD and comorbid depression.

\section{AUTHORS' CONCLUSIONS}

\section{Implications for practice}

The evidence presented in this review is insufficient to permit recommendations regarding the effectiveness or safety of pharmacological interventions for treatment of depression in patients with chronic obstructive pulmonary disease (COPD). We assessed the quality of the evidence as very low due to the small number of randomised controlled trials with various methodological and clinical limitations. Great caution is therefore advised when prescribing antidepressant medication to patients with COPD, as potential respiratory side effects have been shown to occur (Rief 2009; Vozoris 2018). Also, some of the effects of antidepressants occur over a prolonged period, and the trials included in this review were of short duration.

Considering non-pharmacological treatment options where possible, including minimal interventions, cognitive behaviouralbased therapies, education, patient-centred programmes, or a combination of treatments may be a better approach for individuals with chronic illness (McHugh 2013; NICE 2009). Cognitive behavioural therapy is arguably the gold standard in the field of psychological therapies, and trials investigating non-pharmacological therapies for COPD-related depression continue to find promising results (though effect sizes are small) for this patient population (Hynninen 2010; Kunik 2008; Pollok 2016). Also, nurse-led interventions using a cognitive behavioural therapy approach (Lamers 2010; Lee 2015), whether group or individual, have the potential to be effective not only in alleviating depressive symptoms and improving quality of life, but also to identify barriers to treatment or other patient concerns (Maurer 2008). A combination of therapies, including pulmonary rehabilitation programmes and education, may encourage collaborative care model and improve the understanding and management of depression (de Godoy 2003; Howard 2014). Prescribing antidepressant medication without supportive monitoring and, more importantly, without evidence for safety and effectiveness, is not adequate.

\section{Implications for research}

Future research studies need to address not only effectiveness, but also the important issue of safety of antidepressants in treating COPD-related depression. There is a need for rigorous, adequately powered randomised trials to evaluate the role of pharmacological treatment for depression in patients with COPD. In particular, there is a need for studies focusing on longterm effects. Careful consideration must be given in reporting the process of allocation concealment, sequence generation, and adequate blinding of outcome assessors and participants. Some trials potentially eligible for inclusion in our review were excluded because the investigators did not recruit participants with clinically confirmed depression, but applied diagnostic criteria after randomisation. In other trials, participants did not even meet diagnostic criteria for depression and we included in the analysis despite having no or mild depressive symptoms.

As no studies reported data on hospital utilisation (length of stay or re-admission rates) and cost-effectiveness, future trials investigating these outcomes are required (e.g. costeffectiveness measured as reduction of treatment costs, number of medical appointments, or ability to work). Also, investigations examining long-term effectiveness of a pharmacological treatment as an adjunct to psychological treatment in comparison to a psychological treatment alone are needed. Head-to-head comparisons using various interventions may answer the question of how to treat COPD-related depression most effectively. 


\section{A C K N OWLEDGEMENTS}

We would like to acknowledge the assistance of the editors and staff of the Cochrane Common Mental Disorders Group and the Cochrane Airways Group.

We would also like to thank Professor Anna Chur-Hansen and Professor Gregory Crawford from the University of Adelaide Faculty of Health and Medical Sciences for their mentoring and support of this project.

\section{CRG Funding Acknowledgement}

The National Institute for Health Research (NIHR) is the largest single funder of the Cochrane Common Mental Disorders Group.

\section{Disclaimer}

The views and opinions expressed herein are those of the review authors and do not necessarily reflect those of Cardiff University, the NIHR, the National Health Service, or the Department of Health and Social Care. 


\section{REFERE N C E S}

\section{References to studies included in this review}

Borson 1992 \{published data only\}

Borson S, McDonald GJ, Gayle T, Deffebach M, Lakshminarayan S, VanTuinen C. Improvement in mood, physical symptoms, and function with nortriptyline for depression in patients with chronic obstructive pulmonary disease. Psychosomatics 1992;33(2):190-201. [DOI: 10.1016/ S0033-3182(92)71995-1]

\section{Eiser 2005 \{published data only\}}

Eiser N, Harte R, Karvounis S, Phillips C, Isaac MT. Effect of treating depression on quality-of-life and exercise tolerance in severe COPD. COPD: Journal of Chronic Obstructive Pulmonary Disease 2005;2(2):233-41. [DOI: 10.1081/COPD-57596]

\section{He 2016 \{published data only\}}

He Y, Zheng Y, Xu C, Yang H, Wang Z, Zhou L, et al. Sertraline hydrochloride treatment for patients with stable chronic obstructive pulmonary disease complicated with depression: a randomized controlled trial. The Clinical Respiratory Journal 2016;10(3):318-25. [DOI: 10.1111/crj.12219]

\section{Lacasse 2004 \{published data only\}}

Lacasse Y, Beaudoin L, Rousseau L, Maltais F. Randomized trial of paroxetine in end-stage COPD. Monaldi Archives for Chest Disease 2004;61(3):140-7. [DOI: 10.4081/monaldi.2004.692]

\section{References to studies excluded from this review}

\section{Gordon 1985 \{published data only\}}

Gordon GH, Michiels TM, Mahutte CK, Light RW. Effect of desipramine on control of ventilation and depression scores in patients with severe chronic obstructive pulmonary disease. Psychiatry Research 1985;15(1):25-32.

\section{Light 1986 \{published data only\}}

Light RW, Merrill EJ, Despars J, Gordon GH, Mutalipassi LR. Doxepin treatment of depressed patients with chronic obstructive pulmonary disease. Archives of Internal Medicine 1986;146(7):1377-80. [DOI: 10.1001/ archinte.1986.00360190155022]

\section{Moisieva 2018 \{published data only\}}

Moisieieva NV, Burya LV, Kapustianskaya AA, Kolenko IA, Rumyantseva MA, Shumeiko OH. Comprehensive patterns of comorbidity: COPD and depression. Aspects of treatment. Wiadomosci Lekarskie 2018;71(3):588-91.

\section{Momtaz 2015 \{published data only\}}

Momtaz OM, Rabei SM, Tawfike NR, Hasan AA. Effect of treatment of depression and anxiety on physiological state of severe COPD patients. Egyptian Journal of Chest Disease and Tuberculosis 2015;64:29-34.

\section{Singh 1993 \{published data only\}}

Singh NP, Despars JA, Stansbury DW, Avalos K, Light RW. Effects of buspirone on anxiety levels and exercise tolerance in patients with chronic airflow obstruction and mild anxiety. Chest 1993;103(3):800.

\section{Strom 1995 \{published data only\}}

Strom K, Boman G, Pehrsson K, Alton M, Singer J, Rydstrom P-O, et al. Effect of protriptyline, $10 \mathrm{mg}$ daily, on chronic hypoxaemia in chronic obstructive pulmonary disease. European Respiratory Journal 1995;8(3):425-9.

\section{Subbe 2004 \{published and unpublished data\}}

Subbe C, Collier G, Bedson E, Meknkes D. Effect of citalopram on health status, anxiety and depression in patients with chronic obstructive pulmonary disease: a pilot study. trial protocol.

* Subbe C, Collier G, Bedson E, Menkes D. Pilot study to examine the effect of citalopram on health status, anxiety and depression in patients with chronic obstructive pulmonary disease. unpublished data.

Yohannes 2001 \{published data only\}

Yohannes AM, Connolly MJ, Baldwin RC. A feasibility study of antidepressant drug therapy in depressed elderly patients with chronic obstructive pulmonary disease. International Journal of Geriatric Psychiatry 2001;16(5):451-4. [DOI: 10.1002/gps.461]

\section{References to ongoing studies}

Mathews 2016 \{published data only\}

Mathews AM, Kuehn H. Safety of anti-depressant for Chronic Obstructive Pulmonary Disease (SAD-COPD). ClinicalTrials.gov NCT02813447 (first received 27 June 2016).

\section{Additional references}

\section{Abrams 2011}

Abrams TE, Vaughan-Sarrazin M, van der Weg MW. Acute exacerbations of chronic obstructive pulmonary disease and the effect of existing psychiatric comorbidity on subsequent mortality. Psychosomatics 2011;52(5):441-9.

\section{Allen 2009}

Allen NJ, Barres BA. Neuroscience: glia - more than just brain glue. Nature 2009;457(7230):675-7.

\section{Almagro 2002}

Almagro P, Calbo E, Ochoa de Echaguen A, Barreiro B, Quintana S, Heredia JL, et al. Mortality after hospitalization for COPD. Chest 2002;121(5):1441-8.

\section{Anderson 2000}

Anderson IM. Selective serotonin reuptake inhibitors versus tricyclic antidepressants: a meta-analysis of efficacy and tolerability. Journal of Affective Disorders 2000;58(1):19-36.

\section{APA 2000}

American Psychiatric Association. Diagnostic and Statistical Manual of Mental Disorders. 4th Edition. Washington, DC: American Psychiatric Association, 2000. 


\section{APA 2013}

American Psychiatric Association. Diagnostic and Statistical Manual of Mental Disorders. 5th Edition. Washington, DC: American Psychiatric Publishing, 2013.

\section{Arroll 2009}

Arroll B, Elley CR, Fishman T, Goodyear-Smith FA, Kenealy T, Blashki G, et al. Antidepressants versus placebo for depression in primary care: review. Cochrane Database of Systematic Reviews 2009, Issue 3. [DOI: 10.1002/14651858.CD007954]

\section{Atlantis 2013}

Atlantis E, Fahey P, Cochrane B, Smith S. Biodirectional associations between clinically relevant depression or anxiety and COPD: a systematic review and meta-analysis. Chest 2013;144(3):766-77.

\section{ATS 2002}

American Thoracic Society. ATS statement: guidelines for the six-minute walk test. American Journal of Respiratory and Critical Care Medicine 2002;166:111-7.

\section{Beck 1961}

Beck AT, Ward CH. An inventory for measuring depression. Archives of General Psychiatry 1961;4:561-71.

\section{Bentsen 2013}

Bentsen SB, Miaskowski C, Rustoen T. Demographic and clinical characteristics associated with quality of life in patients with chronic obstructive pulmonary disease. Quality of Life Research 2014;23:991-8.

\section{Bespalov 2007}

Bespalov MM, Saarma M. GDNF family receptor complexes are emerging drug targets. Trends in pharmacological sciences 2007;28(2):68-74.

\section{BLF 2006}

British Lung Foundation. Lost in Translation: Bridging the Communication Gap in COPD: a Report by the British Lung Foundation. London: British Lung Foundation, 2006.

\section{Borg 1982}

Borg GAV. Psychophysical basis of perceived exertion. Medicine and Science in Sports and Exercise 1982;14(5):377-81.

\section{Butland 1982}

Butland RJ, Pang J, Gross ER, Woodcock AA, Geddes DM. Two-, six-, and 12-minute walking tests in respiratory disease. British Medical Journal 1982;284(6329):1607-8.

\section{Cafarella 2012}

Cafarella PA, Effing TW, Usmani ZA, Frith PA. Treatments for anxiety and depression in patients with chronic obstructive pulmonary disease: a literature review. Respirology 2012;17:627-38.

\section{Campbell 2000}

Campbell M, Grimshaw J, Steen N. Sample size calculations for cluster randomised trials. Changing professional practice in Europe Group (EU BIOMED II Concerted Action). Journal of Health Services Research and Policy 2000;5(1):12-16.

\section{Carey 2016}

Carey K, Stefos T. The cost of hospital readmissions: evidence from the VA. Health Care Management Science 2016;19(3):241-8.

\section{Cosco 2011}

Cosco T, Doyle F, Ward M, McGee H. Latent structure of the Hospital Anxiety and Depression Scale: A 10-year systematic review. Journal of Psychosomatic Research 2012;72(3):180-4.

\section{Coventry 2013}

Coventry PA, Bower P, Keyworth C, Kenning C, Knopp J, Garrett $C$, et al. The effect of complex interventions on depression and anxiety in chronic obstructive pulmonary disease: systematic review and meta-analysis. PLOS ONE 2013;8(4):e60532.

\section{Cully 2006}

Cully JA, Graham DP, Stanley MA, Ferguson CJ, Sharafkhaneh A, Souchek J, et al. Quality of life in patients with chronic obstructive pulmonary disease and comorbid anxiety or depression. Psychosomatics 2006;47(4):312-9.

\section{Dalal 2011}

Dalal AA, Shah M, Lunacsek O, Hanania NA. Clinical and economic burden of depression/anxiety in chronic obstructive pulmonary disease patients within a managed care population. COPD: Journal of Chronic Obstructive Pulmonary Disease 2011;8:293-9.

\section{de Godoy 2003}

de Godoy DV, de Godoy RF. A randomised controlled trial of the effect of psychotherapy on anxiety and depression in chronic obstructive pulmonary disease. Archives of Physical Medicine and Rehabilitation 2003;84:1154-8.

\section{de Voogd 2009}

de Voogd JN, Wempe JB, Koëter GH, Postema K, van Sonderen E, Ranchor AV, et al. Depressive symptoms as predictors of mortality in patients with COPD. Chest Journal 2009;135(3):619-25.

\section{Deeks 2017}

Deeks JJ, Higgins JP, Altman DG, editor(s) on behalf of the Cochrane Statistical Methods Group. Chapter 9: Analysing data and undertaking metaanalyses. In: Higgins JP, Churchill R, Chandler J, Cumpston MS, editor(s). Cochrane Handbook for Systematic Reviews of Interventions version 5.2.0 (updated June 2017). Cochrane, 2017. Available from handbook.cochrane.org.

\section{DeJean 2013}

DeJean D, Giacomini M, Vanstone M, Brundisini F. Patient experiences of depression and anxiety with chronic disease: a systematic review and qualitative meta-synthesis. Health Quality Ontario 2013;13(16):1-33. 


\section{Di Marco 2006}

Di Marco F, Verga M, Reggenta M, Maria Casanova F, Santus P, Blasi F, et al. Anxiety and depression in COPD patients: the roles of gender and disease severity. Respiratory Medicine 2006;100(10):1767-74.

\section{Dinicola 2013}

Dinicola G, Julian L, Gregorich SE, Blan PD, Katz PP. The role of social support in anxiety for persons with COPD. Journal of Psychosomatic Research 2013;74(2):110-5.

\section{Egger 1997}

Egger M, Davey Smith G, Schneider M, Minder C. Bias in meta-analysis detected by a simple, graphical test. BMJ 1997;315(7109):629-34.

\section{Evans 1997}

Evans M, Hammond M, Wilson K, Lye M, Copeland J. Placebocontrolled treatment trial of depression in elderly physically ill patients. International Journal of Geriatric Psychiatry 1997; 12:817-24.

\section{Fan 2007}

Fan VS, Ramsey SD, Giardino ND, Make BJ, Emery CF, Diaz PT, et al. National Emphysema Treatment Trial (NETT) Research Group. Sex, depression, and risk of hospitalization and mortality in chronic obstructive pulmonary disease. Archives of Internal Medicine 2007;167(21):2345-53.

\section{Felker 2010}

Felker B, Bush KR, Harel O, Shofer JB, Shores MM, Au DH. Added burden of mental disorders on health status among patients with chronic obstructive pulmonary disease. Primary Care Companion to the Journal of Clinical Psychiatry 2010;12(4):PCC.09m00858. [DOI: 10.4088/PCC.09m00858gry]

\section{Ferguson 2001}

Ferguson JM. SSRI antidepressant medications: adverse effects and tolerability. Primary Care Companion to the Journal of Clinical Psychiatry 2001;3(1):22.

\section{Fleehart 2014}

Fleehart S, Fan VS, Nguyen HQ, Lee J, Kohen R, Herting JR, et al. Prevalence and correlates of suicide ideation in patients with COPD: a mixed methods study. International Journal of Chronic Obstructive Pulmonary Disease 2014;10:1321-9.

\section{Glassman 2002}

Glassman AH, O'Connor CM, Califf RM, Swedberg K, Schwartz P, Bigger JT Jr, et al. Sertraline treatment of major depression in patients with acute MI or unstable angina. JAMA 2002;288(6):701-9.

\section{GOLD 2018 update}

Global Initiative for Chronic Obstructive Lung Disease. Global strategy for the diagnosis, management and prevention of chronic obstructive pulmonary disease. Global Initiative for Chronic Obstructive Lung Disease; Revised 2018. www.goldcopd.org/wp-content/uploads/2017/11/GOLD-2018 v6.0-FINAL-revised-20-Nov_WMS.pdf 2018 (accessed prior to 2 November 2018):1-142.

\section{Goodwin 2012}

Goodwin RD, Lavoie KL, Lemeshow AR, Jenkins E, Brown ES, Fedoronko DA. Depression, anxiety and COPD: the unexamined role of nicotine dependence. Nicotine and Tobacco Research 2012;14(2):176-83.

\section{GRADEpro GDT 2015 [Computer program]}

GRADE Working Group. GRADEpro GDT. Version accessed prior to 2 November 2018. Hamilton ON: McMaster University (developed by Evidence Prime), 2015.

\section{Groenewegen 2003}

Groenewegen KH, Schols AM, Wouters EF. Mortality and mortality-related factors after hospitalization for acute exacerbation of COPD. Chest 2003;124(2):459-67.

\section{Gudmundsson 2005}

Gudmundsson G, Gislason T, Janson C, Lindberg E, Hallin R, Ulrik CS, et al. Risk factors for rehospitalisation in COPD: role of health status, anxiety and depression. European Respiratory Journal 2005;26(3):414-9.

\section{Hamilton 1960}

Hamilton M. A rating scale for depression. Journal of Neurology, Neurosurgery and Psychiatry 1960;23:56-62.

\section{Hanania 2011}

Hanania NA, Müllerova H, Locantore NW, Vestbo J, Watkins ML, Wouters EF, et al. the Evaluation of COPD Longitudinally to Identify Predictive Surrogate Endpoints (ECLIPSE) study investigators. Determinants of depression in the ECLIPSE chronic obstructive pulmonary disease cohort. American Journal of Respiratory and Critical Care Medicine 2011;183:60411.

\section{Hickie 2011}

Hickie IB. Antidepressants in elderly people. BMJ 2011;343:d4660.

\section{Higgins 2011}

Higgins JP, Deeks JJ, Altman DG, on behalf of the Cochrane Statistical Methods Group Green S (editors). Chapter 16: Special topics in statistics. In: Higgins JP, Green S, editor(s). Cochrane Handbook for Systematic Reviews of Interventions Version 5.1.0 (updated March 2011). The Cochrane Collaboration, 2011. Available from handbook.cochrane.org.

\section{Higgins 2017}

Higgins JPT, Altman DG, Sterne JAC, editor(s). Chapter 8: Assessing risk of bias in included studies. In: Higgins JPT, Churchill R, Chandler J, Cumpston MS, editor(s). Cochrane Handbook for Systematic Reviews of Interventions version 5.2.0 (updated June 2017). Cochrane, 2017.. Available from handbook.cochrane.org.

\section{Hisaoka-Nakashima 2015}

Hisaoka-Nakashima K, Miyano K, Matsumoto C, Kajitani N, Abe H, Okada-Tsuchioka M, et al. Tricyclic antidepressant amitriptyline-induced glial cell line-derived neurotrophic factor production involves pertussis toxin-sensitive gai/o 
activation in astroglial cells. Journal of Biological Chemistry 2015;290(22):13678-91.

\section{Howard 2014}

Howard C, Dupont S. 'The COPD breathlessness manual': a randomised controlled trial to test a cognitive-behavioural manual versus information booklets on health service use, mood and health status, in patients with chronic obstructive pulmonary disease. Primary Care Respiratory Medicine 2014;24:14076.

\section{Hutter 2010}

Hutter N, Schnurr A, Baumeister H. Health care costs in patients with diabetes mellitus and comorbid mental disorders - a systematic review. Diabetologia 2010;53(12):2470-9.

\section{Hynninen 2010}

Hynninen MJ, Bjerke N, Pallesen S, Bakke PS, Nordhus IH. A randomised controlled trial of cognitive behavioral therapy for anxiety and depression in COPD. Respiratory Medicine 2010;104:986-94.

\section{Jones 1991}

Jones PW, Quirk FH, Baveystock CM. The St George's Respiratory Questionnaire. Respiratory Medicine 1991;85(Suppl B):25-31.

\section{Karajgi 1990}

Karajgi B, Rifkin A, Doddi S, Kolli R. The prevalence of anxiety disorders in patients with chronic obstructive pulmonary disease. American Journal of Psychiatry 1990;147:200-1.

\section{Kessler 2005}

Kessler RC, Chiu WT, Demler O, Merikangas KR, Walters EE. Prevalence, severity, and comorbidity of 12-month DSM-IV disorders in the National Comorbidity Survey Replication. Archives of General Psychiatry 2005;62(6):617-27.

\section{Kim 2000}

Kim HF, Kunik ME, Molinari VA, Hillman SL, Lalani S, Orengo CA, et al. Functional impairment in COPD patients: the impact of anxiety and depression. Psychosomatics 2000;41(6):465-71.

\section{Kim 2014}

Kim KU, Park HK, Jung HY, Ahn JJ, Moon E, Kim YS, et al. Association of depression with disease severity in patients with chronic obstructive pulmonary disease. Lung 2014;192:243-9.

\section{Kunik 2005}

Kunik ME, Roundy K, Veazey C, Souchek J, Richardson P, Wray NP, et al. Surprisingly high prevalence of anxiety and depression in chronic breathing disorders. Chest 2005;127(4):1205-11.

\section{Kunik 2008}

Kunik ME, Veazey C, Cully JA, Souchek J, Graham DP, Hopko D, et al. COPD education and cognitive behavioral therapy group treatment for clinically significant symptoms of depression and anxiety in COPD patients: a randomised controlled trial. Psychological Medicine 2008;38:385-96.

\section{Lamers 2010}

Lamers F, Jonkers CCM, Bosma H, Chavannes NH, Knottnerus JA, van Eijk JT. Improving quality of life in depressed COPD patients: effectiveness of a minimal psychological intervention. COPD: Journal of Chronic Obstructive Pulmonary Disease 2010;7(5):315-22.

\section{Lamprecht 2011}

Lamprecht B, McBurnie MA, Vollmer WM, Gudmundsson G, Welte T, Nizankowska-Mogilnicka E, et al. COPD in never smokers. Results from the population-based burden of obstructive lung disease study. Chest 2011;139(4):752-63.

\section{Lecheler 2017}

Lecheler L, Richter M, Franzen DP, Rampini SK, Cheetham M, Jenewein J, et al. The frequent and underrecognised cooccurrence of acute exacerbated COPD and depression warrants screening: a systematic review. European Respiratory Review 2017;26:144.

\section{Lee 2015}

Lee H, Yoon JY, Lim Y, Jung H, Kim S, Yoo Y, et al. The effect of nurse-led problem-solving therapy on coping, self-efficacy and depressive symptoms for patients with chronic obstructive pulmonary disease: a randomised controlled trial. Age and Ageing 2015;44(3):397-403.

\section{Lopez 2006}

Lopez AD, Shibuya K, Rao C, Mathers CD, Hansell AL, Held LS, et al. Chronic obstructive pulmonary disease: current burden and future projections. European Respiratory Journal 2006;27(2):397-412.

\section{Lovibond 1995}

Lovibond SH, Lovibond PF. Manual for Depression Anxiety Stress Scales. 2nd Edition. Sydney: The Psychology Foundation, University of New South Wales, 1995.

\section{Marciniuk 2011}

Marciniuk DD, Goodridge D, Hernandez P, Rocker G, Balter M, Bailey $\mathrm{P}$, et al. Managing dyspnea in patients with advanced chronic obstructive pulmonary disease: a Canadian Thoracic Society clinical practice guideline. Canadian Respiratory Journal 2011;18(2):69-78.

\section{Masson 2013}

Masson SC, Tejani AM. Minimum clinically important differences identified for commonly used depression rating scales. Journal of Clinical Epidemiology 2013;66(7):805-7.

\section{Mathers 2006}

Mathers CD, Loncar D. Projections of global mortality and burden of disease from 2002 to 2030. PLoS Medicine 2006;3(11):e442.

\section{Maurer 2008}

Maurer J, Rebbapragada V, Borson S, Goldstein R, Kunik ME, Yohannes AM, et al. Anxiety and depression in COPD: current understanding, unanswered questions, and research needs. Chest 2008;134:43S-53S. 


\section{McHugh 2013}

McHugh RK, Whitton SW, Peckham AD, Welge JA, Otto MW. Patient preference for psychological vs pharmacologic treatment of psychiatric disorders: a meta-analytic review. Journal of Clinical Psychiatry 2013;74(6):595-602.

\section{Meader 2011}

Meader N, Mitchell A, Chew-Graham C, Goldberg D, Rizzo M, Bird V, et al. Case identification of depression in patients with chronic physical health problems: a diagnostic accuracy metaanalysis of 113 studies. British Journal of General Practice 2011;61(593):e808-20.

\section{Mignogna 2012}

Mignogna J, Cully JA. Depression and anxiety in patients with COPD: a focus on psychological treatments in ambulatory care settings. Current Respiratory Medicine Reviews 2012;8:137-44.

\section{Mikkelsen 2004}

Mikkelsen RL, Middelboe T, Pisinger C, Stage KB. Anxiety and depression in patients with chronic obstructive pulmonary disease (COPD). A review. Nordic Journal of Psychiatry 2004;58(1):65-70.

\section{Miravitlles 2014}

Miravitlles M, Cantoni J, Naberan K. Factors associated with a low level of physical activity in patients with chronic obstructive pulmonary disease. Lung 2014;192:259-65.

\section{Moret 2009}

Moret C, Isaac M, Briley M. Problems associated with long-term treatment with selective serotonin reuptake inhibitors. Journal of Psychopharmacology 2009;23(8):967-74.

\section{Mottram 2006}

Mottram P, Wilson K, Strobl J. Antidepressants for depressed elderly. Cochrane Database of Systematic Reviews 2006, Issue 1. [DOI: 10.1002/14651858.CD003491]

\section{Naylor 2012}

Naylor C, Parsonage M, McDaid D, Knapp M, Fossey M, Galea A, The Kings Fund and Centre for Mental Health. Long-term conditions and mental health. The cost of co-morbidities. kingsfund.org.uk/publications/long-term-conditions-andmental-health accessed prior to 2 November 2018:1-32.

\section{Ng 2007}

Ng TP, Niti M, Tan WC, Cao Z, Ong KC, Eng P. Depressive symptoms and chronic obstructive pulmonary disease: effect on mortality, hospital readmission, symptom burden, functional status, and quality of life. Archives of Internal Medicine 2007;167(1):60-7.

\section{Ng 2009}

Ng T-P, Niti M, Fones C, Yap KB, Tan W-C. Co-morbid association of depression and COPD: a population-based study. Respiratory Medicine 2009;103:895-901. guideline. National Collaborating Centre for Mental Health. London, UK 2009.

\section{NICE 2010}

National Institute for Health and Clinical Excellence. CG90 Depression: The treatment and management of depression in adults: NICE guideline (updated edition). National Collaborating Centre for Mental Health. London, UK 2010.

\section{Omachi 2009}

Omachi TA, Katz PP, Yelin EH, Gregorich SE, Iribarren C, Blanc PD, et al. Depression and health-related quality of life in chronic obstructive pulmonary disease. American Journal of Medicine 2009;122(8):778.e9-15.

\section{Panagioti 2014}

Panagioti M, Scott C, Blakemore A, Coventry PA. Overview of the prevalence, impact, and management of depression and anxiety in chronic obstructive pulmonary disease. International Journal of COPD 2014;9:1289-306.

\section{Papp 1995}

Papp L, Weiss J, Greenberg H, Rifkin A, Scharf SM, Gorman JM, et al. Sertraline for chronic obstructive pulmonary disease and comorbid anxiety and mood disorders. American Journal of Psychiatry 1995;152:1531.

\section{Patton 1998}

Patton GC, Carlin JB, Coffey C, Wolfe R, Hibbert M, Bowes G. Depression, anxiety, and smoking initiation: a prospective study over 3 years. American Journal of Public Health 1998;88(10):1518-22.

\section{Piek 2010}

Piek E, van der Meer K, Nolen WA. Guideline recommendations for long-term treatment of depression with antidepressants in primary care: a critical review. European Journal of General Practice 2010;16(2):106-12.

\section{Pignone 2002}

Pignone MP, Gaynes BN, Rushton JL, Burchell CM, Orleans CT, Murlow CD, et al. Screening for depression in adults: a summary of the evidence for the U.S. Preventive Services Task Force. Annals of Internal Medicine 2002;136(10):765-76.

\section{Pollok 2016}

Pollok J, van Agteren J, Carson K, Esterman A, Smith B, Licinio J. Psychological therapies for the treatment of depression in chronic obstructive pulmonary disease. Cochrane Database of Systematic Reviews 2016, Issue 9. [DOI: 10.1002/14651858.CD012347]

\section{Pooler 2014}

Pooler A, Beech R. Examining the relationship between anxiety and depression and exacerbations of COPD which result in hospital admission: a systematic review. International Journal of Chronic Obstructive Pulmonary Disease 2014;9(3):15-30.

\section{NICE 2009}

National Institute for Health and Clinical Excellence. CG91 Depression with a chronic physical health problem: NICE 


\section{Pumar 2014}

Pumar MI, Gray CR, Walsh JR, Yang IA, Rolls TA, Ward DL. Anxiety and depression - important psychological comorbidities of COPD. Journal of Thoracic Disease 2014;6(11):1615-31.

\section{Rabe 2007}

Rabe KF, Hurd S, Anzueto A, Barnes PJ, Buist SA, Calverley P, et al. Global Initiative for Chronic Obstructive Lung Disease. Global strategy for the diagnosis, management, and prevention of chronic obstructive pulmonary disease: GOLD executive summary. American Journal of Respiratory and Critical Care Medicine 2007;176(6):532-5.

\section{Rajkowska 2013}

Rajkowska G, Stockmeier CA. Astrocyte pathology in major depressive disorder: insights from human postmortem brain tissue. Current Drug Targets 2013;14(11):1225-36.

\section{Rayner 2010}

Rayner L, Price A, Evans A, Valsraj K, Higginson IJ, Hotopf M. Antidepressants for depression in physically ill people. Cochrane Database of Systematic Reviews 2010, Issue 3. [DOI: 10.1002/14651858.CD007503.pub2]

\section{Remick 1988}

Remick RA. Anticholinergic side effects of tricyclic antidepressants and their management. Progress in NeuroPsychopharmacology \& Biological Psychiatry 1988;12(2):225-31.

\section{RevMan 2014 [Computer program]}

The Nordic Cochrane Centre, The Cochrane Collaboration. Review Manager (RevMan). Version 5.3. Copenhagen: The Nordic Cochrane Centre, The Cochrane Collaboration, 2014.

\section{Rief 2009}

Rief W, Nestoriuc Y, Lilienfeld-Toal A, Dogan I, Schreiber F, Hofmann SG, et al. Differences in adverse effect reporting in placebo groups in SSRI and tricyclic antidepressant trials: a systematic review and meta-analysis. Drug Safety 2009;32:1041-56.

\section{Ryan 2016}

Ryan R, Hill S. How to GRADE the quality of the evidence. Cochrane Consumers and Communication Review Group December 2016.

\section{Sadock 2009}

Sadock BJ, Sadock VA, Ruiz P. Kaplan and Sadock's Comprehensive Textbook of Psychiatry. 9th Edition. Philadelphia, London: Wolters Kluwer Health/Lippincott Williams \& Wilkins, 2009.

\section{Schatzberg 1992}

Schatzberg AF, Rothschild AJ. Serotonin activity in psychotic (delusional) major depression. Journal of Clinical Psychiatry 1992;53:52-5.

\section{Schünemann 2017}

Schünemann HJ, Oxman AD, Vist GE, Higgins JP, Deeks JJ, Glasziou P, et al. on behalf of the Cochrane Applicability and Recommendations Methods Group. Chapter 12:
Interpreting results and drawing conclusions. In: Higgins JPT, Churchill R, Chandler J, Cumpston MS, editor(s). Cochrane Handbook for Systematic Reviews of Interventions version 5.2.0 (updated June 2017). Cochrane, 2017. Available from www.training.cochrane.org/handbook.

\section{Smith 2014}

Smith SM, Sonego S, Ketcheson L, Larson JL. A review of the effectiveness of psychological interventions used for anxiety and depression in chronic obstructive pulmonary disease. $B M J$ Open Respiratory Research 2014;1:1-10.

\section{Solano 2006}

Solano JP, Gomes B, Higginson IJ. A comparison of symptom prevalence in far advanced cancer, AIDS, heart disease, chronic obstructive pulmonary disease and renal disease. Journal of Pain and Symptom Management 2006;31(1):58-69.

\section{Spitzer 1999}

Spitzer RL, Kroenke K, Williams JB, Patient Health Questionnaire Study Group. Validity and utility of a self-report version of PRIME-MD: the PHQ Primary Care Study. JAMA 1999;282:1737-44.

\section{Stage 2006}

Stage K, Middelboe T, Stage T, Sorensen C. Depression in COPD - management and quality of life considerations. International Journal of COPD 2006;1(3):315-20.

\section{Sullivan 1998}

Sullivan PF, Kendler KS. Typology of common psychiatric syndromes. An empirical study. British Journal of Psychiatry 1998;173:312-9.

\section{Tselebis 2016}

Tselebis A, Pachi A, Ilias I, Kosmas E, Bratis D, Moussas G, et al. Strategies to improve anxiety and depression in patients with COPD: a mental health perspective. Neuropsychiatric Disease and Treatment 2016;12:297-328.

\section{van Manen 2002}

van Manen JG, Bindels PJ, Dekker FW, IJzermans CJ, van der Zee JS, Schadé E. Risk of depression in patients with chronic obstructive pulmonary disease and its determinants. Thorax 2002;57(5):412-6.

\section{Vozoris 2018}

Vozoris NT, Wang X, Austin PC, Stephenson AL, O'Donnell DE, Gershon AS, et al. Serotonergic antidepressant use and morbidity and mortality among older adults with COPD. European Respiratory Journal 2018;52:1800475.

\section{Ware 1993}

Ware JE, Snow KK, Kosinski M, Gandek B. SF-36 Health Survey: manual and interpretation guide. Boston MA: Health Institute, New England Medical Center, 1993.

\section{WHO 2017}

World Health Organization. COPD predicted to be the third leading cause of death in 2030. http://www.who.int/en/news- 
room/fact-sheets/detail/chronic-obstructive-pulmonarydisease-(copd) (accessed prior to 2 November 2018).

\section{Wittchen 2011}

Wittchen HU, Jacobi F, Rehm J, Gustavsson A, Svensson M, Jönsson $B$, et al. The size and burden of mental disorders and other disorders of the brain in Europe 2010. European Neuropsychopharmacology 2011;21(9):655-79.

\section{Yang 2018}

Yang IA, Brown JL, George J, Jenkins S, McDonald CF, McDonald V, et al. The COPD-X Plan: Australian and New Zealand Guidelines for the Management of Chronic Obstructive Pulmonary Disease 2018. Version 2.53. Lung Foundation Australia, March 2018.

\section{Yin 2017}

Yin H, Yin S, Lin Q, Xu Y, Xu H, Liu T. Prevalence of comorbidities in chronic obstructive pulmonary disease patients. Medicine 2017;96(19):e6836.

\section{Yohannes 2005}

Yohannes AM, Baldwin RC, Connolly MJ. Predictors of 1-year mortality in patients discharged from hospital following acute exacerbation of chronic obstructive pulmonary disease. Age and Ageing 2005;34:491-6.

\section{Yohannes 2008}

Yohannes AM. Management of anxiety and depression in patients with COPD. Expert Review of Respiratory Medicine 2008;2(3):337-47.

\section{CHARACTERISTICS OF STUDIES}

Characteristics of included studies [ordered by study ID]

\section{Yohannes 2011}

Yohannes A, Connolly M. Do antidepressants work in patients with chronic obstructive pulmonary disease with comorbid depression?. Expert Review of Respiratory Medicine 2011;5(6):727-9.

\section{Yohannes 2014}

Yohannes A, Alexopoulos G. Pharmacologic treatment of depression in older patients with COPD: impact on the course of the disease and health outcomes. Drugs \& Aging 2014;31(7):483-92.

\section{Zhang 2011}

Zhang MW, Ho RC, Cheung MW, Fu E, Mak A. Prevalence of depressive symptoms in patients with chronic obstructive pulmonary disease: a systematic review, meta-analysis and meta-regression. General Hospital Psychiatry Journal 2011;33(3):217-23.

\section{References to other published versions of this review \\ Naqvi 2016}

Naqvi SS, Pollok J, van Agteren JEM, Usmani ZA, Carson KV, Smith BJ, et al. Pharmacological interventions for the treatment of depression in chronic obstructive pulmonary disease. Cochrane Database of Systematic Reviews 2016, Issue 9. [DOI: 10.1002/14651858.CD012346]

* Indicates the major publication for the study

Borson 1992

Methods Study design: Randomised, placebo-controlled, double-blind trial
Country: USA

Participants

Sample size: $\mathrm{N}=36$ randomised, but only 30 participants completed the trial and were included in the analysis

Mean age: Intervention group: 58.7 years (SD \pm 9.9$)$; placebo group: 63.2 years (SD \pm 8.3 )

Gender: $\mathrm{N}=22$ male, $\mathrm{N}=14$ female in total

Inclusion criteria: Primary diagnosis of moderate to severe COPD $\left(\mathrm{FEV}_{1}\right.$ and $\mathrm{FEV}_{1} / \mathrm{FVC}<60 \%$ of predicted) and a coexisting depressive disorder determined by psychiatric assessment (structured clinical interview) based on DSM-III

Exclusion criteria: Other medical illness more disabling than COPD, severe cognitive impairment, recent stroke or myocardial infarction, current alcohol abuse, or other psychotropics that could not be discontinued before the trial commenced. Individuals taking more than $40 \mathrm{~g}$ prednisone daily and those on home oxygen were also excluded. 


\section{Duration: 12 weeks}

Dose: Started at $1 / 4$ of $1 \mathrm{mg} / \mathrm{kg}$ of body weight, which was increased weekly until target reached (usually by 4 th week), maintained for 8 weeks

Number of participants randomised to intervention: $N=18$; participants who completed the trial: $N$ $=13$

Number of participants randomised to the control group: $\mathrm{N}=18$; participants who completed the trial: $\mathrm{N}=17$

Primary outcomes reported:
- Mood change: CGI, HAM-D, PRAS
- Dyspnoea: PFSI, VAS
- Distressing physical symptoms: PRAS
- Functional status: PFSI, Sickness Impact Profile, spirometry, blood gasses, 12-minute walk test

Time frame: All outcomes were measured at baseline and at end of the study.

Also, 3 participants were dysthymic (mild but chronic depression) when entering the study.

The study was supported by the Medical Research Service of the Department of Veterans Affairs and approved by the University of Washington Human Research Committee.

\section{Risk of bias}

\begin{tabular}{|c|c|c|}
\hline Bias & Authors' judgement & Support for judgement \\
\hline $\begin{array}{l}\text { Random sequence genera- } \\
\text { tion (selection bias) }\end{array}$ & Low risk & $\begin{array}{l}\text { Assignment to treatment condition was performed by a pharmacist blinded to } \\
\text { the study questions using a table of random numbers. }\end{array}$ \\
\hline $\begin{array}{l}\text { Allocation concealment } \\
\text { (selection bias) }\end{array}$ & Unclear risk & $\begin{array}{l}\text { All study personnel were blind to medication assignment until completion of } \\
\text { all evaluations; no further details provided to permit judgement on allocation } \\
\text { concealment. }\end{array}$ \\
\hline $\begin{array}{l}\text { Blinding of participants } \\
\text { and personnel (perfor- } \\
\text { mance bias) } \\
\text { All outcomes }\end{array}$ & Low risk & $\begin{array}{l}\text { All study personnel were blind to medication assignment until completion of } \\
\text { all evaluations. }\end{array}$ \\
\hline $\begin{array}{l}\text { Blinding of outcome as- } \\
\text { sessment (detection bias) } \\
\text { All outcomes }\end{array}$ & Low risk & Double-blind, placebo-controlled trial \\
\hline $\begin{array}{l}\text { Incomplete outcome data } \\
\text { (attrition bias) } \\
\text { All outcomes }\end{array}$ & High risk & $\begin{array}{l}\text { Dropout mentioned, but not reported per group. Only participants who com- } \\
\text { pleted the trial from the intervention group were taken into account. However, } \\
\text { dropout in the intervention group was much higher than in the control group } \\
(5: 1) \text {. }\end{array}$ \\
\hline $\begin{array}{l}\text { Selective reporting (re- } \\
\text { porting bias) }\end{array}$ & Unclear risk & $\begin{array}{l}\text { Insufficient information to permit judgement. Prespecified study protocol was } \\
\text { not published or available. }\end{array}$ \\
\hline Other bias & Low risk & No other bias identified. \\
\hline
\end{tabular}




Study design: Randomised, placebo-controlled, double-blind trial. Due to ethical reasons, after 6
weeks of active drug versus placebo intervention, all participants were placed on active-drug treat-
ment for 3 months. This was an unblinded treatment trial without a placebo control group. Only data
from the randomised, double-blinded trial were included in this review.

Country: UK

Sample size: $\mathrm{N}=28$ randomised, $\mathrm{N}=28$ included in analysis
Mean age: 66 years $(\mathrm{SD} \pm 8$ ); range 49 to 79 years
Gender: $\mathrm{N}=14$ male, $\mathrm{N}=14$ female
Inclusion criteria: Well-documented, stable, poorly reversible COPD with a change in FEV ${ }_{1}$ after bron-
chodilators of $<15 \%$ of predicted normal, current or ex-smokers, exercise tolerance limited by dysp-
noea, clinical depression (confirmed by standard psychiatric interview using ICD-10 criteria)
Exclusion criteria: Previously diagnosed with depression, use of psychotropic drugs within 3 months
of study, significant comorbidity limiting mobility

Interventions

Intervention: Selective serotonin reuptake inhibitor (paroxetine)

Control: Placebo

Duration: 6 weeks

Dose: $20 \mathrm{mg}$ daily

Number of participants randomised to intervention: $N=14$; participants who completed the trial: $N$ $=14(\mathrm{~N}=4$ participants in the intervention group were offered $140 \mathrm{mg}$ of lofepramine (every night) due to side effects of the SSRI treatment)

Number of participants randomised to the control group: $N=14$; participants who completed the trial: $\mathrm{N}=14$

Outcomes Primary outcomes reported: HADS, BDI, MADRS

Quality of life: measured by SGRQ

Exercise tolerance: 6-minute walking test

\section{Secondary outcomes reported:}

Lung function: residual volume, $\mathrm{FEV}_{1}, \mathrm{FVC}$ and slow vital capacity, peak expiratory flow

Other: bronchodilator use, nocturnal walking due to dyspnoea, dyspnoea, effect of dyspnoea on quality of life. All measured by 5-point scales.

Notes

Only data from the randomised, double-blind, placebo-controlled trial were included in the review. The second phase of the intervention was an open-label intervention without a placebo.

Also, $\mathrm{N}=4$ participants in the intervention group were offered $140 \mathrm{mg}$ of tricyclic antidepressant (lofepramine) every night due to side effects of the SSRI treatment.

\begin{tabular}{lll}
\hline Risk of bias & \\
\hline Bias & Authors' judgement & Support for judgement \\
\hline $\begin{array}{l}\text { Random sequence genera- } \\
\text { tion (selection bias) }\end{array}$ & Unclear risk & $\begin{array}{l}\text { Insufficient information on methods of randomisation: "patients received ei- } \\
\text { ther paroxetine 20mg daily for } 6 \text { weeks or matched placebo in a randomised } \\
\text { and double-blind fashion" }\end{array}$ \\
\hline
\end{tabular}


Eiser 2005 (Continued)

\begin{tabular}{lll}
$\begin{array}{l}\text { Allocation concealment } \\
\text { (selection bias) }\end{array}$ & Unclear risk & Not described \\
\hline $\begin{array}{l}\text { Blinding of participants } \\
\text { and personnel (perfor- } \\
\text { mance bias) } \\
\text { All outcomes }\end{array}$ & Low risk & $\begin{array}{l}\text { Blinding of participants and personnel only kept until } 6 \text { weeks, after which the } \\
\text { study became an open-label trial. }\end{array}$ \\
\hline $\begin{array}{l}\text { Blinding of outcome as- } \\
\text { sessment (detection bias) } \\
\text { All outcomes }\end{array}$ & Unclear risk & Not reported \\
\hline $\begin{array}{l}\text { Incomplete outcome data } \\
\text { (attrition bias) } \\
\text { All outcomes }\end{array}$ & Low risk & No dropout during double-blind phase of the trial \\
\hline $\begin{array}{l}\text { Selective reporting (re- } \\
\text { porting bias) }\end{array}$ & Unclear risk & $\begin{array}{l}\text { No information on whether a protocol has been published or the trial regis- } \\
\text { tered }\end{array}$ \\
\hline $\begin{array}{l}\text { Other bias } \\
\text { High risk }\end{array}$ & $\begin{array}{l}\text { Due to paroxetine-related side effects, 4 participants were given lofepramine } \\
\text { (TCA). }\end{array}$
\end{tabular}

He 2016

\begin{tabular}{ll} 
Methods & $\begin{array}{l}\text { Study design: Randomised, placebo-controlled, double-blind trial } \\
\text { Country: } \text { China }\end{array}$ \\
\hline Sample size: $N=120$ randomised ( $=120$ included in analysis, although $N=112$ completed the study) \\
Mean age: Intervention 69.8 years (SD \pm 7.2$)$, control 70.2 years (SD \pm 6.8$)$ \\
Gender: $\mathrm{N}=67$ male, $\mathrm{N}=53$ female \\
Inclusion criteria: Stable COPD according to GOLD - stage I or higher; total score on the 17-item Hamil- \\
ton Depression Rating Scale (HAM-D-17) of 17 or higher \\
Exclusion criteria: Presence of cancer, severe physical disability, mental disorders including those re- \\
quiring concomitant use of medications that would impact on mental status, refusing participants, pa- \\
tients with poor compliance
\end{tabular}

Control: Placebo

Duration: 6 weeks

Dose: $50 \mathrm{mg}$ daily

Number of participants randomised to intervention: $N=60$; participants who completed the trial: $N=$ 55

Number of participants randomised to the control group: $\mathrm{N}=60$; participants who completed the trial: $\mathrm{N}=57$

$\begin{array}{ll}\text { Outcomes } & \text { Primary outcomes reported: } \\ \text { Quality of life assessed with COPD Assessment Test (CAT) }\end{array}$


He 2016 (Continued)

\section{Secondary outcomes reported:}

Exercise capacity assessed with 6-minute walk test

HAM-D-17

Other: Parameters of spirometry tests (FVC, $\left.\mathrm{FEV}_{1}, \mathrm{FEV}_{1} / \mathrm{FVC}\right)$ and adverse events were observed and reported.

\section{Notes}

\section{Risk of bias}

\begin{tabular}{|c|c|c|}
\hline Bias & Authors' judgement & Support for judgement \\
\hline $\begin{array}{l}\text { Random sequence genera- } \\
\text { tion (selection bias) }\end{array}$ & Low risk & Assessment via random number tables and sequentially numbered envelopes \\
\hline $\begin{array}{l}\text { Allocation concealment } \\
\text { (selection bias) }\end{array}$ & Unclear risk & No information provided. \\
\hline $\begin{array}{l}\text { Blinding of participants } \\
\text { and personnel (perfor- } \\
\text { mance bias) } \\
\text { All outcomes }\end{array}$ & Low risk & Double-blind randomised controlled trial. No further details reported. \\
\hline $\begin{array}{l}\text { Blinding of outcome as- } \\
\text { sessment (detection bias) } \\
\text { All outcomes }\end{array}$ & Low risk & $\begin{array}{l}1 \text { of the investigators who had not participated in the trial recorded relevant } \\
\text { data from participants' medical records and hospital's mainframe computer } \\
\text { for laboratory data. }\end{array}$ \\
\hline $\begin{array}{l}\text { Incomplete outcome data } \\
\text { (attrition bias) } \\
\text { All outcomes }\end{array}$ & Low risk & Attrition reported. \\
\hline $\begin{array}{l}\text { Selective reporting (re- } \\
\text { porting bias) }\end{array}$ & Unclear risk & $\begin{array}{l}\text { No information on whether a protocol has been published or the trial regis- } \\
\text { tered }\end{array}$ \\
\hline Other bias & Low risk & No other bias identified. \\
\hline
\end{tabular}

\section{Lacasse 2004}

Methods Study design: Randomised, placebo-controlled, double-blind trial

Country: Canada

Gender: $N=10$ male, $N=13$ female $(N=5$ male, $N=7$ female in the intervention arm; $N=5$ male, $N=6$ female in the control arm)

Inclusion criteria: Outpatients aged over 60 , confirmed COPD with history of smoking, $\mathrm{FEV}_{1}<50 \%$ predicted. Significant depressive symptoms as measured by the GDS

Exclusion criteria: Contraindication to antidepressants, current or recent antidepressant or neuroleptic drug use, current participation in pulmonary rehabilitation 
Lacasse 2004 (Continued) Interventions
Intervention: Selective serotonin reuptake inhibitor (paroxetine)

Control: Placebo

Duration: 12 weeks

Dose: Dose was started at $5 \mathrm{mg}$ once daily with weekly increments up to maximum $20 \mathrm{mg}$ once daily or highest dose not associated with side effects. 6 of 8 participants reached the maximum dose of $20 \mathrm{mg}$ once daily at the 4th week of treatment; the other 2 participants were treated with $10 \mathrm{mg}$ once daily.

Number of participants randomised to intervention: $\mathrm{N}=12$; participants who completed the trial: $\mathrm{N}$ $=8$

Number of participants randomised to the control group: $N=11$; participants who completed the trial: $\mathrm{N}=7$

\section{Outcomes Primary outcomes reported:}

- Quality of life measured by CRQ: "The change in score in the 'emotional function' domain of the Chronic Respiratory Questionnaire (CRQ) at 12-week follow-up represented the primary outcome of this trial"

\section{Secondary outcomes reported:}

- Quality of life measured at baseline by SF-36

- Adverse effects measured at each follow-up visit

Other: CRQ scores in mastery, dyspnoea, fatigue, compliance, depression measured by GDS

Notes

\section{Risk of bias}

\begin{tabular}{|c|c|c|}
\hline Bias & Authors' judgement & Support for judgement \\
\hline $\begin{array}{l}\text { Random sequence genera- } \\
\text { tion (selection bias) }\end{array}$ & Low risk & $\begin{array}{l}\text { Insufficient information to permit judgement: "A random numbers table was } \\
\text { used to allocate the patients to receive either Paroxetine or an identical place- } \\
\text { bo" }\end{array}$ \\
\hline $\begin{array}{l}\text { Allocation concealment } \\
\text { (selection bias) }\end{array}$ & Unclear risk & $\begin{array}{l}\text { "The randomisation process was under the responsibility of one of the hospi- } \\
\text { tal pharmacists who was not otherwise involved in the trial" }\end{array}$ \\
\hline $\begin{array}{l}\text { Blinding of participants } \\
\text { and personnel (perfor- } \\
\text { mance bias) } \\
\text { All outcomes }\end{array}$ & Low risk & Double-blind trial \\
\hline
\end{tabular}

Blinding of outcome as- Unclear risk Insufficient information to permit judgement sessment (detection bias)

All outcomes

\begin{tabular}{lll}
\hline $\begin{array}{l}\text { Incomplete outcome data } \\
\text { (attrition bias) } \\
\text { All outcomes }\end{array}$ & Low risk & Attrition reported and equal between groups. \\
\hline $\begin{array}{l}\text { Selective reporting (re- } \\
\text { porting bias) }\end{array}$ & Unclear risk & $\begin{array}{l}\text { Although there is a mention of a study protocol approved by the local ethics } \\
\text { committee, there was no information or reference provided to permit judge- } \\
\text { ment on whether outcomes prespecified in the protocol were reported accord- } \\
\text { ingly. }\end{array}$ \\
\hline
\end{tabular}


Lacasse 2004 (Continued)

Other bias Low risk No other bias identified.

BDI: Beck Depression Inventory

CGI: Clinical Global Improvement Scale

COPD: chronic obstructive pulmonary disease

CRQ: Chronic Respiratory Questionnaire

DSM-III: third edition of the Diagnostic and Statistical Manual of Mental Disorders

$\mathrm{FEV}_{1}$ : forced expiratory volume in one second

FVC: forced vital capacity

GDS: Geriatric Depression Scale

GOLD: Global Initiative for Chronic Obstructive Lung Disease

HADS: Hospital Anxiety and Depression Scale

HAM-D: Hamilton Depression Rating Scale

ICD-10: Tenth Revision of the International Statistical Classification of Diseases and Related Health Problems

MADRS: Montgomery-Asberg Depression Score

PFSI: Pulmonary Functional Status Instrument

PRAS: Patient-Rated Anxiety Scale

SD: standard deviation

SF-36: 36-item Short Form Health Survey

SGRQ: St George's Respiratory Questionnaire

SSRI: selective serotonin reuptake inhibitor

TCA: tricyclic antidepressant

VAS: visual analogue scale

Characteristics of excluded studies [ordered by study ID]

\begin{tabular}{ll}
\hline Study & Reason for exclusion \\
\hline Gordon 1985 & $\begin{array}{l}\text { None of the participants met clinical depression criteria according to DSM-III; the study did not fo- } \\
\text { cus on depression. }\end{array}$ \\
\hline Light 1986 & Participants did not meet DSM-III criteria for depression. \\
\hline Moisieva 2018 & The study did not have a randomised design. \\
\hline Momtaz 2015 & $\begin{array}{l}\text { Results for anxiety and depression were combined, and we received no response from author to } \\
\text { our request for raw data. }\end{array}$ \\
\hline Singh 1993 & $\begin{array}{l}\text { Depression was not an inclusion criterion, and participants were not screened for depression at the } \\
\text { time of recruitment; the study did not focus on depressed COPD patients. }\end{array}$ \\
\hline Strom 1995 & \begin{tabular}{l} 
Inclusion criteria only focused on cOPD; no criteria specified for depression. \\
\hline Subbe 2004
\end{tabular} \\
\hline Yohannes 2001 & Depression was not measured by a validated tool. The participants were only asked: "Does feeling \\
\hline
\end{tabular}

COPD: chronic obstructive pulmonary disease

DSM-III: third edition of the Diagnostic and Statistical Manual of Mental Disorders

Characteristics of ongoing studies [ordered by study ID] 
Mathews 2016

\begin{tabular}{ll}
\hline Trial name or title & Safety of anti-depressant for Chronic Obstructive Pulmonary Disease (SAD-COPD) \\
\hline Methods & $\begin{array}{l}\text { A prospective, randomised, double-blinded, placebo-controlled study to assess the effect of a se- } \\
\text { lective serotonin reuptake inhibitor on 6-minute walk distance, dyspnoea scores, and quality of life } \\
\text { in patients with COPD undergoing pulmonary rehabilitation }\end{array}$ \\
\hline Participants & $\begin{array}{l}30 \text { participants that carry an ICD-9 code diagnosis of COPD and/or interstitial lung disease and CES- } \\
\text { D (Center for Epidemiologic Studies - Depression) score of }>16 \text { will be recruited from Duke Pul- } \\
\text { monary Rehabilitation Center. }\end{array}$
\end{tabular}

Interventions

Intervention: Participants randomised to the intervention arm will be given active study medication (sertraline). Participants will take a $25 \mathrm{mg}$ tablet by mouth daily, starting at visit 1 along with participating in the intensive pulmonary rehabilitation programme. Participants will be assessed at 1-week intervals for tolerability and side effects; and if tolerating study medication, the dose will be increased weekly by $25 \mathrm{mg}$ over the course of the first 4 weeks with maximum effective dose of 100 $\mathrm{mg}$ daily by the end of week 4 . Participants will continue this dose over the course of the remaining 8 weeks of the study, while participating in the pulmonary rehabilitation programme.

Placebo comparator: Participants randomised to the placebo arm will have the same procedures as in the study active-medication arm with the exception that they will be receiving matched placebo.

Outcomes Primary outcomes: Change in 6-minute walk distance, change in dyspnoea scores, change in quality of life

Secondary outcomes: Change in perceived stress, change in anxiety, change in depression, tolerability of medication

\begin{tabular}{ll}
\hline Starting date & 27 June 2016 \\
\hline Contact information & $\begin{array}{l}\text { Contact: Anne M Mathews anne.mathews@dm.duke.edu; Heather Kuehn heather.kuehn@duke.e- } \\
\text { du }\end{array}$ \\
\hline Notes & - \\
\hline
\end{tabular}

COPD: chronic obstructive pulmonary disease

ICD-9: Ninth Revision of the International Classification of Diseases

\section{DATA AND ANALYSES}

\section{Comparison 1. Tricylic antidepressant versus placebo - final follow-up values used}

\begin{tabular}{|c|c|c|c|c|}
\hline Outcome or subgroup title & No. of studies & $\begin{array}{l}\text { No. of partici- } \\
\text { pants }\end{array}$ & Statistical method & Effect size \\
\hline 1 Change in depressive symptoms & 1 & & $\begin{array}{l}\text { Mean Difference (IV, Random, } \\
95 \% \mathrm{CI} \text { ) }\end{array}$ & $\begin{array}{l}\text { Totals not select- } \\
\text { ed }\end{array}$ \\
\hline 2 Adverse events & 1 & & $\begin{array}{l}\text { Mean Difference (IV, Random, } \\
95 \% \mathrm{CI} \text { ) }\end{array}$ & $\begin{array}{l}\text { Totals not select- } \\
\text { ed }\end{array}$ \\
\hline $\begin{array}{l}2.1 \text { Disease-related events: all physi- } \\
\text { cal symptoms }\end{array}$ & 1 & & $\begin{array}{l}\text { Mean Difference (IV, Random, } \\
95 \% \mathrm{CI} \text { ) }\end{array}$ & $0.0[0.0,0.0]$ \\
\hline
\end{tabular}




\begin{tabular}{|c|c|c|c|c|}
\hline Outcome or subgroup title & No. of studies & $\begin{array}{l}\text { No. of partici- } \\
\text { pants }\end{array}$ & Statistical method & Effect size \\
\hline $\begin{array}{l}\text { 2.2 Disease-related events: breath- } \\
\text { lessness symptoms }\end{array}$ & 1 & & $\begin{array}{l}\text { Mean Difference (IV, Random, } \\
95 \% \mathrm{Cl} \text { ) }\end{array}$ & $0.0[0.0,0.0]$ \\
\hline $\begin{array}{l}3 \text { Change in quality of life - overall } \\
\text { score }\end{array}$ & 1 & & $\begin{array}{l}\text { Mean Difference (IV, Random, } \\
95 \% \mathrm{Cl} \text { ) }\end{array}$ & $\begin{array}{l}\text { Totals not select- } \\
\text { ed }\end{array}$ \\
\hline $\begin{array}{l}4 \text { Change in dyspnoea (Pulmonary } \\
\text { Functional Status Instrument) }\end{array}$ & 1 & & $\begin{array}{l}\text { Mean Difference (IV, Random, } \\
95 \% \mathrm{Cl} \text { ) }\end{array}$ & $\begin{array}{l}\text { Totals not select- } \\
\text { ed }\end{array}$ \\
\hline 4.1 Global day-to-day ratings - today & 1 & & $\begin{array}{l}\text { Mean Difference (IV, Random, } \\
95 \% \mathrm{Cl} \text { ) }\end{array}$ & $0.0[0.0,0.0]$ \\
\hline $\begin{array}{l}\text { 4.2 Global day-to-day ratings - with } \\
\text { most day-to-day activities }\end{array}$ & 1 & & $\begin{array}{l}\text { Mean Difference (IV, Random, } \\
95 \% \mathrm{CI} \text { ) }\end{array}$ & $0.0[0.0,0.0]$ \\
\hline $\begin{array}{l}4.3 \text { Global day-to-day ratings - most } \\
\text { days }\end{array}$ & 1 & & $\begin{array}{l}\text { Mean Difference (IV, Random, } \\
95 \% \mathrm{Cl} \text { ) }\end{array}$ & $0.0[0.0,0.0]$ \\
\hline $\begin{array}{l}\text { 4.4 During } 81 \text { activities of daily living - } \\
\text { low demand }\end{array}$ & 1 & & $\begin{array}{l}\text { Mean Difference (IV, Random, } \\
95 \% \mathrm{Cl} \text { ) }\end{array}$ & $0.0[0.0,0.0]$ \\
\hline $\begin{array}{l}\text { 4.5 During } 81 \text { activities of daily living - } \\
\text { moderate demand }\end{array}$ & 1 & & $\begin{array}{l}\text { Mean Difference (IV, Random, } \\
95 \% \mathrm{CI} \text { ) }\end{array}$ & $0.0[0.0,0.0]$ \\
\hline $\begin{array}{l}\text { 4.6 During } 81 \text { activities of daily living - } \\
\text { high demand }\end{array}$ & 1 & & $\begin{array}{l}\text { Mean Difference (IV, Random, } \\
95 \% \mathrm{Cl} \text { ) }\end{array}$ & $0.0[0.0,0.0]$ \\
\hline 4.7 At end of walk & 1 & & $\begin{array}{l}\text { Mean Difference (IV, Random, } \\
95 \% \mathrm{Cl} \text { ) }\end{array}$ & $0.0[0.0,0.0]$ \\
\hline 4.8 Change during walk & 1 & & $\begin{array}{l}\text { Mean Difference (IV, Random, } \\
95 \% \mathrm{CI})\end{array}$ & $0.0[0.0,0.0]$ \\
\hline
\end{tabular}

Analysis 1.1. Comparison 1 Tricylic antidepressant versus placebo final follow-up values used, Outcome 1 Change in depressive symptoms.

\begin{tabular}{|c|c|c|c|c|c|c|c|}
\hline \multirow{3}{*}{$\begin{array}{l}\text { Study or subgroup } \\
\text { Borson } 1992\end{array}$} & \multicolumn{2}{|c|}{ TCA } & \multicolumn{2}{|c|}{ placebo } & \multirow{2}{*}{\multicolumn{2}{|c|}{$\begin{array}{l}\text { Mean Difference } \\
\text { Random, } 95 \% \mathrm{Cl}\end{array}$}} & \multirow{3}{*}{$\begin{array}{c}\begin{array}{c}\text { Mean Difference } \\
\text { Random, 95\% Cl }\end{array} \\
-10.2[-16.75,-3.65]\end{array}$} \\
\hline & $\mathbf{N}$ & Mean(SD) & $\mathbf{N}$ & Mean(SD) & & & \\
\hline & 13 & $12.6(6.9)$ & 17 & $22.8(11.3)$ & 1 & & \\
\hline
\end{tabular}

Analysis 1.2. Comparison 1 Tricylic antidepressant versus placebo - final follow-up values used, Outcome 2 Adverse events.

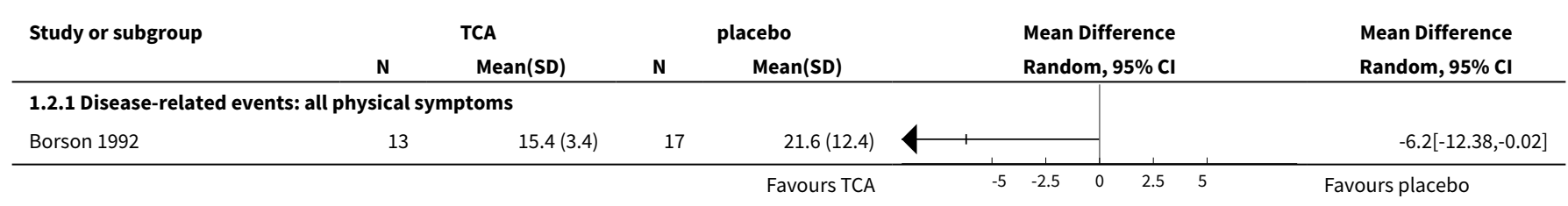




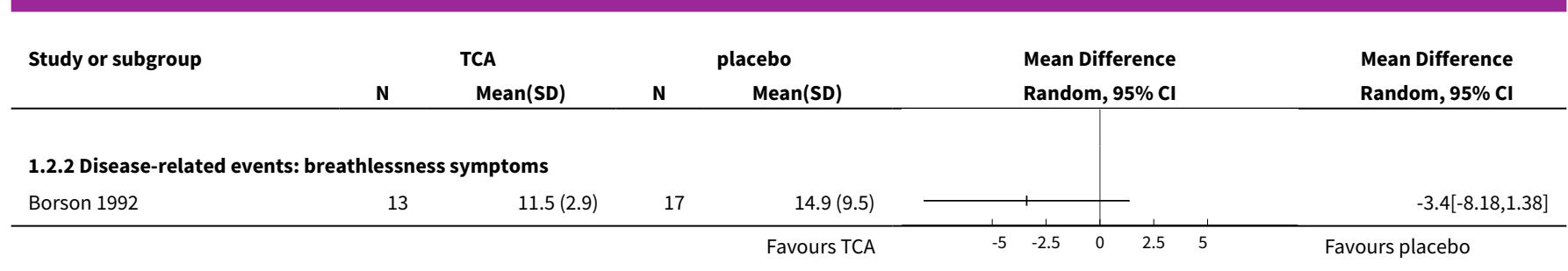

Analysis 1.3. Comparison 1 Tricylic antidepressant versus placebo - final follow-up values used, Outcome 3 Change in quality of life - overall score.

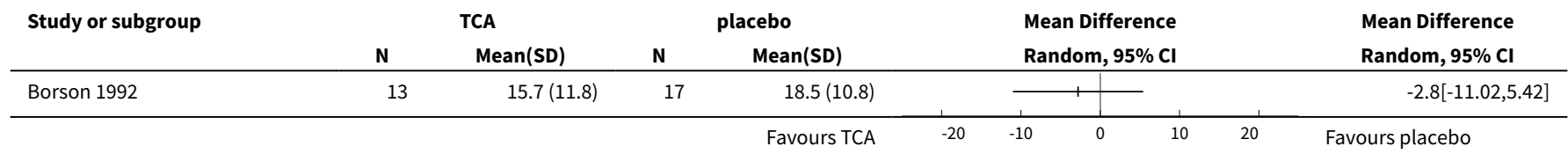

Analysis 1.4. Comparison 1 Tricylic antidepressant versus placebo - final follow-up values used, Outcome $\mathbf{4}$ Change in dyspnoea (Pulmonary Functional Status Instrument).

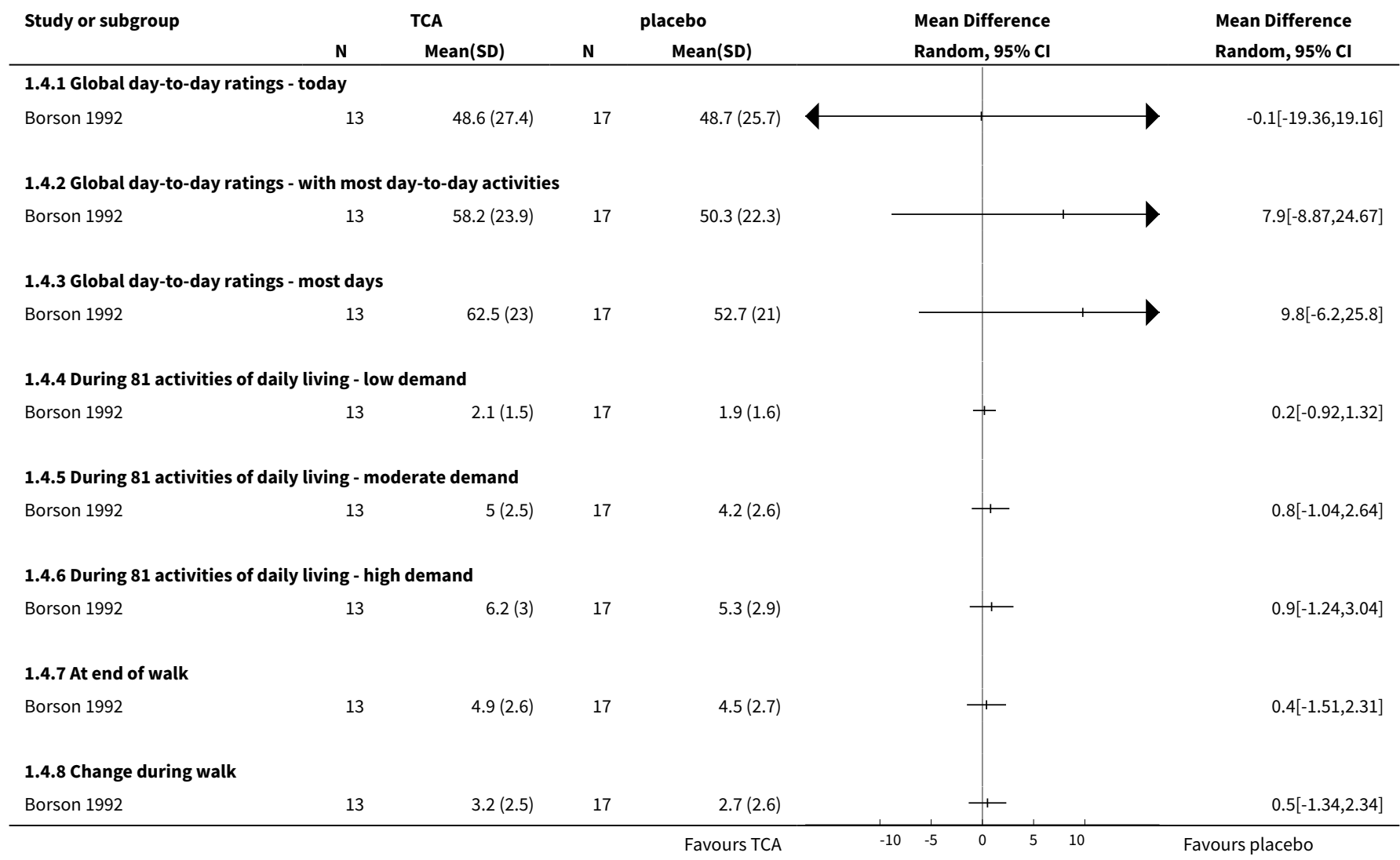


Comparison 2. Selective serotonin reuptake inhibitor versus placebo - final follow-up values used

\begin{tabular}{|c|c|c|c|c|}
\hline $\begin{array}{l}\text { Outcome or subgroup } \\
\text { title }\end{array}$ & No. of studies & $\begin{array}{l}\text { No. of partici- } \\
\text { pants }\end{array}$ & Statistical method & Effect size \\
\hline $\begin{array}{l}1 \text { Change in depressive } \\
\text { symptoms }\end{array}$ & 2 & 148 & $\begin{array}{l}\text { Std. Mean Difference (IV, Random, 95\% } \\
\mathrm{CI} \text { ) }\end{array}$ & $0.75[-1.14,2.64]$ \\
\hline 2 Adverse events & 3 & & Odds Ratio (M-H, Random, 95\% Cl) & Subtotals only \\
\hline 2.1 Nausea & 3 & 171 & Odds Ratio (M-H, Random, 95\% Cl) & $2.32[0.66,8.12]$ \\
\hline 2.2 Dizziness & 2 & 143 & Odds Ratio (M-H, Random, 95\% Cl) & $0.61[0.09,4.06]$ \\
\hline 3 Change in $\mathrm{FEV}_{1}$ & 2 & 148 & Mean Difference (IV, Random, 95\% Cl) & $0.01[-0.03,0.05]$ \\
\hline 4 Change in quality of life & 2 & 148 & $\begin{array}{l}\text { Std. Mean Difference (IV, Random, 95\% } \\
\mathrm{CI} \text { ) }\end{array}$ & $1.17[-0.80,3.15]$ \\
\hline $\begin{array}{l}5 \text { Change in exercise tol- } \\
\text { erance }\end{array}$ & 2 & 148 & Mean Difference (IV, Random, 95\% CI) & $13.88[11.73,16.03]$ \\
\hline
\end{tabular}

Analysis 2.1. Comparison 2 Selective serotonin reuptake inhibitor versus placebo - final follow-up values used, Outcome 1 Change in depressive symptoms.

\begin{tabular}{|c|c|c|c|c|c|c|c|}
\hline \multirow[t]{2}{*}{ Study or subgroup } & \multicolumn{2}{|c|}{ SSRI } & \multicolumn{2}{|c|}{ placebo } & \multirow{2}{*}{$\begin{array}{c}\text { Std. Mean Difference } \\
\text { Random, } 95 \% \mathrm{Cl}\end{array}$} & \multirow[t]{2}{*}{ Weight } & \multirow{2}{*}{$\begin{array}{c}\text { Std. Mean Difference } \\
\text { Random, } 95 \% \mathrm{Cl}\end{array}$} \\
\hline & $\mathbf{N}$ & Mean(SD) & $\mathbf{N}$ & Mean(SD) & & & \\
\hline Eiser 2005 & 14 & $10(4)$ & 14 & $11(4)$ & 十 & $48.68 \%$ & $-0.24[-0.99,0.5]$ \\
\hline He 2016 & 60 & $3.8(1.2)$ & 60 & $2(0.9)$ & + & $51.32 \%$ & $1.69[1.27,2.1]$ \\
\hline Total $\star \star \star ~$ & 74 & & 74 & & & $100 \%$ & $0.75[-1.14,2.64]$ \\
\hline \multicolumn{8}{|c|}{ Heterogeneity: $\mathrm{Tau}^{2}=1.77 ; \mathrm{Chi}^{2}=19.62, \mathrm{df}=1(\mathrm{P}<0.0001) ; \mathrm{I}^{2}=94.9 \%$} \\
\hline
\end{tabular}

Analysis 2.2. Comparison 2 Selective serotonin reuptake inhibitor versus placebo - final follow-up values used, Outcome 2 Adverse events.

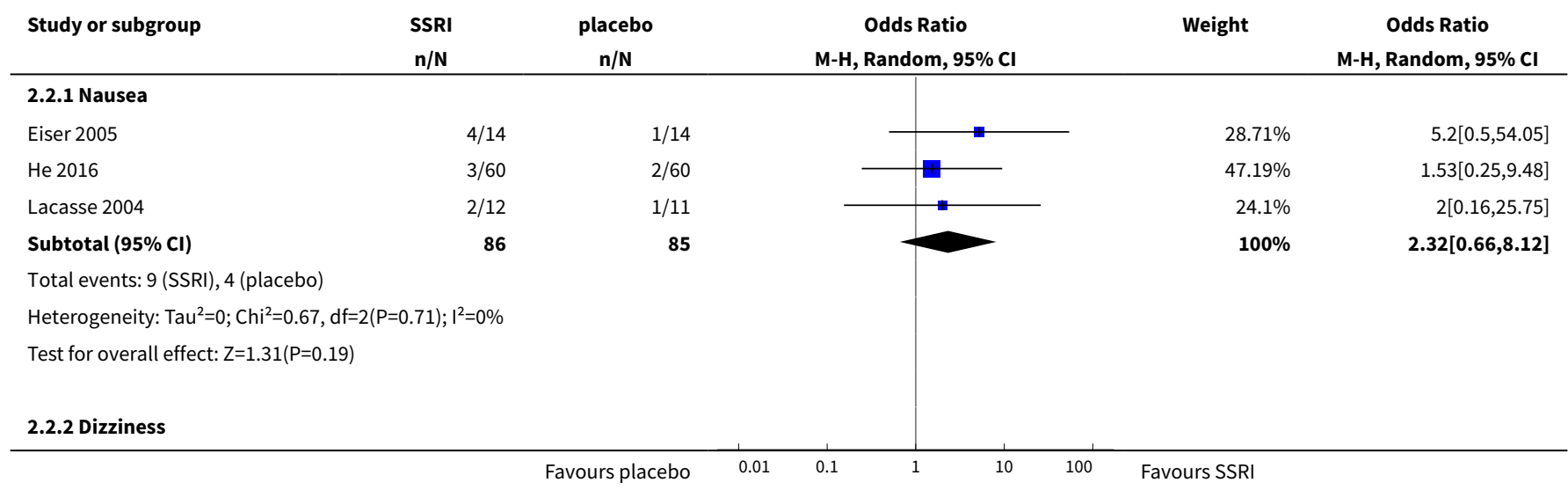




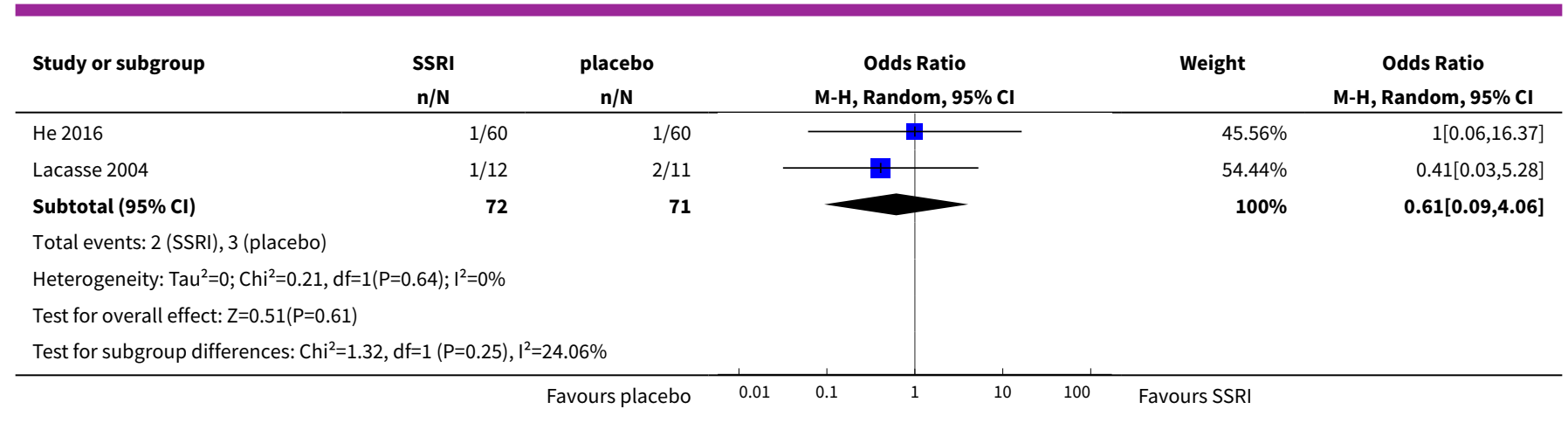

Analysis 2.3. Comparison 2 Selective serotonin reuptake inhibitor versus placebo - final follow-up values used, Outcome 3 Change in FEV 1 .

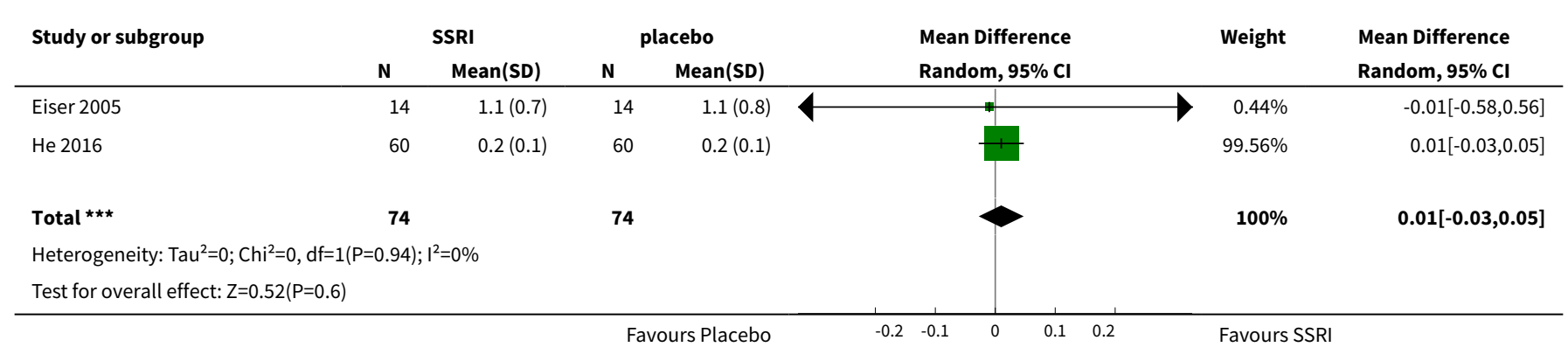

Analysis 2.4. Comparison 2 Selective serotonin reuptake inhibitor versus placebo - final follow-up values used, Outcome 4 Change in quality of life.

\begin{tabular}{|c|c|c|c|c|c|c|c|}
\hline \multirow[t]{2}{*}{ Study or subgroup } & \multicolumn{2}{|c|}{ SSRI } & \multicolumn{2}{|c|}{ placebo } & \multirow{2}{*}{$\begin{array}{c}\text { Std. Mean Difference } \\
\text { Random, } 95 \% \mathrm{Cl}\end{array}$} & \multirow[t]{2}{*}{ Weight } & \multirow{2}{*}{$\begin{array}{c}\text { Std. Mean Difference } \\
\text { Random, } 95 \% \mathrm{Cl}\end{array}$} \\
\hline & $\mathbf{N}$ & $\operatorname{Mean}(S D)$ & $\mathbf{N}$ & $\operatorname{Mean}(S D)$ & & & \\
\hline Eiser 2005 & 14 & $67(16)$ & 14 & $65(11)$ & + & $48.9 \%$ & $0.14[-0.6,0.88]$ \\
\hline He 2016 & 60 & $4.5(1)$ & 60 & $2.1(1.2)$ & + & $51.1 \%$ & $2.16[1.71,2.61]$ \\
\hline 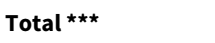 & 74 & & 74 & & & $100 \%$ & $1.17[-0.8,3.15]$ \\
\hline \multicolumn{8}{|c|}{ Heterogeneity: Tau $^{2}=1.94 ; \mathrm{Chi}^{2}=20.7, \mathrm{df}=1(\mathrm{P}<0.0001) ; \mathrm{I}^{2}=95.17 \%$} \\
\hline
\end{tabular}

Analysis 2.5. Comparison 2 Selective serotonin reuptake inhibitor versus placebo - final follow-up values used, Outcome 5 Change in exercise tolerance.

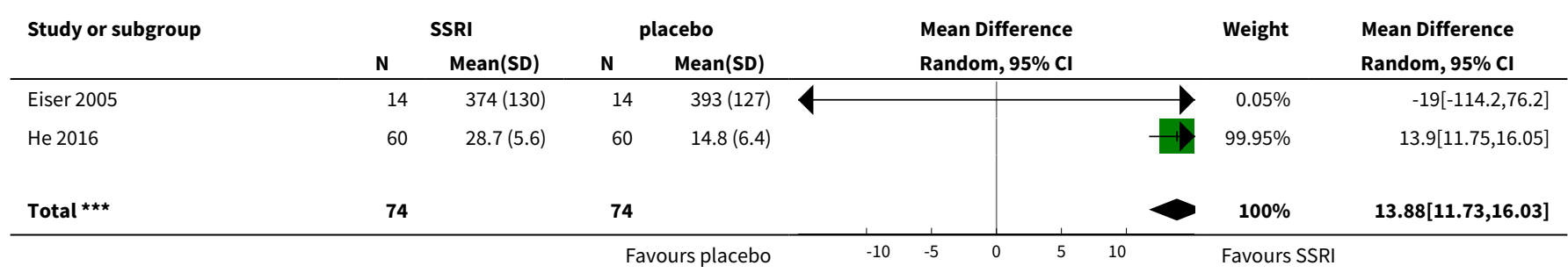




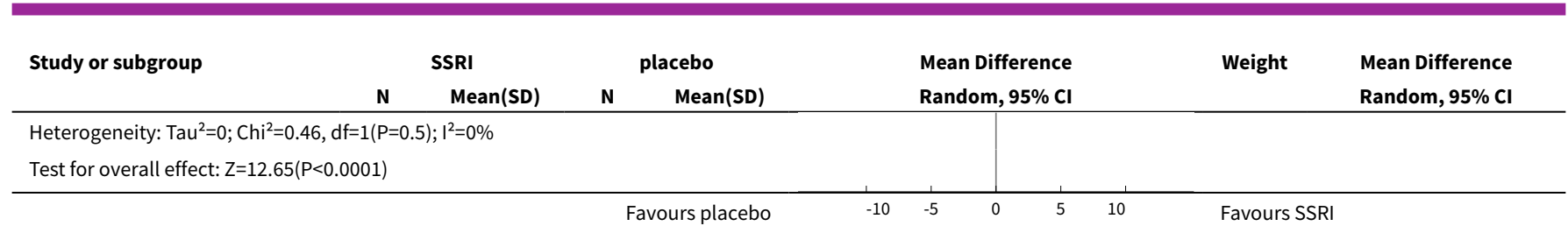




\begin{tabular}{|c|c|c|c|c|c|c|c|c|}
\hline \multirow{2}{*}{\multicolumn{2}{|c|}{ 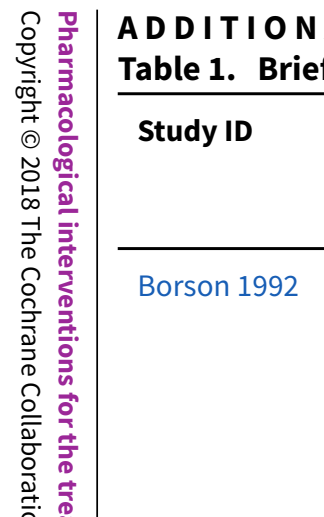 }} & $\begin{array}{l}\text { Study de- } \\
\text { sign/length } \\
\text { of study }\end{array}$ & $\begin{array}{l}\text { Number of partici- } \\
\text { pants }\end{array}$ & $\begin{array}{l}\text { Severity of } \\
\text { COPD }\end{array}$ & Severity of depression & Treatment/dose & $\begin{array}{l}\text { Control } \\
\text { group }\end{array}$ & Setting \\
\hline & & $\begin{array}{l}\text { RCT } \\
\text { double-blind } \\
12 \text { weeks }\end{array}$ & $\begin{array}{l}\mathrm{N}=30 \\
(\mathrm{~N}=13 \text { in treatment } \\
\text { group, } \mathrm{N}=17 \text { in con- } \\
\text { trol group) }\end{array}$ & $\begin{array}{l}\text { Moderate to } \\
\text { severe }\end{array}$ & $\begin{array}{l}\text { Depressive symptoms mea- } \\
\text { sured by HAM-D, and de- } \\
\text { pression confirmed by a } \\
\text { psychiatric exam (DSM-III) }\end{array}$ & $\begin{array}{l}\text { TCA - nortripty- } \\
\text { line (calculated } \\
\text { dose per body } \\
\text { weight) }\end{array}$ & Placebo & $\begin{array}{l}\text { USA } \\
\text { Seattle Veterans Affais } \\
\text { Medical Centre } \\
\text { and private practices } \\
\text { in Seattle }\end{array}$ \\
\hline 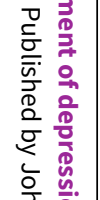 & Eiser 2005 & $\begin{array}{l}\text { RCT } \\
\text { double-blind } \\
6 \text { weeks }\end{array}$ & $\begin{array}{l}\mathrm{N}=28 \\
(\mathrm{~N}=14 \text { in treatment } \\
\text { group, } \mathrm{N}=14 \text { in con- } \\
\text { trol group) }\end{array}$ & $\begin{array}{l}\text { Moderate to } \\
\text { severe }\end{array}$ & $\begin{array}{l}\text { Symptoms measured by } \\
\text { BDI, HADS, and MADRS, } \\
\text { and depression confirmed } \\
\text { by a psychiatric interview } \\
\text { (IDC-10) }\end{array}$ & $\begin{array}{l}\text { SSRI - paroxetine } \\
\text { ( } 20 \mathrm{mg} \text { daily) }\end{array}$ & Placebo & $\begin{array}{l}\text { UK } \\
\text { Lewisham Hospital } \\
\text { Chest Clinic London }\end{array}$ \\
\hline 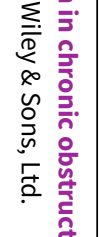 & He 2016 & $\begin{array}{l}\text { RCT } \\
\text { double-blind } \\
6 \text { weeks }\end{array}$ & $\begin{array}{l}\mathrm{N}=120 \\
(\mathrm{~N}=60 \text { in treatment } \\
\text { group, } \mathrm{N}=60 \text { in con- } \\
\text { trol group) }\end{array}$ & $\begin{array}{l}\text { Stage } 1 \text { and } \\
\text { above }\end{array}$ & $\begin{array}{l}\text { Symptoms measured by } \\
\text { HAM-D-17 }\end{array}$ & $\begin{array}{l}\text { SSRI - sertraline } \\
\text { (50 mg daily) }\end{array}$ & Placebo & $\begin{array}{l}\text { China } \\
\text { Department of Res- } \\
\text { piratory Medicine, } \\
\text { Huai'an Second Hospi- } \\
\text { tal }\end{array}$ \\
\hline 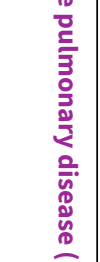 & Lacasse 2004 & $\begin{array}{l}\text { RCT } \\
\text { double-blind } \\
12 \text { weeks }\end{array}$ & $\begin{array}{l}\mathrm{N}=23 \\
(\mathrm{~N}=12 \text { in treatment } \\
\text { group, } \mathrm{N}=11 \text { in con- } \\
\text { trol group) }\end{array}$ & Severe & $\begin{array}{l}\text { Symptoms measured by } \\
\text { GDS, and depression con- } \\
\text { firmed by a psychiatric in- } \\
\text { terview }\end{array}$ & $\begin{array}{l}\text { SSRI - paroxetine } \\
\text { (starting dose } 5 \\
\text { mg daily, ending } \\
\text { dose } 20 \text { mg daily) }\end{array}$ & Placebo & $\begin{array}{l}\text { Canada } \\
\text { Quebec City Respirato- } \\
\text { ry Home } \\
\text { Care Service, Hospital } \\
\text { Laval }\end{array}$ \\
\hline$\vec{\infty}$ & $\begin{array}{l}\text { BDI: Beck Depre } \\
\text { DSM-III: third ec } \\
\text { GDS: Geriatric D } \\
\text { HADS: Hospital } \\
\text { HAM-D: Hamilto } \\
\text { HAM-D-17: } 17 \text {-it } \\
\text { ICD-10: Tenth R } \\
\text { MADRS: Montgo } \\
\text { RCT: randomize } \\
\text { SSRI: selective s } \\
\text { TCA: tricyclic an }\end{array}$ & $\begin{array}{l}\text { ion Inventory } \\
\text { ion of the Diagr } \\
\text { oression Scale } \\
\text { ixiety and Depr } \\
\text { Depression Rat } \\
\text { n Hamilton Dep } \\
\text { ision of the Inte } \\
\text { ery-Asberg Dep } \\
\text { controlled trial } \\
\text { otonin reuptak } \\
\text { depressant }\end{array}$ & $\begin{array}{l}\text { tic and Statistical Manı } \\
\text { sion Scale } \\
\text { Scale } \\
\text { ssion Rating Scale } \\
\text { ational Statistical Class } \\
\text { ssion Score } \\
\text { hhibitor }\end{array}$ & $\begin{array}{l}\text { f Mental Disol } \\
\text { ation of Diseas }\end{array}$ & nd Related Health Problems & & & \\
\hline
\end{tabular}




\section{AP PE N D I C E S}

\section{Appendix 1. CCMDCTR - core MEDLINE search}

\section{OVID Medline: Core search strategy used to inform the Cochrane Common Mental Disorders Group's specialised register}

A weekly search alert based on condition + RCT filter only

1. [MeSH Headings]:

eating disorders/ or anorexia nervosa/ or binge-eating disorder/ or bulimia nervosa/ or female athlete triad syndrome/ or pica/ or hyperphagia/ or bulimia/ or self-injurious behavior/ or self mutilation/ or suicide/ or suicidal ideation/ or suicide, attempted/ or mood disorders/ or affective disorders, psychotic/ or bipolar disorder/ or cyclothymic disorder/ or depressive disorder/ or depression, postpartum/ or depressive disorder, major/ or depressive disorder, treatment-resistant/ or dysthymic disorder/ or seasonal affective disorder/ or neurotic disorders/ or depression/ or adjustment disorders/ or exp antidepressive agents/ or anxiety disorders/ or agoraphobia/ or neurocirculatory asthenia/ or obsessive-compulsive disorder/ or obsessive hoarding/ or panic disorder/ or phobic disorders/ or stress disorders, traumatic/ or combat disorders/or stress disorders, post-traumatic/ or stress disorders, traumatic, acute/ or anxiety/ or anxiety, castration/ or koro/ or anxiety, separation/ or panic/ or exp anti-anxiety agents/ or somatoform disorders/ or body dysmorphic disorders/ or conversion disorder/ or hypochondriasis/ or neurasthenia/ or hysteria/ or munchausen syndrome by proxy/ or munchausen syndrome/ or fatigue syndrome, chronic/ or obsessive behavior/ or compulsive behavior/ or behavior, addictive/ or impulse control disorders/ or firesetting behavior/ or gambling/ or trichotillomania/ or stress, psychological/ or burnout, professional/ or sexual dysfunctions, psychological/ or vaginismus/ or Anhedonia/ or Affective Symptoms/ or *Mental Disorders/

\section{2. [Title/ Author Keywords]:}

(eating disorder ${ }^{\star}$ or anorexia nervosa or bulimi ${ }^{\star}$ or binge eat ${ }^{\star}$ or (self adj (injur ${ }^{\star}$ or mutilat ${ }^{\star}$ )) or suicide ${ }^{\star}$ or suicidal or parasuicid ${ }^{\star}$ or mood disorder ${ }^{\star}$ or affective disorder ${ }^{\star}$ or bipolar i or bipolar ii or (bipolar and (affective or disorder ${ }^{\star}$ )) or mania or manic or cyclothymic ${ }^{\star}$ or depression or depressive or dysthymi* or neurotic or neurosis or adjustment disorder* or antidepress* or anxiety disorder* or agoraphobia or obsess ${ }^{\star}$ or compulsi ${ }^{\star}$ or panic or phobi ${ }^{\star}$ or ptsd or posttrauma* or post trauma* or combat or somatoform or somati\#ation or medical ${ }^{\star}$ unexplained or body dysmorphi* or conversion disorder or hypochondria* or neurastheni* or hysteria or munchausen or chronic fatigue* or gambling or trichotillomania or vaginismus or anhedoni* or affective symptoms or mental disorder* or mental health).ti,kf.

\section{3. [RCT filter]:}

(controlled clinical trial.pt. or randomized controlled trial.pt. or (randomi\#ed or randomi\#ation).ab,ti. or randomly.ab. or (random adj3 (administ ${ }^{\star}$ or allocat ${ }^{\star}$ or assign ${ }^{\star}$ or class ${ }^{\star}$ or control ${ }^{\star}$ or determine or divide $^{\star}$ or distribut ${ }^{\star}$ or expose or fashion or number $^{\star}$ or place $^{\star}$ or recruit ${ }^{\star}$ or subsitut ${ }^{\star}$ or treat $\left.{ }^{\star}\right)$ ).ab. or placebo*.ab,ti. or drug therapy.fs. or trial.ab,ti. or groups.ab. or (control ${ }^{\star}$ adj3 (trial ${ }^{\star}$ or study or studies)).ab,ti. or ((singl ${ }^{\star}$ or doubl ${ }^{\star}$ or tripl ${ }^{\star}$ or trebl ${ }^{\star}$ ) adj3 (blind ${ }^{\star}$ or mask ${ }^{*}$ or dummy $\left.{ }^{*}\right)$.mp. or clinical trial, phase ii/ or clinical trial, phase iii/ or clinical trial, phase iv/ or randomized controlled trial/ or pragmatic clinical trial/ or (quasi adj (experimental or random*)).ti,ab. or ((waitlist ${ }^{\star}$ or wait* list $^{\star}$ or treatment as usual or TAU) adj3 (control or group)).ab.)

\section{4. (1 and 2 and 3$)$}

Records are screened for reports of RCTs within the scope of the Cochrane Common Mental Disorders Group. Secondary reports of RCTs are tagged to the appropriate study record.

Similar weekly search alerts are also conducted on OVID EMBASE and PsycINFO, using relevant subject headings (controlled vocabularies) and search syntax, appropriate to each resource.

\section{Appendix 2. Additional search strategies}

Update Search-1 (20-March-2017)

\section{Ovid Cross-search (2017-03-20)}

PsycINFO 1806 to March Week 2 2017, PsycARTICLES Full Text, Embase 1974 to 2017 Week 12, Ovid MEDLINE(R) Epub Ahead of Print, InProcess \& Other Non-Indexed Citations, Ovid MEDLINE(R) Daily and Ovid MEDLINE(R) 1946 to Present

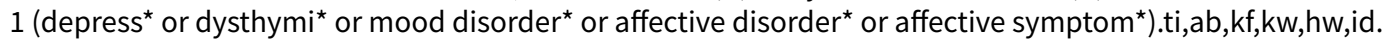

2 ((obstruct* adj3 (pulmonary or lung* or airway* or airflow* or bronch* or respirat $\left.{ }^{\star}\right)$ ) or COPD or emphysema or (chronic ${ }^{\star}$ and bronchiti*)).ti,ab,kf,kw,hw,id. (361994)

3 (random* or RCT or placebo or (control* adj3 (trial or study or group))).ti,ab,kf,kw,id,hw. (8561141)

4 (1 and 2 and 3) (3022)

$5\left(2016^{\star}\right.$ or $\left.2017^{\star}\right) \cdot y r, e d$, an, dd. $(4561633)$

64 and 5 (548)

7 remove duplicates from 6 (473)

Key to field tags:

ti:title; ab:abstract; kf:author keywords(MEDLINE); kw:author keywords (Embase); id:key concepts (PsycINFO); hw:subject heading word; yr:year; ed:entry date (MEDLINE); dd:date delivered (Embase); AN:Accession No. PsycINFO;

\section{CENTRAL, Issue 4, 2017}

Pharmacological interventions for the treatment of depression in chronic obstructive pulmonary disease (Review) 
\#1 (depress* or dysthymi* or mood or "affective disorder*" or "affective symptom*")

\#2 ((obstruct* NEAR (pulmonary or lung* or airway* or airflow* or bronch* or respirat*)) or COPD or emphysema or (chronic ${ }^{\star}$ NEAR bronchiti*))

Published in CENTRAL, Issue 12016 to Issue 4, 2017 n = 89

\section{Update Search-2 (26-Nov-2018)}

\section{Ovid MEDLINE databases}

MEDLINE(R) and Epub Ahead of Print, In-Process \& Other Non-Indexed Citations and Daily <1946 to November 26, 2018>

Search Strategy:

1 exp Pulmonary Disease, Chronic Obstructive/ (50014)

2 ((obstruct ${ }^{\star}$ and (pulmonary or lung* or airway ${ }^{\star}$ or airflow $w^{\star}$ or bronch ${ }^{\star}$ or respirat $\left.{ }^{\star}\right)$ ) or COPD or emphysema or (chronic* and bronchiti $\left.{ }^{\star}\right)$.ti,ab,kf. (141393)

31 or $2(149656)$

4 controlled clinical trial.pt. (92764)

5 randomized controlled trial.pt. (471777)

6 (randomi\#ed or randomi\#ation or randomi\#ing).ti,ab,kf. (562415)

7 (RCT or "at random" or (random* adj3 (administ* or allocat* or assign" or class ${ }^{\star}$ or control* or crossover or cross-over or design* or determine or divide $^{\star}$ or division or distribut ${ }^{\star}$ or expose ${ }^{\star}$ or fashion or number ${ }^{\star}$ or place ${ }^{\star}$ or recruit or subsitut $^{\star}$ or treat $\left.\left.{ }^{\star}\right)\right)$ ).ti,ab,kf. (500722) 8 placebo*.ab,ti,kf. (200661)

9 (trial or study).ab,ti,kf. (7158218)

10 groups.ab. (1855391)

11 (control $^{\star}$ and (trial or study or group ${ }^{\star}$ ) and (placebo or waitlist ${ }^{\star}$ or wait* list $^{\star}$ or ((treatment or care) adj2 usual))).ti,ab,kf,hw. (182660)

12 ((single or double or triple or treble) adj2 (blind* or mask* or dummy)).ti,ab,kf. (161164)

13 double-blind method/ or random allocation/ or single-blind method/ (259767)

14 or/4-13 (8196580)

15 exp animals/ not humans.sh. (4518028)

1614 not 15 (6774846)

17 Depression/ (104935)

18 depressive disorder/ or depressive disorder, major/ (94708)

19 (depress $^{\star}$ or dysthymi ${ }^{\star}$ or mood? or affective disorder ${ }^{\star}$ or affective symptom ${ }^{\star}$ ).ti,kf. (167428)

20 (depress $^{\star}$ adj3 (acute or clinical ${ }^{\star}$ or diagnos ${ }^{\star}$ or disorder ${ }^{\star}$ or major or unipolar or illness or scale* or score* or adult* or patient ${ }^{\star}$ or participant ${ }^{\star}$ or people or inpatient ${ }^{\star}$ or in-patient ${ }^{\star}$ or outpatient ${ }^{\star}$ or out-patient $\left.{ }^{\star}\right)$ ).ab. (136135)

21 (depress $^{\star}$ and (Beck* or BDI* or DSM* or (Statistical Manual adj2 Mental Disorders) or Hamilton or HAM-D or HAMD or MADRS or (International Classification adj2 Disease?) or ICD-10 or ICD-9)).ab. (39235)

22 "with depressi ${ }^{\star} " . a b . ~(23500)$

23 or/17-22 (297594)

243 and 16 and $23(1214)$

$25\left(2016^{\star}\right.$ or $2017^{\star}$ or $\left.2018^{\star}\right)$.yr,dp,dt,ep,ez. (3722698)

2624 and 25 (355)

Ovid Embase < 1974 to 2018 Week 48>

Search Strategy:

1 chronic obstructive lung disease/ (112753)

2 *obstructive airway disease/ (907)

3 ((obstruct* $^{\star}$ and (pulmonary or lung* or airway* or airflow* ${ }^{\star}$ or bronch* or respirat $\left.{ }^{\star}\right)$ ) or COPD or emphysema or (chronic ${ }^{\star}$ and bronchiti $\left.{ }^{\star}\right)$.ti,ab,kw. (211149)

4 or/1-3 (241610)

5 randomized controlled trial/ (523926)

6 randomization.de. (80124)

7 controlled clinical trial/ and (Disease Management or Drug Therapy or Prevention or Rehabilitation or Therapy).fs. (252274)

8 *clinical trial/ (17544)

9 placebo.de. (326769)

10 placebo.ti,ab. (279306)

11 trial.ti. (256582)

12 (randomi\#ed or randomi\#ation or randomi\#ing).ti,ab,kw. (799511) 
13 (RCT or "at random" or (random* adj3 (administ* or allocat* or assign* or class ${ }^{\star}$ or control ${ }^{\star}$ or determine ${ }^{\star}$ or divide* or division or distribut $^{\star}$ or expose* or fashion or number ${ }^{\star}$ or place* or recruit* or subsitut* or treat*))).ti,ab,kw. (634066)

14 ((singl\$ or doubl\$ or trebl\$ or tripl\$) adj3 (blind\$ or mask\$ or dummy)).mp. (281505)

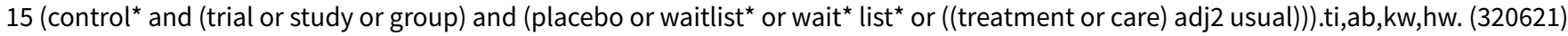

16 or/5-15 (1546292)

17 ((animal or nonhuman) not (human and (animal or nonhuman))).de. (5264241)

1816 not $17(1408025)$

19 (depress $^{\star}$ or dysthymi ${ }^{\star}$ or mood or "affective disorder ${ }^{\star}$ or "affective symptom*").ti,kw. (228590)

20 (depress $^{\star}$ adj3 (acute or clinical ${ }^{\star}$ or diagnos* or disorder ${ }^{\star}$ or major or unipolar or illness or scale* or score* or adult ${ }^{\star}$ or patient $^{\star}$ or $^{\star}$ participant ${ }^{\star}$ or people or inpatient ${ }^{\star}$ or in-patient ${ }^{\star}$ or outpatient ${ }^{\star}$ or out-patient $\left.{ }^{\star}\right)$ ).ab. (194627)

21 (depress $^{\star}$ and $\left(\right.$ Beck $^{\star}$ or BDI* or DSM* or (Statistical Manual adj2 Mental Disorders) or Hamilton or HAM-D or HAMD or MADRS or (International Classification adj2 Disease?) or ICD-10 or ICD-9)).ab. (61054)

22 "with depressi*".ab. (33197)

23 depression/ or agitated depression/ or atypical depression/ or endogenous depression/ or involutional depression/ or late life depression/ or major depression/ or masked depression/ or minor depression/ or "mixed anxiety and depression"/ or post-stroke depression/ or postoperative depression/ or reactive depression/ (374345)

24 or/19-23 (490635)

254 and 18 and 24 (820)

26 (depress* adj3 ((obstruct* adj3 (pulmonary or lung* or airway* or airflow* or bronch $^{\star}$ or respirat*)) or COPD or emphysema or (chronic* and bronchiti*))).ti,ab,kw. (843)

2718 and $26(101)$

2825 or $27(845)$

$29\left(2016^{\star}\right.$ or $2017^{\star}$ or $\left.2018^{\star}\right) . y r, d p, d c .(4830864)$

3028 and $29(238)$

Ovid: PsycINFO <1806 to November Week $32018>$

Search Strategy:

1 exp chronic obstructive pulmonary disease/ (1270)

2 ((obstruct* and (pulmonary or lung* or airway* or airflow* or bronch $^{\star}$ or respirat $\left.{ }^{\star}\right)$ ) or COPD or emphysema or (chronic* and bronchiti*)).ti,ab,id. (4262)

31 or $2(4387)$

4 clinical trials.sh. (11146)

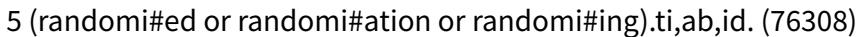

6 (RCT or at random or (random ${ }^{\star}$ adj3 (administ ${ }^{\star}$ or allocat ${ }^{\star}$ or assign ${ }^{\star}$ or class ${ }^{\star}$ or control ${ }^{\star}$ or determine ${ }^{\star}$ or divide* or division or distribut ${ }^{\star}$

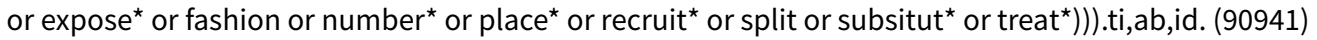

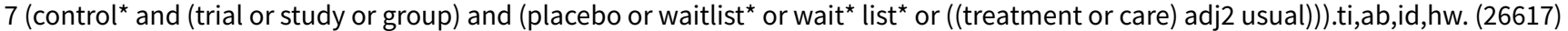

8 ((single or double or triple or treble) adj2 (blind* or mask* or dummy)).ti,ab,id. (24670)

9 trial.ti. (26899)

10 placebo.ti,ab,id,hw. (38105)

11 treatment outcome.md. (19203)

12 treatment effectiveness evaluation.sh. (22438)

13 mental health program evaluation.sh. (2052)

14 or/4-13 (179672)

15 (depress* or dysthymi* or mood? or "affective disorder*" or "affective symptom*").ti,ab,id. (329755)

163 and 14 and 15 (102)

$17\left(2016^{\star}\right.$ or $2017^{\star}$ or $\left.2018^{\star}\right) \cdot y r$,an. $(525740)$

1816 and $17(20)$

\section{CENTRAL, Issue 11 of 12, November 2018}

\#1 (depress* or dysthymi* or mood or "affective disorder*" or "affective symptom*")

\#2 ((obstruct* NEAR (pulmonary or lung* or airway* or airflow* or bronch* or respirat $\left.{ }^{\star}\right)$ ) or COPD or emphysema or (chronic* NEAR bronchiti*))

Date added to CENTRAL trials database: 1-May-2016 to 27-Nov-2018 $n=304$ 


\section{CONTRIBUTIONS OF AUTHORS}

Justyna Pollok: Designing the review; coordinating the review; data collection for the review; undertaking searches; screening search results; organising retrieval of papers; screening papers against eligibility criteria; appraising quality of papers; extracting data from papers; writing to authors of papers for additional information; data management for the review; entering data into RevMan; analysis of data; interpretation of data; writing the review.

Joep van Agteren: Data collection for the review; screening search results; screening papers against eligibility criteria; appraising quality of papers; extracting data from papers; providing advice on analysis of data.

Kristin Carson-Chahhoud: providing advice on analysis of data; providing general advice on the review.

\section{DECLARATIONS OF INTEREST}

Justyna Pollok: none known

Joep van Agteren: none known

Kristin Carson-Chahhoud: none known

\section{SOURCES OF SUPPORT}

\section{Internal sources}

- No sources of support supplied

\section{External sources}

- Respiratory Medicine Department at the Queen Elizabeth Hospital, Adelaide, Australia.

\section{DIFFERENCES BETWEEN PROTOCOL AND REVIEW}

None

\section{INDEX TERMS}

\section{Medical Subject Headings (MeSH)}

Antidepressive Agents, Tricyclic [adverse effects] [*therapeutic use]; Depression [ ${ }^{\star}$ drug therapy] [etiology]; Dizziness [chemically induced]; Dyspnea [drug therapy]; Exercise Tolerance [drug effects]; Forced Expiratory Volume [drug effects]; Nausea [chemically induced]; Nortriptyline [adverse effects] [therapeutic use]; Paroxetine [adverse effects] [therapeutic use]; Placebos [therapeutic use]; Pulmonary Disease, Chronic Obstructive [*psychology]; Quality of Life; Randomized Controlled Trials as Topic; Serotonin Uptake Inhibitors [adverse effects] [*therapeutic use]; Sertraline [adverse effects] [therapeutic use]

\section{MeSH check words}

Humans 